\title{
ENABLING MULTI-SITE STORMWATER ENVIRONMENTAL COMPLIANCE APPROVALS IN ONTARIO, CANADA
}

\author{
By \\ Paul Orchard B.A., Wilfrid Laurier University, Waterloo, Ontario 2010 \\ A thesis presented to Ryerson University \\ In partial fulfillment of the \\ requirements for the degree of \\ Master of Applied Science \\ In the Program of \\ Environmental Applied Science and Management
}

Toronto, Ontario, Canada, 2019

(C) Paul Orchard 2019 
AUTHOR'S DECLARATION

AUTHOR'S DECLARATION AUTHOR'S DECLARATION FOR ELECTRONIC SUBMISSION OF A THESIS

I hereby declare that I am the sole author of this thesis. This is a true copy of the thesis, including any required final revisions, as accepted by my examiners.

I authorize Ryerson University to lend this thesis to other institutions or individuals for the purpose of scholarly research.

I further authorize Ryerson University to reproduce this thesis by photocopying or by other means, in total or in part, at the request of other institutions or individuals for the purpose of scholarly research. I understand that my thesis may be made electronically available to the public. 
Enabling Multi-Site Stormwater Environmental Compliance Approvals in Ontario, Canada Master of Applied Science, 2019

Paul Orchard

Environmental Applied Science and Management, Ryerson University

\begin{abstract}
In attempt to improve stormwater management and compliance the Ministry of Environment Conservation and Parks (MECP) has proposed a multi-site Environmental Compliance Approval (ECA) system for managing stormwater compliance at the subwatershed level. This research focuses on the identification and selection of stormwater objectives, criteria, targets, and thresholds to be included as part of the approval. This research also identifies and recommends traditional and alternative monitoring techniques for inclusion in a multi-site permit. Recommendations are provided for database architecture including storage, manipulation, and viewing of monitoring data.

The selected stormwater objectives, criteria, targets, thresholds, monitoring techniques, and frequencies were compiled in a multi-site stormwater ECA framework to assist with the MECP with the implementation of multi-site stormwater ECAs within Ontario. The framework serves as an overview of important parameters that can be effectively monitored within a multi-site stormwater ECA.
\end{abstract}




\section{ACKNOWLEDGEMENTS}

I would like to thank two specific individuals who supported me through my Master's degree, without these individuals the completion of this Degree would not be possible. Thank you to Dr. Darko Joksimovic for your guidance and patience throughout this 5-year period, and for understanding the challenges associated with part-time studies. To my wife for supporting me and raising our two children while I dedicated spare time to the completion of this Master's degree. 
Table of Contents

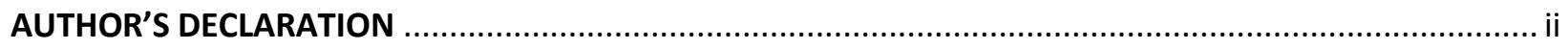

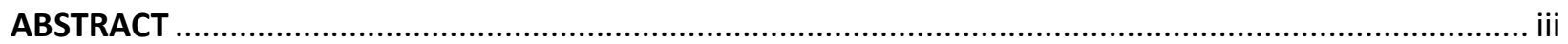

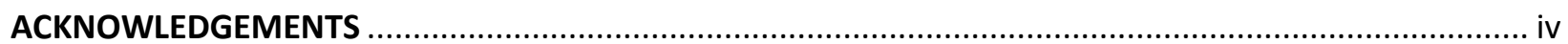

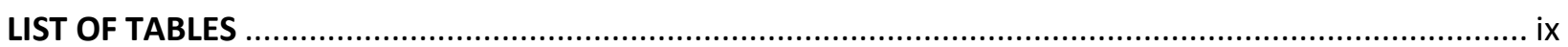

LIST OF FIGURES

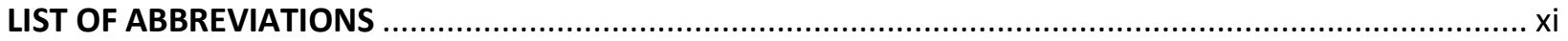

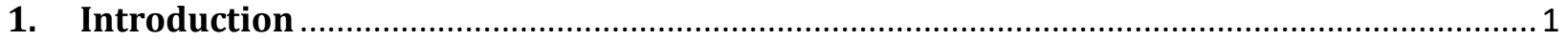

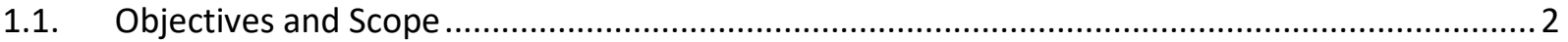

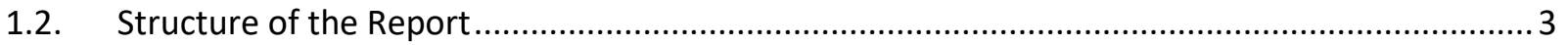

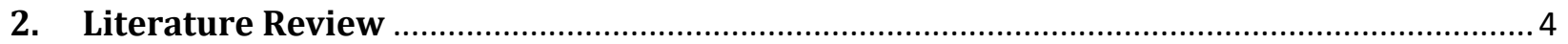

2.1. History of Stormwater Management in Ontario.................................................................... 4

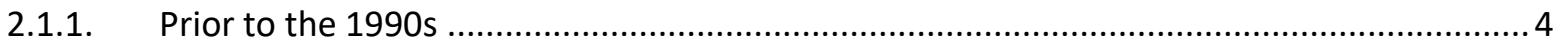

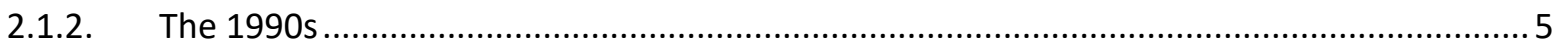

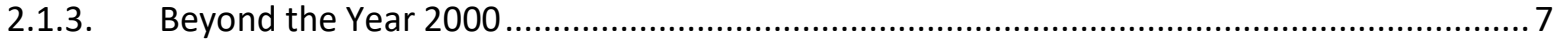

2.2. Current Environmental Compliance Approval System …................................................... 8

2.3. Proposed Multi-Site Environmental Compliance Approval System........................................10

2.4. Stormwater Objectives, Criteria, Targets, and Thresholds for Multi-Site ECAs........................11

2.4.1. Water Quantity Objective, Criteria, Targets, and Thresholds........................................12

2.4.2. Water Quality Objective, Criteria, Targets, and Thresholds ........................................... 13

2.4.3. Stream Morphology Objective Criteria, Targets, and Thresholds ..................................15

2.4.4. Terrestrial Environment Objective, Criteria, Targets, and Thresholds .............................15

2.4.5. Aquatic Environment Objective, Criteria, Targets, and Thresholds................................ 16

2.5. Watershed Based Regulation Examples ….......................................................................... 16

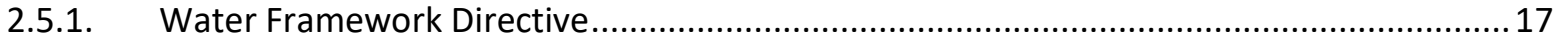

2.5.2. National Pollutant Discharge Elimination System: Municipal Separate Storm Sewer

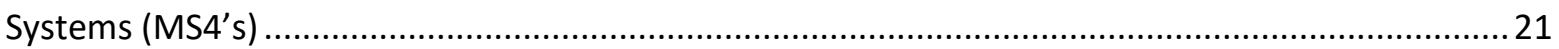

2.5.3. Ontario's Integrated Watershed Management .............................................................. 23

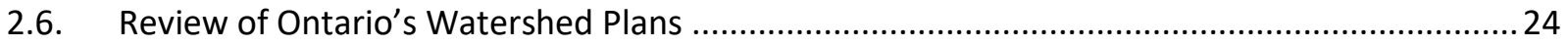

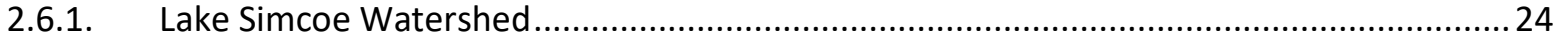

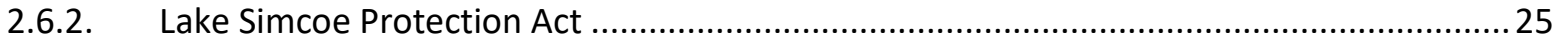

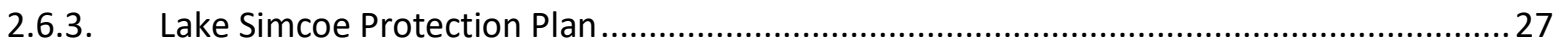

2.6.3.1. Aquatic Life Objective, Criteria, Targets, \& Monitoring ............................................28 
2.6.3.2. Water Quality Objective, Criteria, Targets, \& Monitoring .......................................29

2.6.3.3. Water Quantity Objective, Criteria, Targets, \& Monitoring .......................................32

2.6.3.4. Shorelines and Natural Heritage Objective, Criteria, Targets, \& Monitoring ..............33

2.6.3.5. Other Threats and Activities Objective, Criteria, Targets, \& Monitoring.................... 34

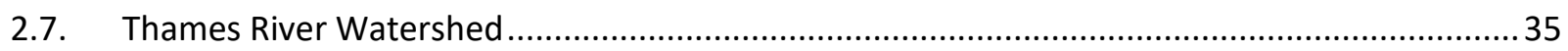

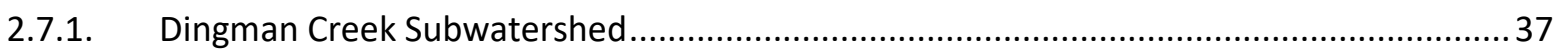

2.7.1.1. Water Quantity Objectives, Criteria, Targets, \& Monitoring .....................................37

2.7.1.2. Water Quality Objectives, Criteria, Targets, \& Monitoring...................................... 38

2.7.1.3. Stream Erosion and Morphology Objectives, Criteria, Targets, \& Monitoring ........... 40

2.7.1.4. Geology and Hydrogeology Objectives, Criteria, Targets, \& Monitoring ................... 40

2.7.1.5. Terrestrial Natural Heritage Objectives, Criteria, Targets, \& Monitoring ................... 41

2.7.1.6. Aquatic Resources Objectives, Criteria, Targets, \& Monitoring .............................. 41

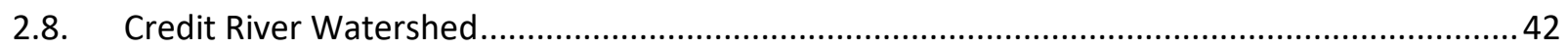

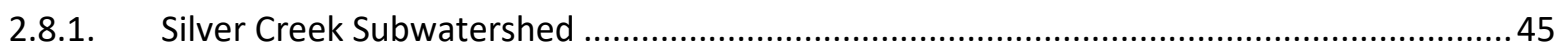

2.8.1.1. Water Quantity Objectives, Criteria, Targets, \& Monitoring .................................... 47

2.8.1.2. Water Quality Objectives, Criteria, Targets, \& Monitoring.......................................49

2.8.1.3. Stream Morphology Objectives, Criteria, Targets, \& Monitoring ..............................50

2.8.1.4. Terrestrial Objectives, Criteria, Targets, \& Monitoring .............................................51

2.8.1.5. Aquatic Objectives, Criteria, Targets, \& Monitoring …............................................51

2.9. Monitoring Technologies for the Stormwater Framework Parameters Monitoring of

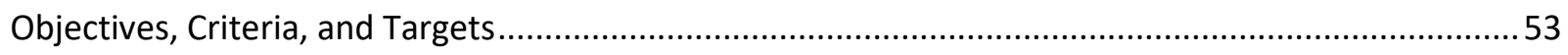

2.9.1. Monitoring of Water Quality Objectives, Criteria, and Targets .........................................53

2.9.2. Monitoring of Water Quantity Objectives, Criteria, and Targets ....................................56

2.9.3. Monitoring of Stream Morphology Objectives, Criteria, and Targets ...............................59

2.9.4. Monitoring of Terrestrial Objectives, Criteria, and Targets .............................................61

2.9.5. Monitoring of Aquatic Objectives, Criteria, and Targets ................................................62

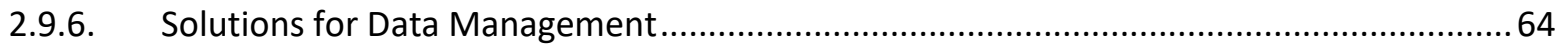

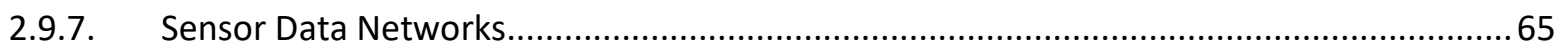

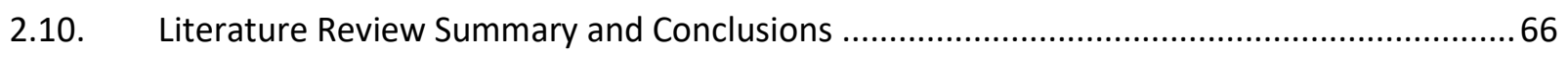

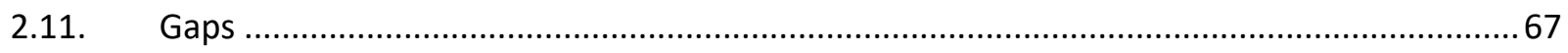

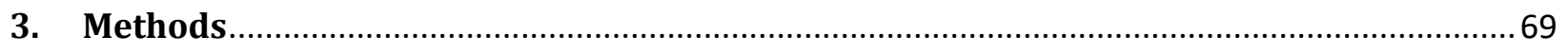

4. Selection of Stormwater Objectives, Criteria, and Targets …......................................... 72

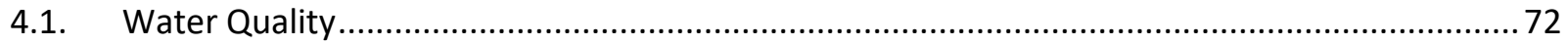




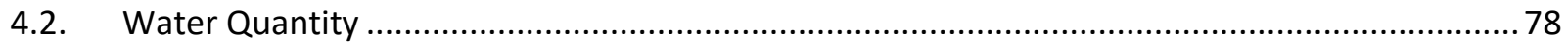

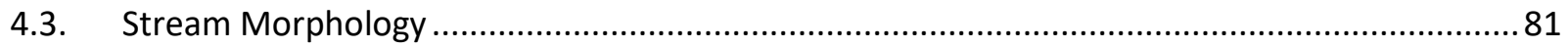

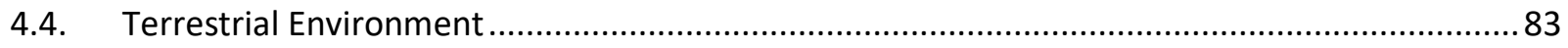

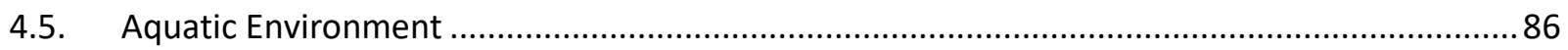

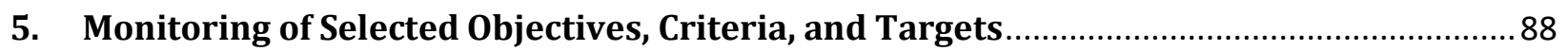

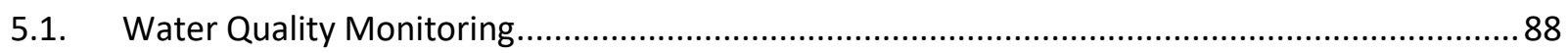

5.1.1. Traditional Water Quality Monitoring Techniques .......................................................90

5.1.2. Alternative Water Quality Monitoring Techniques ..................................................... 91

5.1.2.1. Alternative Total Phosphorus Monitoring Techniques ............................................99

5.1.2.2. Alternative Nitrate Monitoring Techniques .........................................................93

5.1.2.3. Alternative Ammonia Monitoring Techniques....................................................... 94

5.1.2.4. Alternative BOD Monitoring Techniques .......................................................... 95

5.1.2.5. Alternative Dissolved Oxygen Monitoring Techniques............................................95

5.1.2.6. Alternative Metals Monitoring Techniques ..........................................................96

5.1.2.7. Alternative Total Suspended Solids Monitoring Techniques ...................................97

5.1.2.8. Alternative Temperature Monitoring Techniques .................................................98

5.1.2.9. Alternative E.coli Monitoring Techniques................................................................99

5.1.2.10. Alternative Chloride Monitoring Techniques.........................................................99

5.1.2.11. Alternative $\mathrm{pH}$ Monitoring Techniques............................................................. 100

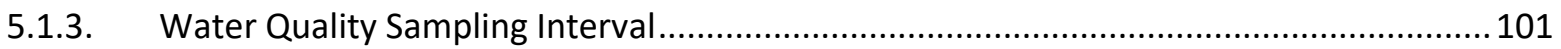

5.1.4. Instrument Robustness and Environmental Enclosure Considerations........................... 102

5.1.5. Selection of Preferred Water Quality Monitoring Method ...........................................102

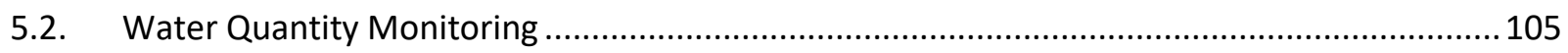

5.2.1. Traditional Water Quantity Monitoring Techniques ....................................................106

5.2.2. Alternative Water Quantity Monitoring Techniques ................................................... 107

5.2.2.1. Alternative Streamflow/Baseflow Monitoring Techniques .................................... 108

5.2.2.2. Alternative Groundwater Level Monitoring Techniques .....................................110

5.2.2.3. Alternative Percent Change in Flood Plain, Wetland, and Woodlot Coverage..........111

5.2.3. Selection of Preferred Water Quantity Monitoring Method .........................................112

5.3. Stream Morphology Monitoring Traditional \& Alternative Monitoring Techniques................112

5.3.1. Selection of Preferred Stream Morphology Monitoring Method...................................114

5.4. Terrestrial Environment Monitoring Traditional \& Alternative Monitoring Techniques .........114

5.4.1. Selection of Preferred Terrestrial Environment Monitoring Method............................... 115 
5.5. Aquatic Environment Monitoring Traditional \& Alternative Monitoring Techniques ..............116

5.5.1. Selection of Preferred Aquatic Environment Monitoring Method ..................................118

5.6. Integrated Information System Architecture................................................................. 118

6. Multi-Site Framework Simulation for Lovers Creek Subwatershed ...............................121

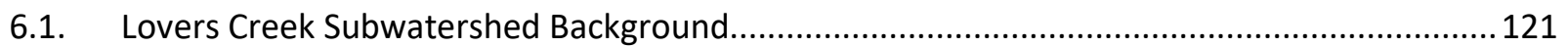

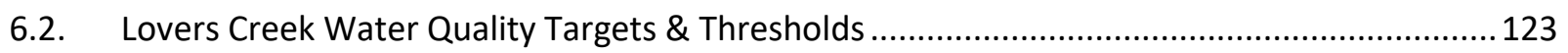

6.3. Lovers Creek Water Quantity Targets and Thresholds ..................................................... 124

6.4. Lovers Creek Stream Morphology Targets \& Thresholds ................................................... 126

6.5. Lovers Creek Terrestrial Environment Targets \& Thresholds ............................................... 126

6.6. Lovers Creek Aquatic Environment Targets \& Thresholds.................................................127

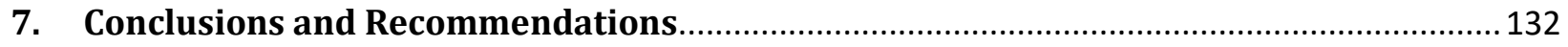

7.1. Multi-Site ECA Framework and Monitoring Requirements ................................................ 132

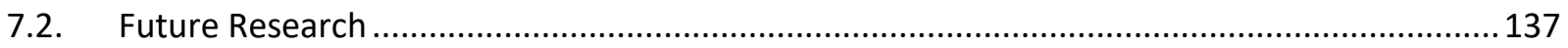

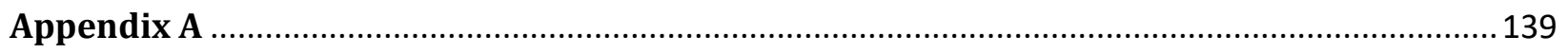

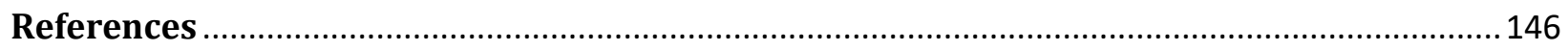




\section{LIST OF TABLES}

Table 1: Multi-Site ECA Water Quality Objective, Criteria, Targets, and Thresholds 76

Table 2: Multi-Site ECA Water Quantity Objective, Criteria, Targets, and Thresholds .............................80

Table 3: Multi-Site ECA Stream Morphology Objective, Criteria, Targets, and Thresholds ......................83

Table 4: Multi-Site ECA Terrestrial Environment Objective, Criteria, Targets, and Thresholds ................85

Table 5: Multi-Site ECA Aquatic Environment Objective, Criteria, Targets, and Thresholds....................87

Table 6: Water Quality Monitoring Traditional vs. Alternative ........................................................... 104

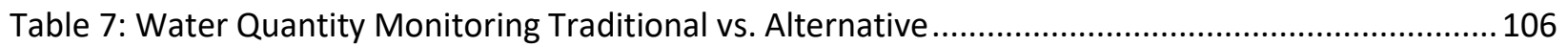

Table 8: Stream Morphology Monitoring Traditional vs. Alternative ..................................................113

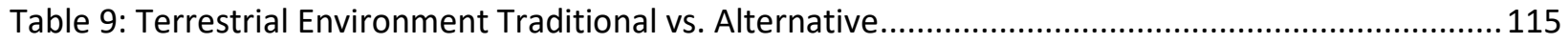

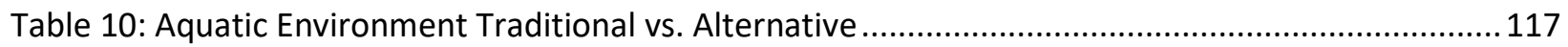

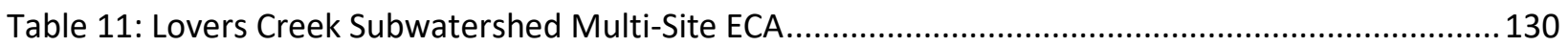

Table 12: Framework for Multi-Site Stormwater Environmental Compliance Approvals.......................135 


\section{LIST OF FIGURES}

Figure 1: Example of Setting Objectives, Criteria, Targets, and Thresholds .......................................12

Figure 2: Lake Simcoe Monitoring Stations (Ministry of the Environment and Climate Change 2015) .....32

Figure 3: Lake Simcoe Hydrology Monitoring Stations (Ministry of the Environment and Climate Change

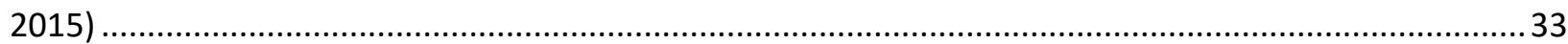

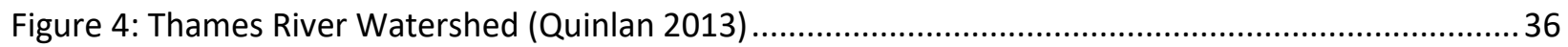

Figure 5: Credit Valley Conservation Authority Governance (Credit Valley Conservation Authority 2010)

Figure 6: Credit Valley Conservation Subwatershed Status (Credit Valley Conservation Authority 2010) 43

Figure 7: Recharge Status Silver Creek (Credit Valley Conservation; Schroeter \& Associates;

Environmental Water Resources Group; Aquafor Beech Limited; Jacques Whitford Environmental Limited; Waterloo Hydrogeologic Inc. 2003a).

Figure 8: CVC Real-Time Water Quality Network System Configuration (Credit Valley Conservation 2017)

Figure 9: Real-Time Water Quantity for Black River LSRCA (Environment Canada 2018).......................57

Figure 10: Adafruit eTape Liquid Level Sensor (Adafruit 2018) ............................................................58

Figure 11: UAV (A) 5cm Resolution vs Sattelite (B) $80 \mathrm{~cm}$ Resolution (Afshari et al. 2016) .....................60

Figure 12: Near Real-Time Forest Monitoring Diagram (Pratihast et al. 2016) .......................................62

Figure 13: Outline of Integrated Information System based on IOT (Fang et al. 2014) ............................65

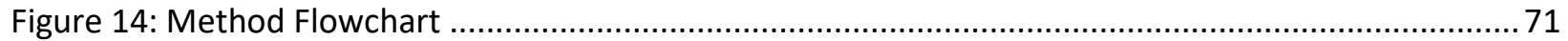

Figure 15: PWQO Dissolved Oxygen Guideline (Ministry of Environment and Climate Change 2016) .....77

Figure 16: Open Source Turbidity Sensor (DFRobot 2017) ...............................................................92

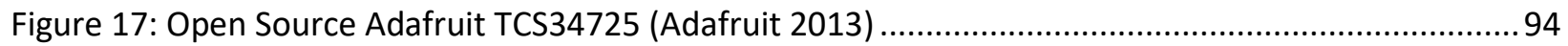

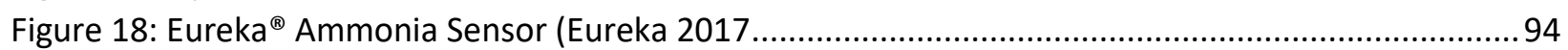

Figure 19: ModernWater BOD Sensor (ModernWater n.d.)............................................................... 95

Figure 20: Open Source Dissolved Oxygen Sensor (3Peak 2018) .......................................................96

Figure 21: Open Source Temperature Sensor (Maxim 2008) ...............................................................98

Figure 22: Open Source Electrical Conductivity Sensor (DFRobot 2018) ..............................................100

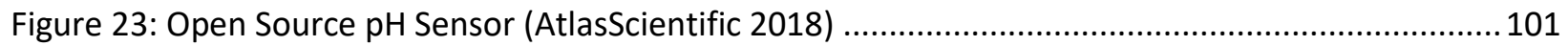

Figure 24: Open Source eTape Liquid Level Sensor (Adafruit 2018) ...................................................108

Figure 25: Open Source Optomax Digital Liquid Level Sensor (SST 2018) ...........................................109

Figure 26: Open Source HolyKell Water Level Sensor (HolyKell 2018) .................................................110

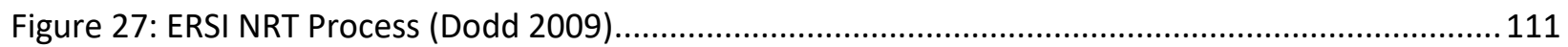

Figure 28: Lovers Creek Stormwater Control (Lake Simcoe Regional Conservation Authority 2012) ...... 121

Figure 29: Lovers Creek Controlled \& Uncontrolled Areas (Lake Simcoe Regional Conservation Authority

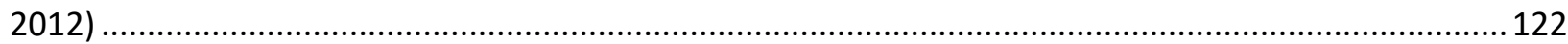

Figure 30: Lovers Creek Proposed Monitoring Station Locations......................................................... 124

Figure 31: Lovers Creek Baseflow (Lake Simcoe Regional Conservation Authority 2012) ......................125

Figure 32: Lovers Creek Land Cover (Lake Simcoe Regional Conservation Authority 2012) ...................127

Figure 33: Historical and Proposed Brook Trout Monitoring Locations (Lake Simcoe Regional

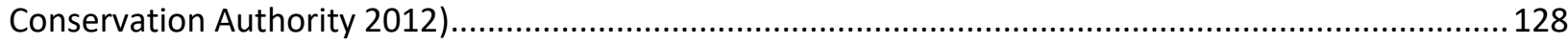

Figure 34: Historical and Proposed Mottled Sculpin Monitoring Locations (Lake Simcoe Regional Conservation Authority 2012). 129 


\begin{tabular}{|c|c|}
\hline \multicolumn{2}{|c|}{ LIST OF ABBREVIATIONS } \\
\hline API & Application Program Interface \\
\hline BOD & Biochemical Oxygen Demand \\
\hline BQE & Biological Quality Elements \\
\hline CA & Conservation Authority \\
\hline CCIL & Canadian Council of Independent Laboratories \\
\hline CCME & Canadian Council of Ministers of the Environment \\
\hline CVC & Credit Valley Conservation \\
\hline CWA & Clean Water Act \\
\hline DO & Dissolved Oxygen \\
\hline ECA & Environmental Compliance Approval \\
\hline eDNA & Environmental Deoxyribonucleic Acid \\
\hline GIS & Geographic Information System \\
\hline IWM & Integrated Watershed Management \\
\hline IOT & Internet of Things \\
\hline IIS & Integrated Information System \\
\hline LSPA & Lake Simcoe Protection Act \\
\hline LSPP & Lake Simcoe Protection Plan \\
\hline LSPIV & Large Scale Particle Image Velocimetry \\
\hline MECP & Ministry of Environment Conservation and Parks \\
\hline MOECC & Ministry of Environment and Climate Change \\
\hline MS4 & Municipal Separate Storm Sewers \\
\hline MVWHDO & Minimum Volume-Weighted Hypolimnetic Dissolved Oxygen \\
\hline NPDES & National Pollutant Discharge Elimination System \\
\hline NRT & Near Real-Time \\
\hline ORP & Oxidation Reduction Potential \\
\hline POC & Parameter of Concern \\
\hline PPM & Parts Per Million \\
\hline PQWO & Provincial Water Quality Objectives \\
\hline
\end{tabular}




$\begin{array}{ll}\text { PWQMN } & \text { Provincial Water Quality Monitoring Network } \\ \text { RUSLE } & \text { Revised Universal Soil Loss Equation } \\ \text { SWMP } & \text { Stormwater Management Program } \\ \text { TMDL } & \text { Total Maximum Daily Load } \\ \text { TRCA } & \text { Toronto and Region Conservation Authority } \\ \text { TSS } & \text { Total Suspended Solids } \\ \text { UAV } & \text { Unmanned Aerial Vehicles } \\ \text { USEPA } & \text { United States Environmental Protection Agency } \\ \text { UV } & \text { Ultraviolet } \\ \text { WMG } & \text { Watershed Management Groups } \\ \text { WFD } & \text { Water Framework Directive } \\ \text { WQI } & \text { Water Quality Index }\end{array}$




\section{Introduction}

Urbanization throughout Ontario has placed significant environmental pressures on receiving water bodies. An Increase in urbanization presents significant challenges relating to stormwater control. With Ontario's population expected to grow by approximately 31 percent over the next 28 years (Ministry of the Finance 2014) it is important that stormwater runoff is effectively regulated and managed to limit the impact on receiving water bodies. Without effective regulation and management, stormwater threatens to continue to change the hydrologic cycle, alter stream response to storm events, change stream morphology, degrade water quality, and affect aquatic habitat and ecology (Ministry of the Environment 2003). Ontario's watersheds have seen continual degradation because of development and changes to the physical characteristics of the watershed. Despite the recognized importance of wetlands and drainage areas, approximately $96.7 \%$ of these areas have been lost since the initial settlement in the Toronto area, 38.2\% loss in Durham, 37.9\% loss in Peterborough, and $43 \%$ loss in Northumberland (Molar et. al., 2012).

Effective stormwater management is not a simple task. In Ontario, watershed and subwatershed plans act as leading documents to help manage upstream activities to protect downstream receiving waters. Within these plans several other guidance documents are introduced which include; master stormwater management plans, erosion and sediment control plans, and pollution prevention plans. These documents serve as the overall guidance for the watershed, permitting of specific stormwater controls are covered under the Ontario Ministry of Environment, Conservation, and Parks (MECP), formerly the Ontario Ministry of Environment and Climate Change (MOECC), Environmental Compliance Approval (ECA) system.

Under the current ECA process stormwater controls are permitted based on the individual control. For example, a residential subdivision's stormwater management pond would be subject to an ECA. The ECA serves as the governing permit for the specific control and is issued with a number of best management practices, operation and maintenance procedures, and other administrative items to ensure the stormwater control is properly operated and maintained (Ministry of the Environment 2012). In 2014, the MECP Innovations Branch proposed an update 
to the current ECA system. This proposal came because of the administrative burden relating to enforcement and issuance of approvals. A number of stormwater controls were not being maintained and sometimes being installed and operated without an approved ECA (Ministry of the Environment and Climate Change 2014). As a result of the limited effectiveness of the current ECA system the MECP has proposed revising the permitting structure from a site specific ECA to a subwatershed based multi-site ECA.

To evaluate this proposed change several implementation gaps and challenges will need to be overcome. Examples of watershed-based regulation from the United States, Europe, and Canada can serve as suitable models, however careful adaptation of these examples is required. Identifying representative objectives, criteria, targets, and thresholds for a multi-site permit is the first step to successful implementation. Ensuring that the targets and associated thresholds can be effectively monitored will ensure that the permit can be evaluated to determine the effectiveness of the stormwater controls within the subwatershed based multi-site ECA.

\subsection{Objectives and Scope}

The objective of this research is to develop a framework for a multi-site ECA permit system for stormwater management in Ontario. This research will provide insight into the various objectives, criteria, targets, and thresholds, hereinafter defined as the 'framework parameters', which multi-site ECAs will need to encompass to provide protection of Ontario's subwatersheds. As part of the framework development, evaluation of traditional and alternative environmental monitoring methods in support of the framework parameters will be crucial for the proper implementation of the proposed multi-site ECA system.

The scope of work carried out to achieve the research objectives includes:

1) Identify and select the following framework parameters for inclusion in a multi-site ECA system:
a. Stormwater Objectives;
b. Stormwater Criteria;
c. Stormwater Targets; and,
d. Stormwater Thresholds. 
2) Evaluate and propose traditional or alternative monitoring solutions for the framework that will provide representative data for a multi-site ECA system.

3) Provide a summary table and recommendations for a multi-site ECA framework including framework parameters and monitoring of the parameters.

4) Simulate a multi-site ECA implementation using the framework parameters for Lovers Creek subwatershed in the Lake Simcoe watershed

The above-mentioned scope items were selected based on their applicability to support the research objectives and relevance to a multi-site ECA system framework.

\subsection{Structure of the Report}

Section 2 of this report consists of a literature review which examines the history of stormwater management in Ontario, the current and proposed multi-site ECA system for Ontario, watershed-based regulation examples, and examines three subwatersheds and their associated objectives, criteria, targets, thresholds, and monitoring methods. Section 3 outlines the methods used for achieving the objectives of this research. Section 4 evaluates and selects the parameters to be included in the multi-site ECA framework. The selection of the parameters to be included in the framework was carried out to achieve the first research objective. Section 5 evaluates traditional and alternative monitoring technologies that could be deployed within permit areas to monitor the framework parameters. Section 6 provides a simulation of a multi-site permit on Lovers Creek subwatershed using the multi-site ECA framework. Section 7 includes the summary table which outlines the multi-site ECA framework parameters and the proposed monitoring methods as well as conclusions and recommendations for implementation. 


\section{Literature Review}

The implementation of multi-site ECA objectives, criteria, targets, and thresholds and how to effectively monitor the permits compliance required an extensive literature review. Understanding the history of stormwater management within Ontario allows for the identification of potential objectives and criteria for which a multi-site ECA can draw upon. A review of the current ECA system compared to the proposed multi-site ECA system was conducted to identify the differences between the current and proposed systems while outlining the implementation gaps that exist. Watershed based regulation has been implemented in the United States, across Europe and within Ontario. While these examples of watershed-based regulation are not solely focused on the permitting of stormwater controls, they do provide insight into a possible administrative framework for the Ontario based multi-site ECA system. Furthermore, existing monitoring technologies were evaluated to determine their suitability for monitoring multi-site ECA compliance.

\subsection{History of Stormwater Management in Ontario}

To understand the current state of stormwater management in Ontario a historical review outlining the evolution of stormwater management is essential. While changes to Ontario stormwater management practices have occurred over the past decades, the permitting of stormwater controls has seen limited change. Reviewing stormwater management in Ontario has historically been divided into three time periods, prior to the 1990s, the 1990s, and beyond the year 2000 (Ternier 2012; Watt et al., 2003). The historical review outlined below will follow the same time periods.

\subsubsection{Prior to the 1990s}

Sewer networks were the primary form of stormwater management between 1880 and 1970 (Watt et al., 2003). These sewer networks were used to deal with the increased volume of stormwater runoff and the increased magnitude and flow of runoff. During this time these sewer networks were used to transport stormwater from upstream urbanized areas to downstream receiving waters (Watt et al., 2003). Minor sewer systems were focused on managing minor storms in the 2 - 10-year range with pipes sized to covey these peak flows (Watt et al., 2003). As urbanization increased there became a need for larger sewers to limit local flooding. Although 
environmental impact on receiving waters was occurring, limited measures were implemented to mitigate this issue.

Stormwater management in 1970 s continued to be primarily focused on flood control to limit damage to properties (Bradford and Gharabaghi 2004). However, during this period additional stormwater control measures were introduced. The introduction of the major sewer and stormwater management ponds allowed for control of 100-year storms (Watt et al., 2003). While flooding was still the primary focus of stormwater management prior to the 1990s, concerns had expanded to flood peaks and changes to stream morphology due to sediment inflows and changes to transport capacity (Zimmer et al. 2007). Additionally, water quality became a concern in the 1980s, which was a precursor for amendments and changes to stormwater management in the 1990s (Credit Valley Conservation Authority and Toronto Region Conservation Authority 2010). Although new management measures were introduced, the increased urbanization of southern Ontario lead to more impervious surfaces such as roads, driveways, parking lots, and roof tops which lead to increased stormwater runoff resulting in a number of environmental impacts on receiving waters (Bradford and Gharabaghi 2004). Additionally, the notion of pre-development flows equaling post-development flows began to govern decision making (Ternier 2012). In 1987 the Ministry of Natural Resources realized additional stormwater control guidance was required and as a result the 'Guidelines on Erosion and Sediment Control for Urban Construction Sites' was introduced (Ministry of Natural Resources 1987). This guidance document was introduced to help mitigate eroded sediment occurring during the construction phase of any urban development.

\subsubsection{The 1990s}

The 1990s brought about change to the way stormwater was managed in Ontario. While flood control was still a primary focus of stormwater management, additional variables such as stormwater quality was introduced. In 1991, the 'Interim Stormwater Quality Control Guidelines for New Development' were introduced in attempt to primarily govern and monitoring stormwater quality (Ministry of Natural Resources and Ministry of Environment 1991). The 1991 guidelines brought forward additional environmental concerns such as erosion, fisheries, groundwater recharge, and water quality (Ministry of Natural Resources and Ministry of 
Environment 1991). The "goal of the Interim Stormwater Quality Control Guidelines is the protection and enhancement of pre-development hydrologic and water quality regimes" which coincided with the need for proper control from a developer, municipality, conservation authority, and provincial agency standpoint (Ministry of Natural Resources and Ministry of Environment 1991).

In 1993, a series of guidance documents were introduced outlining the need for stormwater management at the watershed and subwatershed level. In June of 1993, the Ministry of Environment and Energy along with the Ministry of Natural Resources issued the 'Water Management on a Watershed Basis: Implementing an Ecosystem Approach' which identified the correlation between human activities and the associated environmental impact on water bodies (Ministry of Natural Resources and Ministry of Environment and Energy 1993c). This guideline document was revolutionary at the time because it attempted to apply the ecosystem approach to land use planning through watershed management plans (Ministry of Natural Resources and Ministry of Environment and Energy 1993c). Although this refers to the overall management of the watershed, the goal of the multi-site ECA is similar from the standpoint of a management system based on the ecosystem approach. Also in 1993, the 'Subwatershed Planning' document was published which outlines the importance of subwatershed planning within the overall goals of the watershed plan (Ministry of Natural Resources and Ministry of Environment and Energy 1993b). The guideline was intended for land use planning, land developers, and experts in resource management and described the key items required for a subwatershed plan. This guidance document is key for the implementation of a multi-site ECA based on subwatershed boundaries because it describes how subwatershed plans are developed and outlines the key considerations which will need to be accounted for within the multi-site ECA permit. The third guidance document issued in 1993 was the 'Integrating Water Management Objectives into Municipal Planning Documents' publication. This document was developed to assist municipalities in developing official plan policies. Within the official plan policies are watershed and subwatershed plans which further outline the goals and objectives relating to water resources protection and management (Ministry of Natural Resources and Ministry of Environment and Energy 1993a). 
In 1994, the "Stormwater Management Practices Planning and Design Manual' was issued by the Ontario Ministry of Environment and Energy. The 1994 planning and design manual represented a significant shift in stormwater management and brought forward a holistic approach to management starting at the watershed and subwatershed level (Ministry of the Environment and Energy 1994). This document highlighted the fact that stormwater management in Ontario was no longer primarily focused on flood control but rather a whole other host of management areas while implementing the idea of the 'treatment train approach' (Ministry of the Environment and Energy 1994). Identifying that stormwater management required lot level controls, conveyance controls, and end-of-pipe controls represented the foundation of the modern day ECA which are required for the individual controls regardless of their location within the 'treatment train approach'.

\subsubsection{Beyond the Year 2000}

In March 2003, the Ministry of Environment released the 'Stormwater Management, Planning and Design Manual' as an update to the 1994 manual discussed previously. Updates to the manual most notably dealt with in-stream erosion control and water balance objectives, namely pre-development flow conditions equaling post-development flow conditions (Bradford and Gharabaghi 2004). Emphasis on the 'treatment train approach' was further developed in the 2003 update with a focus on lot-level controls for stormwater management (Bradford and Gharabaghi 2004). Building on the 1994 manual in 2003 the objectives of stormwater management were clearly focused on protecting ground and surface water quality, preventing stream erosion, maintain groundwater and baseflow, and protection of aquatic habitat and aquatic species (Ministry of the Environment 2003). The 2003 manual is seen as the most relevant guidance document for stormwater management and control in Ontario, however the manual neglects to comment on potential implementation gaps because of Ontario's cold weather climate.

In order to further the emphasis on controlling stormwater at the source, the Toronto Region Conservation Authority and Credit Valley Conservation Authority developed the 'Low Impact Development Stormwater Management Planning and Design Guide' which was created to provide engineers, ecologists and planners with information relating to the design and 
implementation of Low Impact Development (LID) (Credit Valley Conservation Authority and Toronto Region Conservation Authority 2010). In order to meet the goals of the 2003 manual, LIDs can be implemented to maintain the hydrologic and water quality characteristics which echo pre-development conditions (Zimmer et al. 2007). Within the LID manual design considerations for cold climates are evaluated which helps fill the implementation gaps previous noted within the 2003 manual. LIDs represent additional methods for stormwater management throughout the entire 'treatment train approach' and will represent an important function in the proper implementation and operation of a multi-site ECA approach for stormwater permitting in Ontario.

\subsection{Current Environmental Compliance Approval System}

Environmental Compliance Approvals in Ontario govern the release of pollutants to air, land, and water in addition to the storage, transport and disposal of waste. The release of pollutants to air, land, and water does not take into consideration the cumulative effect or benefits of controls put in place to limit the release of contaminants. The culmination of these permits could represent environmental degradation. These activities are governed under the Environmental Protection Act, R.S.O. 1990, Chapter E.19, and the Ontario Water Resources Act, R.S.O. 1990, Chapter O.40 (Ministry of the Environment 2012). Under the Environmental Compliance Approval system, stormwater controls fall under sewage and are issued for lot-level, conveyance, and end-of-pipe controls. The current system requires the approval for each specific type of control whether it be for municipal works or industrial activities (Ministry of the Environment 2012). Under the current system stormwater ECAs can be issued for industrial or municipal and private sewage works. For industrial applications a completed ECA Application Form in addition to the following documents are required as part of the application process (Ministry of the Environment 2012):

- Design Report;

- Stormwater Management Plan;

- Stormwater Management Report;

- Environmental Impact Analysis;

- Surface Water Impact Assessment; 
- Groundwater Impact Assessment

- Site Plan

- Sewage Quantity and Quality Characteristics;

- Engineering Drawings and Specifications.

For municipal and private sewage works, the MECP understands that the process for these types of projects have multiple stages including planning and design. These projects are also highly variable in comparison to industrial applications. The following documents are required in addition to the ECA Application Form for municipal and private sewage works (Ministry of the Environment 2012):

- Design Reports for Municipal or Private Sewage Works;

○ Design Report for Sanitary Sewers

○ Design Report for Storm Sewers

○ Design Report for Sewage Pumping Stations

○ Design Report for Stormwater Management

○ Design Report for Sewage Treatment and Disposal Works

- Preliminary Engineering Report

- Environmental Impact Analysis

- Surface Water Impact

- Groundwater Impact Assessment

- Final Plans

- Stormwater Management Plan

○ Storm and Sanitary Sewers

- Major Sewage Works (Sewage Treatment and Disposal Facilities, Stormwater Management Facilities, Pumping Stations)

- Sewage Works - Specifications

- Detailed Description of Proposed Works

Stormwater ECAs are issued with many best management practices, operation and maintenance items, and other administrative controls which govern the construction and 
operation of the specific control. The operation and maintenance section of the ECA requires the owner of the stormwater control to maintain compliance with the Ministry issued approval. For example, a stormwater management pond will be designed with a minimum liquid retention volume which is to be maintained always under the ECA requirements. An example of an ECA for a stormwater management pond is found in Appendix A. Under the example approval the owner of the control is required to inspect the pond at least once per year to prevent excessive sediment and vegetation build-up (Ministry of the Environment and Climate Change 2013). Temporary erosion and sediment control is required during construction with inspection of these controls to occur every 2 weeks and after each significant storm event (Ministry of the Environment and Climate Change 2013). The operation and maintenance section of this ECA is an example of the enforcement and administrative burden on the MECP. The sheer number of wet ponds constructed in subdivisions in addition to other stormwater controls requires a substantial amount of Ministry staff to ensure the controls are being maintained in accordance with their ECA. It is unknown whether the current ECA system is achieving environmental benefit or failing to meet the environmental needs of the watershed. However, given the lack of oversight and enforcement the current system is failing from an administrative standpoint. The lack of information associated with individual stormwater controls and if they are in compliance and performing as designed limits our understanding of the effectiveness of the current system.

\subsection{Proposed Multi-Site Environmental Compliance Approval System}

The degradation of Ontario's watersheds has placed increased importance on altering the current stormwater permitting approach. A number of watersheds have seen issues relating to the lack of stormwater controls including decreased water quality, decreased aquatic health, and increased peak flow (Toronto and Region Conservation Authority 2008). Within the Humber River Watershed, only about " $25 \%$ of the urban area in the watershed has some level of stormwater management (Toronto and Region Conservation Authority 2008)." These issues are widespread throughout Southern Ontario and impact a variety of other watersheds. The current stormwater permitting practice will continue to degrade Ontario's watersheds unless amendments and changes are implemented. To combat these issues the Ministry of Environment and Climate Change Innovations Branch has proposed to revise the site-specific nature of the current ECA 
process with a multi-site ECA approval based on subwatershed boundaries. Within this system the numerous municipal and private stormwater ECAs (excluding industrial) would be combined into one multi-site ECA. The proposed system aims to better realize the commitment to improving stormwater management under the Great Lakes Strategy (Government of Ontario 2012), draft Canada-Ontario Agreement (Government of Canada 2014), and the Lake Simcoe Protection Plan (Ministry of Environment et. al 2009). Under the proposed multi-site ECA system the Ministry would set out the multi-site ECA objectives, criteria, and targets for the specific permit area. The municipalities would be responsible for maintaining the approval and ensuring the specific targets are being met. Where municipalities are having difficulty with maintaining permit compliance it would lead to further investigation of existing stormwater and the potential for construction of new controls. The municipality could use the multi-site ECA as a mechanism to inventory, investigation, and rectify specific control issues within their permit area to achieve compliance at the receiving water level. Municipalities could involve several private stakeholders, non-profit organizations, and volunteer groups to assist in the implementation of the multi-site ECA. The multi-site ECA would need to include criteria that are directly related to stormwater impacts (Ministry of the Environment and Climate Change 2014). Criteria and targets would need to be issued that can be effectively monitored with the current available technology and financial resources available.

\subsection{Stormwater Objectives, Criteria, Targets, and Thresholds for Multi-Site ECAs}

According to the TRCA, stormwater management in Ontario is governed by four main objectives, including: stormwater quantity, stormwater quality, erosion, and water balance practices (Toronto and Region Conservation Authority 2012). Outside of the aforementioned objectives other objectives such as stream morphology, the terrestrial environment, and the aquatic environment required objectives as these other variables can cause stormwater issues and be impacted by stormwater issues (Ministry of Environment, Ministry of Natural Resources 2009)(Credit Valley Conservation Authority 2005)(Upper Thames River Conservation Authority 2012). Managing the quality and quantity of runoff through effective stormwater management can greatly improve and preserve Ontario's receiving water bodies (Toronto and Region Conservation Authority 2012). 
Stormwater objectives act as the primary theme for preservation and protection within a specific watershed or subwatershed. Stormwater objectives can include common themes for protection as well as specific issues that a watershed is experiencing. Stormwater criteria are the parameters under which the objectives are described. The criteria support the overall objective but can include more than one parameter. These parameters can be quantitative or qualitative parameters depending on the objective. Stormwater targets and thresholds are specific variables for which the criteria are governed. For example, the targets for stormwater quantity include streamflow, baseflow, groundwater level, and percent change in flood plain, wetlands, or woodlots. Thresholds then become a specific value for which the targets are monitored. Figure 1 outlines the principle behind objectives, criteria, targets, and thresholds setting for a multi-site ECA.

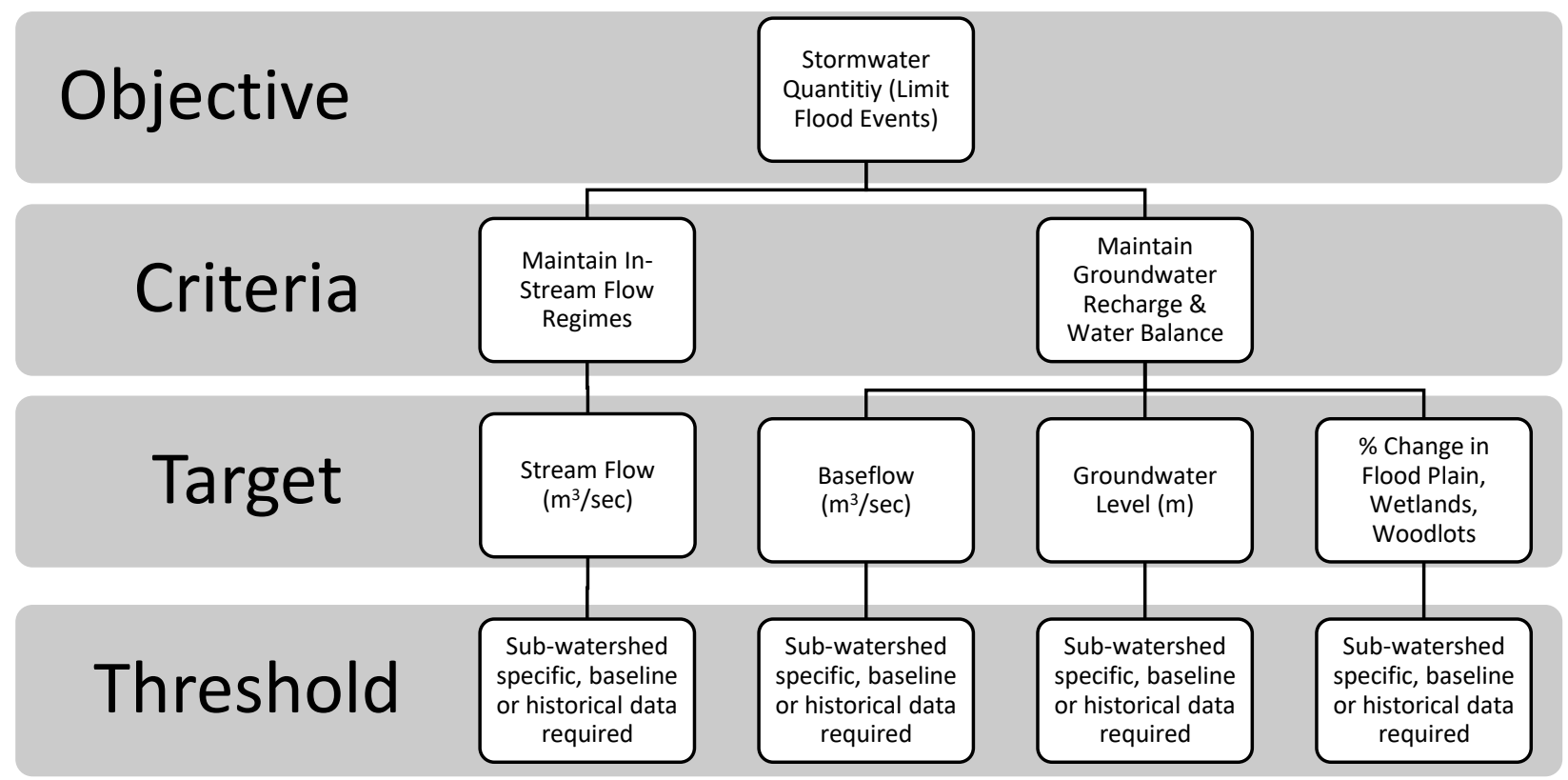

Figure 1: Example of Setting Objectives, Criteria, Targets, and Thresholds

2.4.1. Water Quantity Objective, Criteria, Targets, and Thresholds

The earliest goal of the stormwater quantity objective in Ontario deals with flood protection. Flood protection is a concern due to downstream properties being affected by increased flooding due to upstream activities and/or land modifications. A common target and 
threshold was for pre-development flows are to match post-development flows for all storms up to 100 year storms which in theory will limit the flood potential (Toronto and Region Conservation Authority 2012).

In most watersheds across Ontario, the criteria dealing with stormwater quantity address maintaining in-streamflow regimes and maintaining groundwater recharge and water balance. Groundwater recharge is defined as the replenishment of the groundwater system from precipitation (Toronto and Region Conservation Authority 2012). Natural feature protection allows for the preservation of woodlands, wetlands, and watercourses which are key features for preserving the natural features of a watershed. Groundwater recharge criteria is measured by catchment slopes, water table elevations, depth to bedrock, soil infiltration rates, flood plains, wetlands, and drinking water well proximity (Toronto and Region Conservation Authority 2012).

Targets associated with these two criteria include streamflow, baseflow, groundwater level, and percent change in flood plain, wetland, and woodlot coverage. The subsequent thresholds are subwatershed specific which requires baseline or historical data to set the specific numerical threshold associated with the stormwater quantity targets.

\subsubsection{Water Quality Objective, Criteria, Targets, and Thresholds}

Stormwater quality is important for protecting Ontario's receiving waters which are used for recreational activities, as a source for potable drinking water, and which provide economic benefit. Under the Fisheries Act the discharge of deleterious substances is prohibited which would degrade or alter the water quality therefore effecting fish and fish habitat (Minister of Justice 2013).

Stormwater quality criteria correspond to the improved water quality which frames the overall protection of Ontario's receiving waters in efforts to protect water resources. Primary stormwater quality governance is associated with $80 \%$ total suspended solids (TSS) removal (Toronto and Region Conservation Authority 2012). While TSS removal is a minimum requirement, additional quality targets can be introduced such as water quality parameters posted under the Provincial Water Quality Objectives (PWQO) as well as subwatershed specific contaminants of concern. Examples of PWQO targets include: 
- Total phosphorus;

- Nitrate;

- Ammonia;

- Biological Oxygen Demand (BOD);

- Dissolved oxygen (DO);

- Metals;

- Temperature;

- E.coli;

- Chloride; and,

- $\mathrm{pH}$.

The above noted water quality parameters are common parameters of concern for Ontario watersheds. Their relevance to specific watersheds is evaluated in Section 2.6. Stormwater runoff can contribute to the concentrations of these parameters in receiving waters making mitigation and control of them essential to watershed health. Ontario specific research is in abundance for several of the aforementioned parameters and how they can impact local relieving waters.

Total phosphorus and other nutrient loading contributes to eutrophication problems which have been studied in depth throughout Ontario (Phosphorus et al. 1981)(Winter and Duthie 2000)(Eyles, Meriano, and Chow-Fraser 2013)(Long et al. 2014)(Kim et al. 2016). Kim et al. 2016 studied the relationship between total phosphorous and watershed attributes such as land use cover and physiographic characteristics to better understand how these parameters impact concentrations in the Bay of Quinte watershed. Nitrate, chlorides, BOD, and DO loading has both a role in eutrophication and ecological impact (Hill 1978)(Bazinet, Gilbert, and Wallace 2010). Maintaining the terrestrial environment, which is a common theme in watershed protection, can help mitigate the potential nitrate impacts on receiving waters (Sliva and Williams 2001). With ongoing land development, nutrient loading will continue to be a concern for Ontario watersheds. Other stormwater contaminants of concern including metals have an impact on both ecology and human health receptors giving reason for their inclusion within the various watershed plans (Brindle 1990)(Meriano, Eyles, and Howard 2009). E.coli and other bacteria 
related to stormwater runoff from warm-blooded animals are a primary concern for drinking water and recreational standards (Lyautey et al. 2010)(Garzio-Hadzick et al. 2010). These management of these common environmental contaminants of concern are included in the PWQO's and watershed plans due to their potential impact on the natural environment.

\subsubsection{Stream Morphology Objective Criteria, Targets, and Thresholds}

Stream morphology is another common objective within stormwater management in Ontario. Within the stream morphology objective, the primary criteria include; limiting stream erosion and preservation of stream morphology as well as maintaining and preserving flood plains. Stream morphology crosses over with the stormwater quantity objective given that stream erosion mitigation is often controlled by reducing and limiting peak flow, and implementing source control to reduce total runoff (Toronto and Region Conservation Authority 2012). Stream morphology targets include; percent change in stream cross-sections, \% change in channelization, and \% change in flood plain coverage.

Controlling stormwater at the source is perceived as a way to limit stream morphology impacts. This is achieved through limiting the percent of impervious surfaces within the watershed. Additionally, end-of-pipe controls can be effective for limiting erosion in the receiving waters (Nemes et al. 2010). A minimum target retention time of $25 \mathrm{~mm}$ over 48 hours is required for stormwater management ponds within Toronto (Toronto and Region Conservation Authority 2012). For on-site measures the TRCA requires a retention depth of $5 \mathrm{~mm}$ (Toronto and Region Conservation Authority 2012).

\subsubsection{Terrestrial Environment Objective, Criteria, Targets, and Thresholds}

The terrestrial environment objective is an important stormwater objective because it impacts the function of the other stormwater objectives. For example loss of vegetation and woodlot cover can negatively impact water quality parameters such as total phosphorous loading (Evans et al. 1996)(Eimers et al. 2005).

The primary criteria which govern the terrestrial environment objective include the preservation and restoration of woodlots as well as the preservation and restoration of wetlands. Common targets include the following: 
- Percent change in natural vegetative and woodlot cover;

- Percent change in naturalized riparian areas;

- Percent change in wetland area; and,

- Percent change in shoreline.

Thresholds for terrestrial environment targets are generally watershed specific due to geographical variability. Applying the same percent coverage for all subwatersheds within Ontario would limit the effectiveness of the multi-site ECA permitting system.

\subsubsection{Aquatic Environment Objective, Criteria, Targets, and Thresholds}

Aquatic health is important for the proper function of Ontario's watersheds and subwatersheds (Loomer and Cooke 2003). As a result, aquatic environment objectives are included as part of stormwater management objectives throughout Ontario. Aquatic environments can be greatly impacted if other stormwater objectives such as water quantity, water quality, stream morphology, and terrestrial are not properly governed and monitored.

The primary criteria for aquatic health include improved water quality and maintaining and promoting species biodiversity and biomass density. Water quality plays a crucial role in supporting aquatic health. In the Lake Simcoe Watershed, for example, phosphorus loading and the depletion of dissolved oxygen has severely impacted the cold-water fish habitat within Lake Simcoe (Evans et al. 1996). Maintaining and promoting biodiversity and biomass density can be impacted by invasive species as well as other chemical and physical changes throughout the watershed (Toronto and Region Conservation Authority 2012).

For the maintenance and promotion of species biodiversity and biomass density, targets can include factors such as percent change in biodiversity, biomass density, and presence or absence of invasive species.

\subsection{Watershed Based Regulation Examples}

Watershed based regulation has been implemented in several geographical regions around the world in efforts to apply the 'ecosystem approach' to water resource management. A key part of this approach is to avoid relying on political boundaries to govern and regulate water resources. While the examples discussed in the following sections are not exact permitting 
models for the Ontario based multi-site ECA system, they represent a watershed-based approach to water resource management.

\subsubsection{Water Framework Directive}

In 2000, the European Water Framework Directive (WFD) became a legally binding policy that provided a single common framework for water management and protection in Europe. European water resource management began to take shape as far back as 1975 when the first drinking water and drinking water directives were enacted (Kaika 2003). While the process started in 1975 the current WFD was a result of a 12-year long policy process that began with the Water Policy Ministerial Seminar in Frankfurt in 1988, which had implementation difficulties as a result of a directive on ecological quality in 1993 (Kallis 2001). In 1996, the European Community Policy was developed and was the basis for the WFD proposal in 1997. Three years later on June 30th, 2000 the WFD was enacted which encompassed 27 countries across Europe and represented a water policy focused on water resource management through the 'ecosystem approach' (Kallis 2001).

The primary goal of the WFD is to improve European aquatic habitats and achieve 'good ecological status', defined as a slight deviation from 'high ecological status' with no or little human impact (Moss 2008). The achievement of 'good ecological status' was to be realized 15 years after the year 2000 implementation date. 'Good ecological status' is based off of five 'biological quality elements (BQE)', hydro-morphological and physio-chemical quality elements with BQE being the most important (Borja et al. 2010). The five BQE's under the WFD include: phytoplankton, macroalgae, phanerogams, macroinvertebrates, and fishes. The BQE's in addition to hydro-morphological and physio-chemical quality elements serve as the WFD's primary indicators for success or failure of the legislation. Identifying indicators for the Ontario based multi-site ECA which can be directly related to stormwater events will be crucial for the implementation of a successful permitting system. Similar to the proposed Ontario based system setting targets for the indicators or criteria is required. Under the WFD, targets are set by comparing present situations to reference conditions. Reference conditions do not equal 'pristine' conditions but rather a slight deviation from the reference condition (Borja et al. 2010). There are four ways to determine a reference condition: 
1. Identifying minimally impacted receiving waters similar in nature;

2. Reviewing historical data which represents a pristine water course;

3. The use of predictive models; and,

4. Expert judgement.

Determining reference conditions based off the aforementioned parameters presents implementation difficulties due to the lack of pristine areas in Europe, determination of which historical data set to use, and limitations in modelling technologies (Borja et al. 2010). Nonetheless, the proposed Ontario based multi-site ECA system will need to determine and decide on the appropriate methodology for setting targets for each subwatershed permit.

Monitoring of the BQE's, hydro-morphological, and physio-chemical quality elements to determine if the targets are achieved is an important function of the WFD. BQE's such as phytoplankton are monitored for species composition and counting's twice a year, while macroalgae, macroinvertebrates, and fishes are monitoring for species composition and counting every three years. Phanerogams are monitored for surface area of eelgrass beds and saltmarshes every three years (de Jonge, Elliott, and Brauer 2006). Hydro-morphological quality elements such as the geomorphology of a system is evaluated through soundings one per year. Physio-chemical quality elements including: temperature, oxygen, salinity, nutrients, and $\mathrm{pH}$ are sampled once per three months. Other pollutants that are deemed a concern are also sampled once per three months while pollutants that are deemed priority substance are sampled once per month (de Jonge, Elliott, and Brauer 2006). While these elements are monitored in accordance with the WFD a number of issues arise when trying to ensure monitoring methods are consistent across Europe. Sampling methods, lab procedures, and assessment metrics have in some cases developed non-representative stressors (Hering et al. 2010). To limit these discrepancies, the intercalibration process was developed by the European Commission to standardize measurement and assessment across the WFD.

Before the 1970s, single parameters were measured at a limited number of monitoring stations leading to limited representative data sets (de Jonge, Elliott, and Brauer 2006). In the 1970s, marine monitoring and protection became more prevalent with nutrients being measured 
due to the reduction in species diversity (de Jonge, Elliott, and Brauer 2006). Historically, these water quality parameters were monitored using a surveillance monitoring method. With the implementation of the WFD two additional types of monitoring, operational monitoring, and investigative monitoring are utilized to monitor not only water quality but the BQE's and hydromorphological parameters as well.

Surveillance monitoring is conducted to identify any change within a water course. As previously mentioned, surveillance monitoring was used to identify change within a water course. According to the WFD the objective of surveillance monitoring is to provide information for:

- Supplementing and validating the assessment of the likelihood that watercourses will fail to meet the various quality objectives;

- To design future monitoring programs that are efficient and effective;

- Assessment of long-term changes in natural conditions to distinguish between non-natural and naturally occurring changes within the watershed; and,

- The assessment of long-term changes from anthropogenic sources (Ferreira et al. 2007).

The minimum monitoring frequencies are defined under the WFD however the number of monitoring locations is not. The frequency of observations should be sufficient enough to obtain a representative picture of the water body status (Ferreira et al. 2007).

Operational monitoring also known as compliance monitoring is completed to assess predefined targets which are set to represent a threshold for action (Borja et al. 2010). Under the WFD, operational monitoring focuses on assessing the water bodies risk of failing their environmental objectives and to assess changes within the water body with emphasis on the BQE's, the hydro-morphological parameters, and the physio-chemical parameters (Ferreira et al. 2007).

Investigative monitoring is carried out when a change within the aquatic environment is occurring. This type of monitoring attempts to understand why there is a change within the 
aquatic environment and to identify if mitigation or protective measures are required. Operational monitoring is also carried out to understand the magnitude and impacts of accidental pollution. The outcome of the operational monitoring is then used to establish a mitigation approach to limit the environmental impacts associated with accidental pollution (Ferreira et al. 2007).

As previously mentioned the monitoring frequencies for the various BQE's, hydromorphological, and physio-chemical parameters are outlined under the WFD but the number of monitoring stations per water body is not defined (Borja et al. 2010). The lack of guidance or regulation on the number of monitoring stations has been drawing criticism from the various stakeholders within the WFD. The issue with the limited guidance is that the monitoring programs should have enough monitoring stations to ensure spatial and temporal factors are appropriately assessed (Ferreira et al. 2007).

The requirement of reaching 'good ecological status' for all water bodies by 2015 has passed. Since the deadline has recently passed it is difficult to assess the overall effectiveness of the WFD. A large amount of monitoring data has been collected, however, as this data is not centrally stored, assessment of this data will take a great deal of time (Hering et al. 2010). Preliminary assessment in England identified that only 32\% of waters in England will achieve 'good' or 'good potential' status by 2015 (Priestley 2015). The WFD recognizes that there are specific circumstances where the 2015 deadline may not be met and implemented Articles 4 and 5 to allow for potential shortcomings which are as follows:

1. The 2015 deadline can be extended to 2027 if achieving 'good' status would be disproportionally expensive, or the magnitude of improvement is to great that the 2015 targets are not realistically or technically feasible;

2. Less stringent standards can be employed if the water body is impacted by human activity to the point where restoration to natural levels would be disproportionally expensive or not technically feasible; and,

3. Temporary degradation can be allowed should a unforeseen circumstance occur such as flooding, prolonged drought, or accidents (Priestley 2015). 
As the WFD is a legally binding piece of legislation member states can be fined for noncompliance. The fines do not follow specific non-compliance thresholds and are defined through a European Commission evaluation process. The European Commission will monitor the progress of the WFD and will make judgement based on the response from the non-compliant Government. It has been noted that there are currently 30-40 ongoing infringement proceedings under the WFD (Priestley 2015). Although there are mechanisms for punishing non-compliance it appears that the WFD is an evolving piece of legislation that is looking to work with the Member States to promote restoration of European waters rather than financially punish its members.

\subsubsection{National Pollutant Discharge Elimination System: Municipal Separate Storm Sewer Systems (MS4's)}

The National Pollutant Discharge Elimination System (NPDES) first came into existence under the Clean Water Act (CWA) in 1972 (Dornsife 2005). The CWA was enacted to restore and maintain the chemical, physical and biological characteristics of waters within the United States. Within the CWA the NPDES was introduced which made it "unlawful to discharge a pollutant unless that discharge takes place in compliance with either a NPDES permit or a dredge and fill permit (Dornsife 2005)." Additional point sources such as man-made ditches and pipes in industrial, municipal and other facilities are required to obtain permits if discharge occurs directly to surface waters. Similarly, to the current ECA system the NPDES permit acts as a permission to pollute if the terms of the permit are upheld.

In 1987, an amendment to the CWA was enacted under section 402(p) which addressed the growing concern of point source stormwater pollution which included municipal separate storm sewers (MS4s) (Harrop 2001). Essentially the MS4s govern the stormwater conveyance system from point of stormwater collection until the discharge point into receiving waters under the NPDES (Minan 2005). This came about because urban runoff was determined to be the leading source of water quality issues which incurs significant economic impact (United States Environmental Protection Agency 1988) (Minan 2005). Stormwater discharges from storm sewers are required to reduce pollutants to the maximum extent practicable under the MS4 permit requirements (Minan 2005). Although stormwater is generally a nonpoint source pollutant, the collection and discharge at stormwater outfalls is considered a point source and is 
regulated under the MS4 (Dornsife 2005). While MS4 legislation was introduced in 1987 it took until 1990 for the first MS4 permits to be issued which were for medium and large cities. In 1999, permits were issued for smaller urban and rural areas.

Each MS4 area is required under the legislation to develop and implement a Stormwater Management Program (SWMP) to reduced contamination of stormwater runoff and eliminate illicit discharges throughout the permit area (United States Environmental Protection Agency 2014). Additionally, the United States Environmental Protection Agency (USEPA) encourages municipalities to utilize a watershed-based approach through the issuing of system-wide permits. Through the use of system-wide permits and stormwater management programs based on the specific permit area, a representative permit can be implemented (Harrop 2001). Permit areas are also encouraged to form Watershed Management Groups (WMG) which can assist with the development and implementation of the SWMP. In the Ontario context the multi-site ECA permit area would need to implement representative stormwater management programs based on the specific environmental concerns of the specific permit area.

The primary goal of the MS4 permits are to improve water quality in receiving waters and to limit the environmental impact relating to point source stormwater discharges. The USEPA had a lack of information relating to effluent limits for pollutant concentration and mass. As a result, the USEPA developed an interim policy for water quality limits (United States Environmental Protection Agency 1996). While the interim policy provided recommendations for water quality standards under the MS4 permit the USEPA does not establish defined standards for all permits. The focus is on improving Best Management Practices and the development of SWMP as a means for developing water quality standards (Dornsife 2005). The Watershed Management Program Plan for Los Angeles River Upper Reach permit area is an example of the development of best management practices and standards based off a specific permit area. Vehicle brake pads and lead-based wheel weights were identified as a significant source of copper loadings (CWE Corporation 2014). As a result of these findings brake pads containing copper and lead-based wheel weights are to be phased out within the permit area (CWE Corporation 2014). The water quality standards for the permit area were based off of historical total maximum daily loads (TMDLs) for nitrogen, trash, metals, and bacteria (CWE Corporation 2014). Determining the 
number of sampling locations is dependent on the SWMP. As the MS4 permits deal with specifically water quality the monitoring methods utilized could assist with fulfilling the water quality objective within the Ontario based system.

Of the 1059 MS4 permits issued in 1990, only two compliance actions have been filed as of the year 2000. (Harrop 2001). These two compliance actions deal with permit areas failing to develop a SWMP to deal with adverse stormwater quality discharges. Non-compliance can result in significant financial penalties which can be issued to the permit area by the USEPA (Minan 2005). While non-compliance penalties may need to be assessed under the multi-site ECA system, it is outside the scope of this research.

\subsubsection{Ontario's Integrated Watershed Management}

Integrated water resource management has been a part of Ontario legislation dating back to as early as 1946 and resulted in the creation of the Conservation Authorities Act which in turn produced the modern day Conservation Authorities (CA) throughout Ontario (Mitchell et al. 2014). Evolving over the decades Ontario's Integrated Watershed Management (IWM) in its current form is based off of the ecosystem approach where the following items are important (Mitchell et al. 2014):

- Receiving waters is considered the management unit rather than an administrative or political boundary;

- Upstream conditions as they related to downstream effects are examined;

- Surface water quality and quantity as it relates to groundwater quality and quantity;

- Water quality and quantity issues;

- Water as it relates to other natural resources; and,

- The involvement of various stakeholders in the planning and implementation stages.

One of the key items to come out of the 1946 Conservation Authorities Act was the idea of watershed plans which serve as a governing document for a specific watershed. Watershed planning throughout Ontario is in decline due to implementation and funding gaps (Conservation 
Ontario 2010). Watershed and subwatershed plans are key to the implementation of a multi-site ECA approval system as they outline the specific threats and needs to the permit area. Another key IWM implementation issue is the emergence of provincial legislation centered around specific issues such as the Oak Ridges Moraine Act and the Green Belt Act (Conservation Ontario 2010). Should a multi-site ECA permitting system be implemented, a renewed focus on IWM and watershed planning is required in order to collect data, identify and evaluate problems to be monitored and improved (Carter 2006).

\subsection{Review of Ontario's Watershed Plans}

The following section reviews three different watersheds within southern Ontario. The purpose of this review is to identify common stormwater framework parameters that could be used for the development of a multi-site ECA framework. The selected watersheds were identified based on their availability of watershed plans or subwatershed plans. In the case of the Lake Simcoe Watershed supplementary legislation implemented for the protection of the watershed was also evaluated. Where available, monitoring networks within the watersheds were reviewed to determine if existing networks could be included within a multi-site ECA monitoring network.

\subsubsection{Lake Simcoe Watershed}

The Lake Simcoe watershed is a very important natural resource and valuable socioeconomic entity for southern Ontario (Palmer et al. 2011). With diverse land-uses throughout the watershed a wide variety of environmental impacts and pressures which threaten the sustainability of the watershed. Partially located within the Oak Ridges Moraine and the Greenbelt, Lake Simcoe encompasses provincially significant wetlands, woodlands, and agricultural lands (Ministry of Environment, Ministry of Natural Resources 2009). Several environmental threats have occurred throughout history relating to human activities and urbanization throughout the area.

Water quality issues have been a primary concern since the 1970s when eutrophication was first noted and a decline in the cold water fishery and excessive growth of algae and shoreline macrophytes was evident (Palmer et al. 2011)(Eimers et al. 2005). Increased development in the region lead to increased total phosphorous loading throughout the lake which lead to 
eutrophication of the lake through the excessive production of algae and macrophytes (Eimers et al. 2005).

In addition to phosphorous concerns, invasive species began to threaten the lake with the establishment of dreissenid mussels more commonly known as the zebra mussel. Physiochemical and biological changes have been linked to the establishment of the zebra mussel since first introduced into the lake through the hull of a boat in 1991 (Palmer et al. 2011).

Another area of focus and threat to the Lake Simcoe watershed is climate change. Thermal stability of the water column ice-free season has increased over time as a result of increased air temperature throughout these ice-free months (Palmer et al. 2011). The increased lake temperature has caused changes on lake chemistry and biota (Palmer et al. 2011).

Development and urbanization of the Lake Simcoe area has contributed to threats and concerns associated with the watershed. In 2001, the population within the Lake Simcoe area was estimated at 382,887 and is projected to grow by $30 \%$ to 642,000 by 2031 (Palmer et al. 2011)(Ministry of Infrastructure 2006). Water quantity has been identified as a significant threat to the watershed. The increased development has resulted in greater stormwater runoff which has increased phosphorous loading, and altered aquatic habitats (Evans et al. 1996)(Ministry of Environment, Ministry of Natural Resources 2009).

While the environmental stressors are not the only impacts on the Lake Simcoe watershed, they represent key items of concern. To combat these issues provincial legislation and local planning was introduced and is outlined in the following subsections.

\subsubsection{Lake Simcoe Protection Act}

In 2008 the Lake Simcoe Protection Act (LSPA) was enacted by the Legislative Assembly of the Province of Ontario to protect and restore the ecological health of the Lake Simcoe watershed (Legislative Assembly of the Province of Ontario 2008). This legislated statute allowed for the establishment of a legally binding Lake Simcoe Protection Plan (LSPP) to ensure the protection and preservation of the Lake Simcoe Watershed. Several key subsections were formulated under the Act and subsequently the Lake Simcoe Protection Plan to ensure policies and planning reflect the specific concerns of the Lake Simcoe Watershed. Within these 
subsections a number of goals are identified, which included (Legislative Assembly of the Province of Ontario 2008):

- Protection, improve or restore variables that contribute to ecological health of Lake Simcoe;

○ Improved water quality;

- Restoration and preservation of hydrology;

- Identification of key natural heritage features and their functions, and;

- Identification of key hydrologic features and their functions.

- Restore a self-sustaining coldwater fish community;

- Reduce phosphorous loading and other nutrients of concern;

- Reduce discharge of pollutants;

- $\quad$ Respond to adverse effects of invasive species, prevent invasive species from entering;

- Improve Lake Simcoe's capacity to adapt to climate change;

- Provide ongoing scientific research and monitoring related to ecological health of Lake Simcoe and promote those activities;

- Improve conditions for environmentally sustainable recreational activities;

- Promote environmentally sustainable land and water uses, activities and development practices;

- Build on protections for Lake Simcoe watershed through other Acts \& Plans;

O Oak Ridges Moraine Conservation Plan;

○ Greenbelt Plan;

○ Clean Water Act 2006;

- Conservation Authorities Act;

- Ontario Water Resources Act;

○ Planning Act;

- Any other objectives set out in the Lake Simcoe Protection Plan.

Within the LSPA is an outline of the contents required under the LSPP which include some key items that related to this research include assessment of criteria and targets mentioned within the objectives above. This is the key provision within the LSPA that allows for a multi-site 
stormwater ECA to be developed based on the recommendations on objectives, criteria, and targets within the LSPP.

Another key subsection of the LSPA relating to multi-site stormwater ECAs includes the requirement of preparation of a report every 5 years that describes the monitoring results of various monitoring programs and a description to the extent to which the objectives outlined in the LSPP are being achieved (Legislative Assembly of the Province of Ontario 2008).

\subsubsection{Lake Simcoe Protection Plan}

Under the Lake Simcoe Protection Act of 2008 the establishment and amendment of the Lake Simcoe Protection Plan was required (Ministry of Environment, Ministry of Natural Resources 2009). The LSPP is intended to provide guidance of the various objectives noted with in the Lake Simcoe Protection Act.

The ecosystem approach is a key principal within the LSPP. Stakeholders understood that the Lake Simcoe watershed is an interconnected system which required the evaluation of cumulative impacts in order to protect and restore the ecological health of the watershed (Ministry of Environment, Ministry of Natural Resources 2009). The subwatershed approach to management and policy implementation was required under the LSPP. While some issues may affect the watershed as a whole, the stakeholders identified that specific concerns may be

focused in selected parts of a subwatershed which will require more detailed guidance (Ministry of Environment, Ministry of Natural Resources 2009). The precautionary approach is to be used when implementing the LSPP as well as the adaptive management approach which allows for improvement and adaptation of policies and management overtime. The LSPP also looks to employ sustainable development throughout the watershed and a shared responsibility between the various Lake Simcoe watershed stakeholders. All of these considerations need to be incorporated while ensuring cost-effective measures are implemented for the protection and restoration of the ecological health of the watershed (Ministry of Environment, Ministry of Natural Resources 2009). 
The main objective of the plan is to protect and restore ecological health of the Lake Simcoe watershed. Many other objectives identified within the Lake Simcoe Protection Act which are included in the current version of the Lake Simcoe Protection Plan are as follows:

- $\quad$ Protect and restore aquatic life;

- Protect and restore water quality;

- $\quad$ Reduce water quantity;

- Protect and restore shorelines and natural heritage;

- $\quad$ Limit the spread and introduction of invasive species;

- Limit the effect of climate change; and,

- Protect and restore recreational activities.

\subsubsection{Aquatic Life Objective, Criteria, Targets, \& Monitoring}

The aquatic life objective within the Plan is intended to improve aquatic habitat and restore aquatic communities throughout the watershed (Ministry of Environment, Ministry of Natural Resources 2009). Lake Simcoe's coldwater fishery is extremely important to the ecological function of the lake and is a good indicator for the overall health of aquatic specifies within the watershed (Evans et al. 1996). Lake Simcoe and its tributaries support a variety of aquatic species including; coldwater fish such as lake trout and lake whitefish, warmwater fish such as bass and perch, invertebrates, amphibians, reptiles, benthos, and plankton (Ministry of Environment, Ministry of Natural Resources 2009).

To meet with aquatic life objective, the LSPP outlines three key criteria. The three key criteria for improving and restoring aquatic habitat and communities include (Ministry of Environment, Ministry of Natural Resources 2009):

- Natural reproduction and survival of native aquatic species;

- Presence and abundance of key sensitive species; and,

- Shifts in cold, warm and tributary fish community composition.

The target and thresholds developed to fulfill the criteria and objective is related to total threshold of $7 \mathrm{mg} / \mathrm{L}$ by September 15 of each year is based on a key habitat requirement for 
coldwater fish species and sets out to achieve the aforementioned criteria and objective (Ministry of Environment, Ministry of Natural Resources 2009).

Monitoring of the objective, criteria, target, and threshold is clearly outlined within the LSPP and involves many key stakeholders to be involved. Some key monitoring initiatives include:

- Surveys of winter and open-water anglers;

- $\quad$ Fish diet and growth studies;

- Monitoring of fish biodiversity;

- Monitoring of invasive species; and,

- Monitoring of aquatic habitat;

Dissolved oxygen is measured by the MECP at 1 meter increments from surface to bottom at all 8 open lake sampling stations (Ministry of the Environment and Climate Change 2015). Concentrations are reported in the annual monitoring report which compares historical data to the previous monitoring year.

\subsubsection{Water Quality Objective, Criteria, Targets, \& Monitoring}

Improved water quality is another important objective and criteria outlined within the LSPP. Variable land uses have placed significant pressure on the watershed through the increase of nutrients primarily phosphorus, heavy metal contamination, organic chemicals contamination, excessive sediment loading, chloride contamination, and pathogens such as E.coli (Ministry of Environment, Ministry of Natural Resources 2009). Excessive phosphorus loading has been identified as a significant threat to water quality issues within Lake Simcoe. Excessive loading leads to increased algae growth therefore depleting dissolved oxygen levels within the deep waters of the lake which in turn impacts the coldwater species within the lake (Eimers et al. 2005).

To deal with the water quality objective, the Plan outlines four key targets to evaluate the progress of achieving this objective. The four targets for evaluating the water quality objective within the LSPP include: (Ministry of Environment, Ministry of Natural Resources 2009)

- Dissolved oxygen in Lake Simcoe;

- Total phosphorus; 
○ Concentration;

○ Loading.

- Pathogens;

○ Beach closures.

- Other water quality parameters;

○ Chlorides;

- Other nutrients (nitrogen);

- Total suspended solids;

○ Heavy metals;

- Organic chemicals.

The thresholds set out to assess the targets are also outlined within the LSPP. Since the dissolved oxygen and total phosphorus criteria are tied to one another the threshold for these targets are to reduce phosphorus loading to achieve a dissolved oxygen target of $7 \mathrm{mg} / \mathrm{L}$ in the lake. In order to meet this target a long term phosphorus loading threshold is set at 44 tonnes per year (Ministry of Environment, Ministry of Natural Resources 2009). The pathogens threshold is evaluated through simply a reduction of pathogen loading to eliminate beach closures. Specific values are not prescribed for target at this present time. In terms of thresholds for the targets of other water quality parameters the thresholds are set in accordance with the Provincial Water Quality Objectives (PWQO) or better.

As previously mentioned in Section 2.6.2.1 Aquatic Life Objectives, Criteria, and Targets dissolved oxygen is measured by the MECP at 1 meter increments from surface to bottom at all 8 open lake sampling stations (Ministry of the Environment and Climate Change 2015). Phosphorus loading rates were determined using Nicholls 1997 model, which correlates phosphorus loading and minimum volume-weighted hypolimnetic dissolved oxygen (MVWHDO) based on numerical relationships between loading rate, lake phosphorus concentration, chlorophyll a, and dissolved oxygen (Palmer et al. 2011)(Nicholls 1997). Monitoring frequency of other water quality parameters in accordance with the PWQO's was not defined within the LSPP however the watershed's tributaries are known to exceed the PWQO's for phosphorus and other parameters (Ministry of Environment, Ministry of Natural Resources 2009). 
Given the importance of the water quality objective, three policies support the LSPP'S water quality improvement strategy. Policy relating to sewage treatment, stormwater management, and on-site and subsurface sewage treatment, construction and mineral aggregate resource activities, scientific water quality monitoring and research, phosphorus reduction strategy, and stewardship are defined within the LSPP. Stormwater management policy and scientific water quality monitoring and research is of specific important to this research and is examined further.

The stormwater management policy calls for comprehensive master plans to improve stormwater for both existing and proposed development. According to the LSPP, applications for major development must demonstrate how phosphorus loading and changes in water balance will be lessened (Ministry of Environment, Ministry of Natural Resources 2009). The MECP will place stringent requirements on approvals for new stormwater works and review or revise existing approvals.

The scientific water quality monitoring and research policy requires an adaptive management approach to water quality issues and promotes partnerships to monitor water quality within the Lake Simcoe watershed (Ministry of Environment, Ministry of Natural Resources 2009). According to the policy routine monitoring of water quality is required within Lake Simcoe and its tributaries including monitoring of the water quality parameters. A total of 20 tributary/lake monitoring stations and 3 water treatment plants are currently being monitoring for the water quality parameters as outlined in the Plan (Ministry of the Environment and Climate Change 2015). Locations of the monitoring stations are provided in Figure 2 


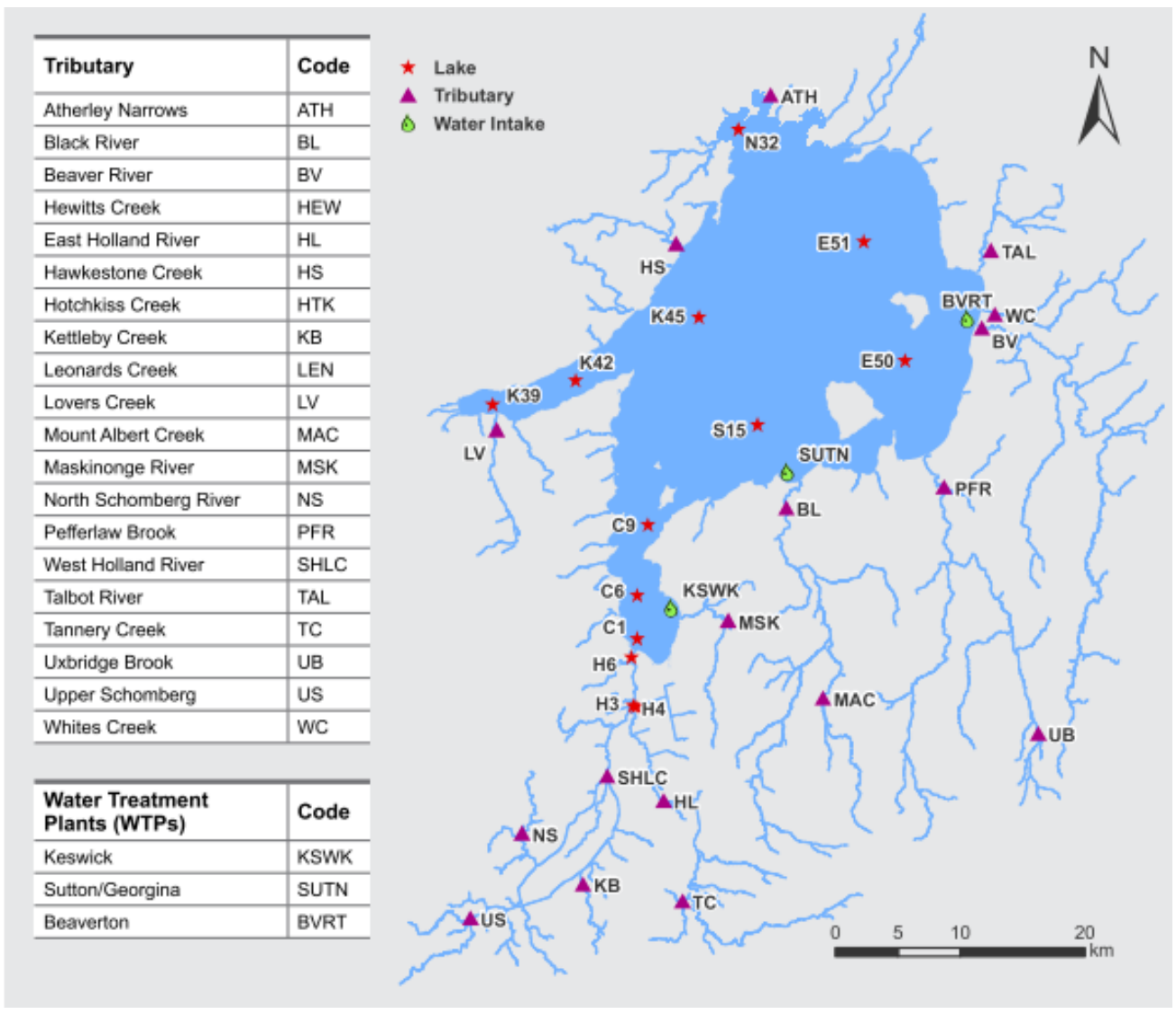

Figure 2: Lake Simcoe Monitoring Stations (Ministry of the Environment and Climate Change 2015)

\subsubsection{Water Quantity Objective, Criteria, Targets, \& Monitoring}

Water supply issues relating to groundwater and surface water are identified within the LSPP under the water quantity objective. Proper streamflow is required to preserve aquatic habitat. If flows are not preserved water quantity stresses cause changes to the natural flow rates therefore impacting various aquatic species (Ministry of Environment, Ministry of Natural Resources 2009).

To assess the water quantity objectives key criteria are outlined within the Plan which include:

- Maintaining in-streamflow regimes; and,

- Implementing effective water conservation and efficiency plans.

While specific targets relating to streamflow thresholds are not laid out within the LSPP, the LSPP identifies that the in-streamflow thresholds are to be set out within the various subwatershed plans of the Lake Simcoe watershed. Based on the Lake Simcoe Monitoring Report 
for 2014, five hydrological monitoring stations which measure quick flow and baseflow (Ministry of the Environment and Climate Change 2015). Locations of the hydrological monitoring stations are provided in Figure 3.

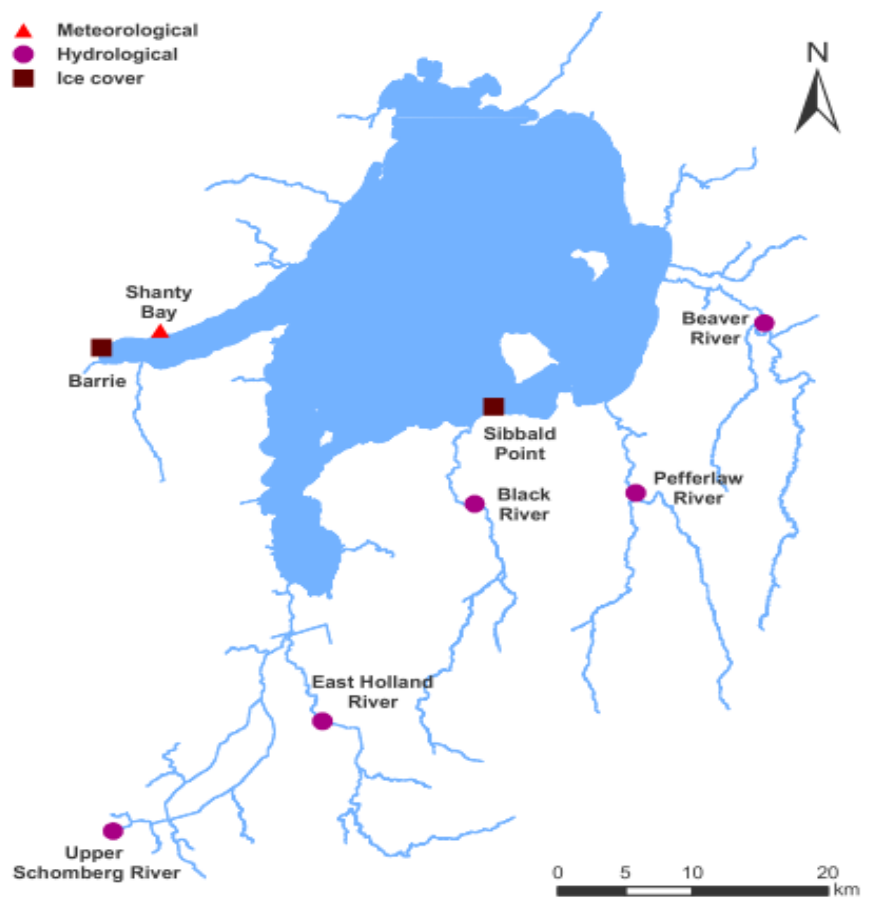

Figure 3: Lake Simcoe Hydrology Monitoring Stations (Ministry of the Environment and Climate Change 2015)

\subsubsection{Shorelines and Natural Heritage Objective, Criteria, Targets, \& Monitoring}

The shorelines and natural heritage objective within the LSPP set out to promote an ecologically healthy Lake Simcoe shoreline and natural heritage system which will improve water quality and quantity. Currently $47 \%$ of Lake Simcoe's land area of occupied by agricultural lands with developed lands and non-agricultural lands and roads accounting for 18\% (Ministry of Environment, Ministry of Natural Resources 2009). The high percentage of agricultural lands presents issues such as wind erosion and dust emissions during the summer months leading to atmospheric deposition of phosphorus therefore increasing annual loading rates (Palmer et al. 2011, Brown et al. 2011). Shore line modification has also adversely impacted important ecological and hydrological linkages between land and water which results in both ecological and water quantity impacts. 
In order to assess the shorelines and natural heritage objective, five criteria have been identified within the Plan including (Ministry of Environment, Ministry of Natural Resources 2009):

- Change over time in the proportion of wetland, forested valley land, natural riparian an upland forest considering habitat quality;

- Degree of fragmentation of wetland, forested valley land, riparian, and upland forest;

- Natural shoreline coverage;

- Change over time of key biological indicators; and,

- Status of recharge areas.

The Plan outlines 7 targets in order to assess the criteria and in turn the shoreline and natural heritage objective. The seven targets are as follows (Ministry of Environment, Ministry of Natural Resources 2009):

- No further loss to natural shorelines;

- Achieve greater proportion of natural vegetation in large quality patches;

- Achieve at least $40 \%$ high quality natural vegetative cover in the watershed;

- Achieve protection of wetlands;

- Achieve naturalized riparian areas;

- Restore natural areas and features; and,

- Achieved increased ecological health based on the status of indicator species and maintenance of natural biodiversity.

\subsubsection{Other Threats and Activities Objective, Criteria, Targets, \& Monitoring}

The primary issues within this objective include the introduction of invasive species, climate change, and recreation activities. Numerous invasive species have been introduced into Lake Simcoe in the past century some of which include the common carp, black crappie, zebra mussels, and the round goby (Ministry of Environment, Ministry of Natural Resources 2009).

The primary criteria for this objective are the presence of newly introduced species while the target is simply prevention of new invasive species. 
Climate change is another important aspect of this objective. Climate change impacts all the objectives and therefore is considered a very important objective within the LSPP. For example, climate change can affect water temperature therefor impacting the cold-water fishery and habitat. Similarly, to invasive species climate change will be difficult to quantify within the multi-site ECA approval system however its effect on other objectives will need to be identified and addressed when implementing and issuing multi-site ECA approvals.

\subsection{Thames River Watershed}

The Thames River watershed is located in southwestern Ontario near Lake Huron, Lake St. Clair, and Lake Erin as shown in Figure 4. The watershed is approximately 5,825 $\mathrm{km}^{2}$ making it the second largest watershed in southwestern Ontario (Quinlan 2013). This watershed is governed by two conservation authorities, the Upper Thames River Conservation Authority and the Lower Thames Valley Conservation Authority. 


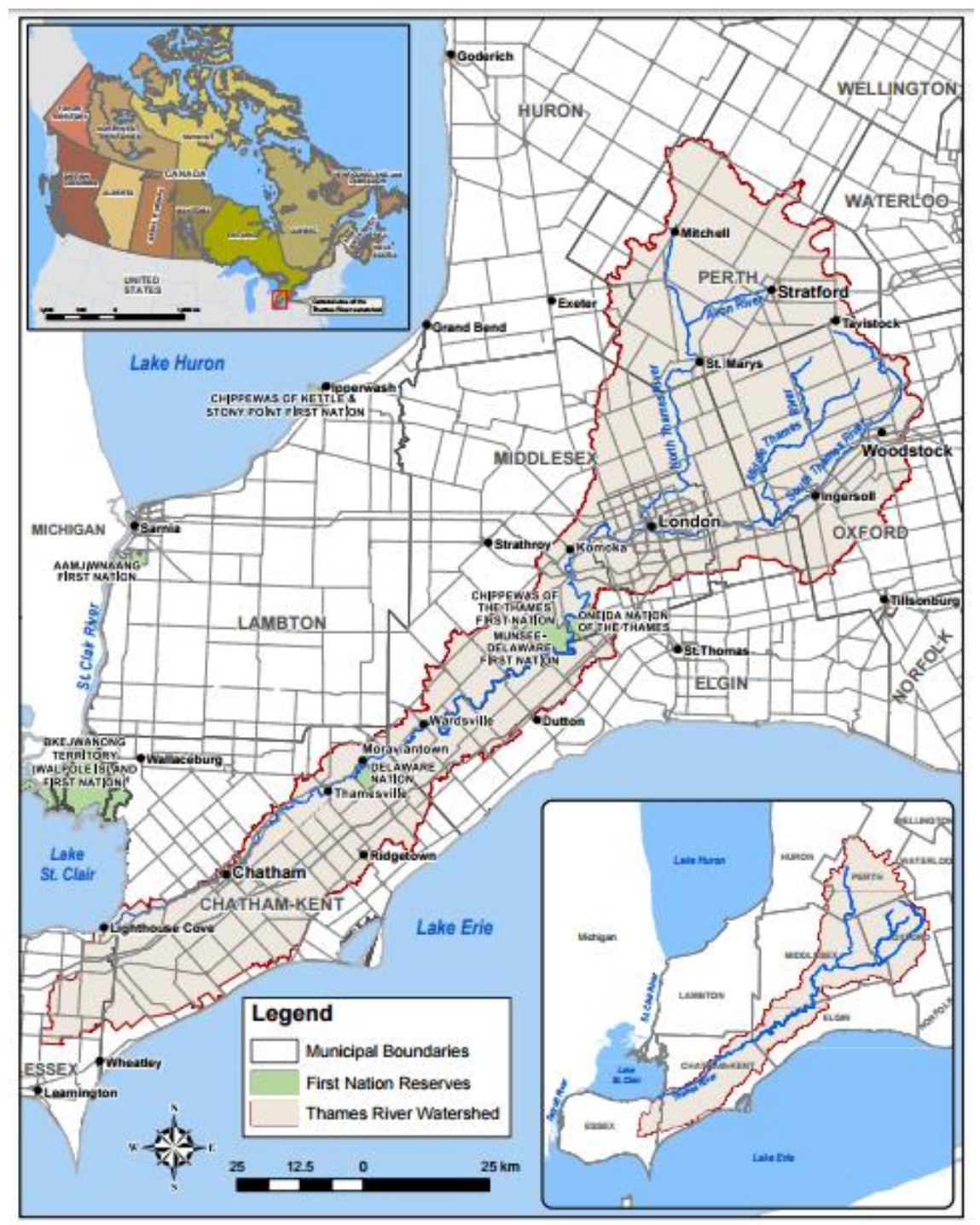

Figure 4: Thames River Watershed (Quinlan 2013)

Similarly, to the Lake Simcoe Watershed, the Thames River Watershed identifies various categories of natural heritage features that need to be maintained and monitored within 10-year report cards, including:

- Hydrology;

- Physiography;

- River Morphology;

- Biotic Environments;

- Vegetation; and,

- Fauna. 
In addition to identifying natural heritage features the Thames River watershed also outlined cultural heritage features to be maintained and monitoring within 10-year report cards including:

- Resource Harvesting;

- Water Transport;

- Riparian Settlement;

- Culture \& Recreation; and,

- Jurisdictional Uses.

The primary natural heritage features listed above are consistent with the Lake Simcoe watershed however an overall watershed plan for the Thames River watershed is not available. Several subwatershed plans have been developed by the City of London which is located within the Upper Thames.

\subsubsection{Dingman Creek Subwatershed}

The Dingman Creek subwatershed is located within the City of London's municipal boundaries and has been identified as a potential pilot sub watershed for the proposed multisite ECA system. The primary surrounding land use is agricultural with approximately 30 tributaries making up the subwatershed which drain into the main channel of Dingman Creek which flows into the Thames River (Delcan 2005). The original subwatershed plan for Dingman Creek was completed in 1995 however an updated version was prepared in 2005. In 1995, the environmental objectives of the study was to enhance the water balance of the subwatershed, protect surface waters, establish healthy aquatic ecosystems, and establish a healthy terrestrial ecosystem (Delcan 2005). Between the 1995 study and the 2005 study limited land use change occurred.

\subsubsection{Water Quantity Objectives, Criteria, Targets, \& Monitoring}

Water quantity is identified as a key objective within the Dingman Creek subwatershed study. The water quantity criteria within the water quantity objective is to limit flood events by ensuring post-development flows equal pre-development flows. The two targets governing the water quantity objective are streamflow and baseflow. 


\section{$\underline{\text { Streamflow }}$}

The 2005 report assessed historical streamflow monitoring results and compared them to the more current monitoring results. The criteria for water quantity within the Dingman Creek Subwatershed are similar to other watersheds throughout Ontario: maintain pre-development flows with land development. During 1974 - 1981 increased streamflows were identified with pre-development flows measured at $0.039 \mathrm{~m}^{3} / \mathrm{s}$ and post development flows measured at 0.056 $\mathrm{m}^{3} / \mathrm{s}$ (Delcan 2005). Although the target for streamflow is maintaining flow after development, no specific value has been set as the threshold within the study. Development periods have been identified within the report between 1966 and 2000. Based on the data collected average annual flow has been maintained however peak flow or maximum daily flow has increased over time from approximately $1.28 \mathrm{~m}^{3} / \mathrm{s}$ in Period I (1966 - 1973) to 1.48 in Period IV (1991 - 2000) (Delcan 2005). Current data is collected from two streamflow monitoring stations, Dingman Cr. Upstream (02DNGUS) and Dingman Cr. Below Lambeth (02GE005). Within the latest annual report card streamflow for a 5 year averaging period (2006-2010) was measured at $1.8 \mathrm{~m}^{3} / \mathrm{s}$ (Upper Thames River Conservation Authority 2012). Compared to historical measurements increased streamflow is apparent.

\section{Baseflow}

In order to fulfill the water quantity objective baseflow is identified as another target for determining if pre-development flows are equaling post-development flows. Baseflow measurements were collected on three different dates for the updated subwatershed study. Measurements were collected on June 2, 2003, July 31, 2003, and September 12, 2003 at twelve (12) different locations (Delcan 2005). Based on the data collected tributaries located within urbanized areas have higher baseflow when compared to agricultural areas as found in the 1995 study (Delcan 2005).

\subsubsection{Water Quality Objectives, Criteria, Targets, \& Monitoring}

The water quality objective for the Dingman Creek subwatershed is considered to include water chemistry parameters such as metals and nutrients as well as bacterial parameters (Delcan 2005). Water quality data has been collected since 1995 and is used for broader planning 
purposes and general comparison to water quality objectives. The subwatershed plan takes into consideration point source, non-point source, and event-related inputs into the creek (Delcan 2005). Primary point source inputs include two wastewater treatment plant outflows. Stormwater releases from various stormwater management facilities are non-point source releases. Water quality monitoring for the following parameters has been conducted since 1973 (Delcan 2005):

- Suspended solids;

- Total phosphorous;

- E.coli and Fecal Coliforms;

- Copper and Zinc; and,

- Ammonia and Nitrate.

The plan considered water quality concentrations to reflect typical agricultural settings with the poorest locations located near where channel degradation has occurred resulting in increased sediment loading, low gradients, and increased pooling of stagnant water (Delcan 2005).

In 2003 an update was conducted to analyze possible changes in water chemistry since monitoring began at the three Provincial Water Quality Monitoring Network (PWQMN) stations. The records were divided into three separate time periods; pre-development (prior to 1973), post development (1974 - 1993), and post development (1993 - 2003) with all data compared to the PWQO's. Based on a review of the data post development period 1993 - 2003 saw less concentrations of total phosphorous, ammonia, fecal coliforms, copper, and zinc compared to the other periods (Delcan 2005). Chloride increased in post development period $1993-2003$ when compared to the other periods which has been attributed to increased road salt as a result of more roads in the post development period (Delcan 2005). The decreased concentrations of water quality parameters has largely been attributed to better stormwater controls; septic system inspection, tree planting, livestock access prevention efforts, erosion and sediment control, and nutrient management plans (Delcan 2005).

Monitoring locations and programs within the Dingman Creek subwatershed are limited, which decreases the accuracy and understanding of water quality trends over time. To 
implement a multi-site ECA, additional monitoring stations may be required to appropriately assess the performance of the permit.

\subsubsection{Stream Erosion and Morphology Objectives, Criteria, Targets, \& Monitoring}

Another objective of the Dingman Creek subwatershed plan is to limit stream erosion and preserve stream morphology. It is estimated that approximately $75 \%$ of the stream reaches within the subwatershed have been altered which impacts the subwatershed's flow regime (Delcan 2005). Erosion was noted to be high ranging from 0.1 to 0.5 meters per year which was thought to be related to channelization, urbanization, and agricultural activities (Delcan 2005). In 2003 an update to stream erosion and morphology was completed. The update focused on overlaying 1993/1994 stream cross sections and comparing them to 2003 . The results of this investigation found that limited change has occurred except for one location located downstream. Although limited changes to stream cross sections was noted erosion throughout the subwatershed was observed and was attributed to both natural and non-natural causes. The stream erosion rates have remained consistent when comparing historical erosion rates. The majority of the erosion is a result of the stream stratigraphy primarily fine textured material with a higher affinity for natural erosion (Delcan 2005). Although preserving stream erosion and morphology is an objective within the Dingman Creek subwatershed plan targets and thresholds were not discussed within the plan.

\subsubsection{Geology and Hydrogeology Objectives, Criteria, Targets, \& Monitoring}

Geology and hydrogeology are objectives of the Dingman Creek subwatershed plan as it relates to groundwater recharge. The plan identifies four aquifers within the subwatershed. Three aquifers located in the overburden that supply local water wells and one confined aquifer in bedrock (Delcan 2005). The primary zone associated with groundwater recharge in with subwatershed is west of Wonderland Road which has been identified as a key protection area. Similarly, to the LSPP, groundwater recharge is an important objective for the Dingman Creek subwatershed plan. Targets for groundwater recharge is based on recharge rates in mm/year. However, limited field confirmation has been conducted to confirm if hydrogeologic models are estimating the recharge rates correctly. Baseflow has also been identified as a target for groundwater recharge. Baseflow measurements account for approximately $40 \%$ of the annual 
groundwater recharge estimated for the subwatershed (Delcan 2005). Thresholds for groundwater recharge have not been set under the Dingman Creek subwatershed plan. As baseflow contributes to groundwater recharge, baseflow objectives, criteria, and targets may be linked to a water quantity objective within a multi-site ECA.

\subsubsection{Terrestrial Natural Heritage Objectives, Criteria, Targets, \& Monitoring}

Terrestrial natural heritage is an objective within the Dingman Creek subwatershed plan with a primary criterion of maintaining terrestrial natural heritage. Various terrestrial features were identified including (Delcan 2005):

- 6 provincially significant areas;

- 8 candidate environmentally significant areas or potential locally significant features, and, - 17 large, mature forests.

These features are important functions of the hydrologic feature of the Dingman Creek subwatershed. The objective of terrestrial natural heritage within the subwatershed plan is to restore, maintain or enhance natural features. Although thresholds for the natural heritage objective have not been identified, change overtime is monitored through geographic information systems (GIS) data available from various studies and sources. Maintaining terrestrial natural heritage is an important criterion for any subwatershed plan however it may be difficult to set targets that can be effectively monitored within a multi-site ECA.

\subsubsection{Aquatic Resources Objectives, Criteria, Targets, \& Monitoring}

Preserving aquatic resources is another criterion outlined in the Dingman Creek subwatershed plan. Baseline conditions prior to 1995 were assessed within the plan. Assessing aquatic health was carried out using two criteria which included fish habitat and biological communities. Fish Habitat was assessed using habitat suitability indices and biological communities were evaluated using biotic integrity (Delcan 2005). Although criteria were set for the aquatic resource's objective no specific targets or thresholds were set. Based on the findings in the subwatershed plan the removal of in-stream structures could improve aquatic resources within the subwatershed. The Dingman Dam was identified as a potential structure to remove however in-stream erosion may result. 


\subsection{Credit River Watershed}

The Credit River Watershed is located in Greater Toronto Area and encompasses the Town of Caledon, Town of Erin, City of Brampton, Town of Halton Hills, Town of Milton, City of Mississauga, and the Town of Oakville (Credit Valley Conservation Authority 2010). The Credit Valley Conservation (CVC) was formed as part of the Provincial Act in 1964 which created thirtysix Conservation Authorities in Ontario. The CVC governs the Credit River Watershed and associated subwatersheds along with 15 kilometers of Lake Ontario shoreline and 6 kilometers into Lake Ontario (Credit Valley Conservation Authority 2010). Figure 5 outlines the CVC governance.

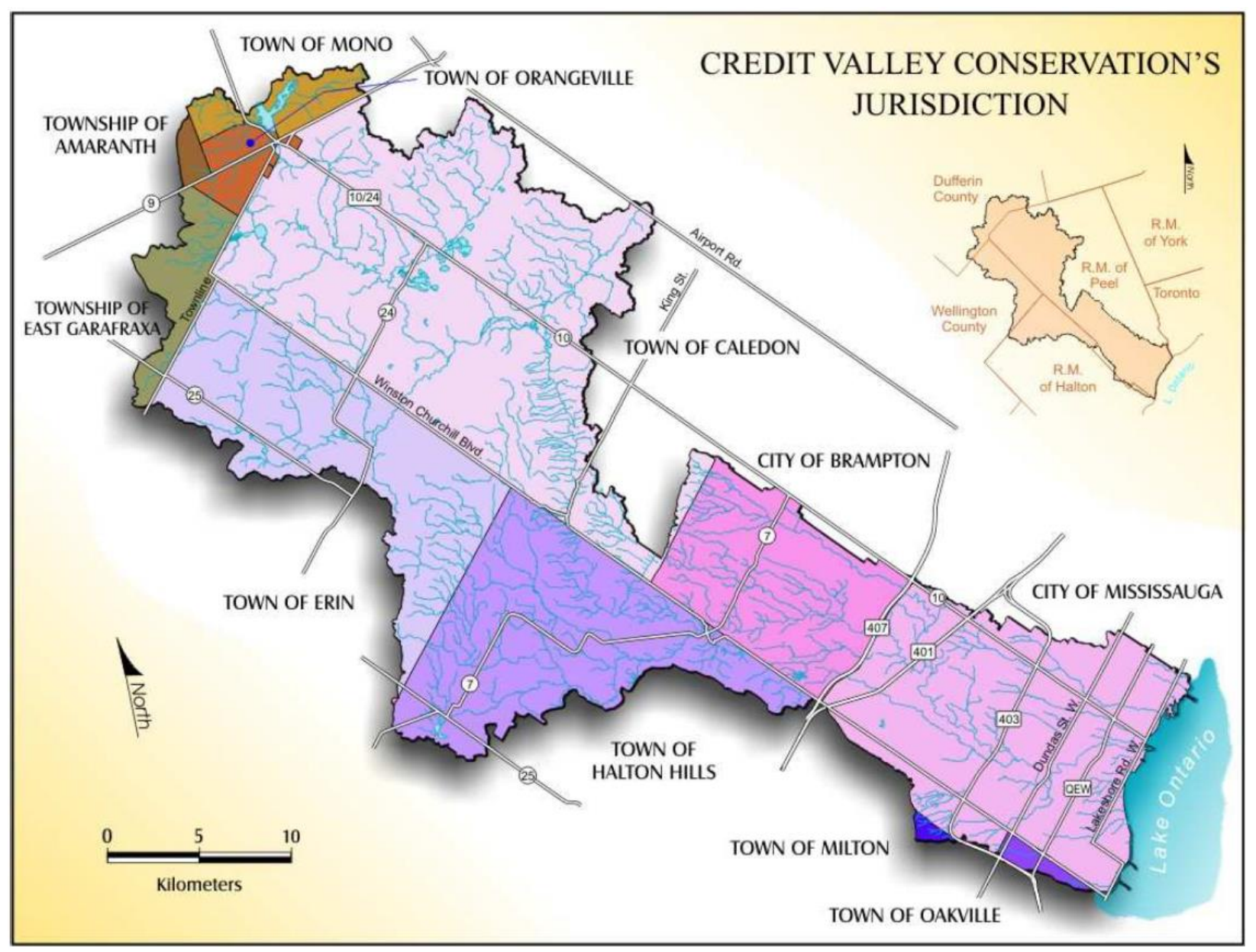

Figure 5: Credit Valley Conservation Authority Governance (Credit Valley Conservation Authority 2010)

The watershed is divided into three separate physical zones which include the upper watershed, middle watershed, and lower watershed and Lake Ontario shoreline. Within these 
physiographic zones a total of 22 subwatersheds have been established. The subwatershed planning process within the CVC region encompasses four stages including:
1) Characterization;
2) Impact Assessment;
3) Implementation, and,
4) Monitoring.

The 22 subwatersheds are at various stages of the subwatershed planning process as outlined above. Figure 6 outlines the location of the subwatersheds as well as the stage of subwatershed planning as of 2008 .

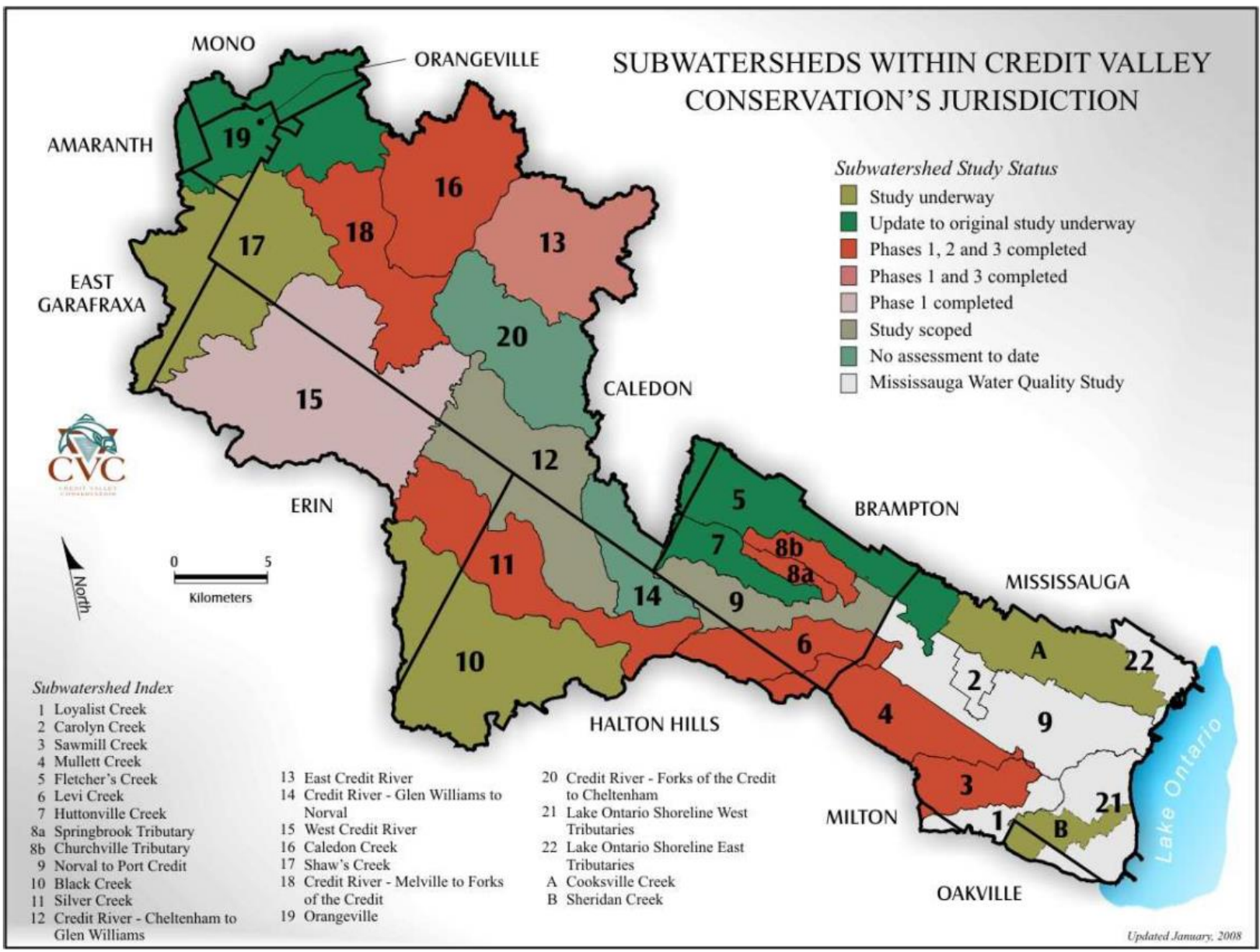

Figure 6: Credit Valley Conservation Subwatershed Status (Credit Valley Conservation Authority 2010)

The Credit River Watershed goals are divided into five objectives which are as follows (Credit Valley Conservation Authority 2010): 
- Water Quantity;

- Water Quality;

- Terrestrial and Aquatic Species, Communities and Ecosystems;

- Natural Hazards; and,

- Social and Economic.

For the water quantity objective various criteria have been identified including (Credit Valley Conservation Authority 2010);

- Preserve and re-establish the natural hydrological cycle;

- Achieve a balance of flow and sediment transport;

- Control streamflow;

- $\quad$ Limit flood events; and

- Maintain groundwater and baseflow.

For the water quality objective the following criteria have been identified (Credit Valley Conservation Authority 2010):

- Maintain or enhance water and sediment quality;

- $\quad$ Protect drinking water;

- Protect groundwater quality to support watershed function;

- Improve water quality for body contact; and,

- Improve water aesthetics including odour, turbidity and clarity.

For the terrestrial and aquatic species, communities and ecosystems the following criteria have been identified (Credit Valley Conservation Authority 2010):

- Protect, restore or enhance integrity of the ecosystem;

- Protect, restore or enhance native terrestrial and aquatic plant and animal health;

- Promote integrated ecosystem management of aquatic systems, terrestrial systems, and areas;

- Protect, restore and enhance natural systems in urban environment;

- Ensure significant natural features are protected continuously; and, 
- Secure sensitive land for protection.

For the natural hazards objective the following criteria have been identified (Credit Valley Conservation Authority 2010):

- Identify floor hazards in rivers, streams and Lake Ontario shoreline;

- Identify and protect watercourses and wetlands; and,

- Implement Ontario Regulation 160/06;

For the social and economic objective the following criteria have been identified (Credit Valley Conservation Authority 2010):

- Promote interconnected watershed;

- Protect human physical, social and economic health of the watershed; and,

- Provide recreational opportunities.

The objectives and criteria have been identified within the Credit River Watershed Plan however no specific targets or thresholds were identified. The subwatershed plans and other technical reports are to outline the specific targets and thresholds (if any) for the subwatershed which can then be used to monitor the overall health of the subwatershed and be included within the multi-site permitting system.

\subsubsection{Silver Creek Subwatershed}

The Silver Creek subwatershed is located within the Credit River Watershed and is governed by the CVC The Silver Creek subwatershed is located north of Brampton and Mississauga, Ontario bisected by the Niagara Escarpment which supports the terrestrial and wildlife system of the subwatershed (Credit Valley Conservation; Schroeter \& Associates; Environmental Water Resources Group; Aquafor Beech Limited; Jacques Whitford Environmental Limited; Waterloo Hydrogeologic Inc. 2003b). This specific subwatershed within the Credit River Watershed is important to the natural function of the overall watershed due to large volumes of water recharge, storage and movement through the Silver Creek subwatershed. (Credit Valley Conservation; Schroeter \& Associates; Environmental Water Resources Group; Aquafor Beech Limited; Jacques Whitford Environmental Limited; Waterloo Hydrogeologic Inc. 2003b). As 
outlined in the subwatershed plan the goals of the for the Silver Creek subwatershed including(Credit Valley Conservation; Schroeter \& Associates; Environmental Water Resources Group; Aquafor Beech Limited; Jacques Whitford Environmental Limited; Waterloo Hydrogeologic Inc. 2003b):

- Protected

○ Subwatershed functions

- Maintain

○ Baseflow

○ Stream temperature

- Valley corridors

$\circ$ Health of the system

- Enhance

- Water quality

- Fish habitat and communities

- Woodlots and develop new woodlots

- Educate, partnerships and connections to other communities and subwatersheds

- Implementation of policy, enforcement, and integration with Official Plans

- Understand and Address

- Permanent monitoring of key ecological function to support future decisionmaking

- Cumulative effects of water taking and development on water quality and quantity

- Carrying capacity of Silver Creek

- Impacts of people movement

- Encourage

○ Wellhead protections strategies

○ Stewardship

Based on the goals of the Silver Creek subwatershed the following section outlines the objectives, criteria, and targets, and thresholds for the Silver Creek subwatershed. 


\subsubsection{Water Quantity Objectives, Criteria, Targets, \& Monitoring}

Water quantity is a key objective for the Silver Creek subwatershed especially due to its importance within the overall Credit River Watershed. Similarly, to other subwatershed objects related to water quantity the criteria is to achieve pre-development flows the same as postdevelopment flows. Water quantity is measured by monitoring both streamflow and baseflow. As previously mentioned the Silver Creek subwatershed's baseflow is important because a significant amount of the watersheds overall baseflow occurs within this subwatershed (Credit Valley Conservation; Schroeter \& Associates; Environmental Water Resources Group; Aquafor Beech Limited; Jacques Whitford Environmental Limited; Waterloo Hydrogeologic Inc. 2003b). In 1999 the CVC implemented a watershed wide monitoring program which includes the monitoring of both baseflow and streamflow water quantity monitoring. The subwatershed study for Silver Creek outlined an average subwatershed baseflow of $0.026 \mathrm{~L} / \mathrm{sec} / \mathrm{ha}$ (Credit Valley Conservation; Schroeter \& Associates; Environmental Water Resources Group; Aquafor Beech Limited; Jacques Whitford Environmental Limited; Waterloo Hydrogeologic Inc. 2003a). Based on the subwatershed plan major groundwater recharge and discharge areas were map and will continue to be monitored for trends overtime with the hope of maintaining baseflow in line with historic averages. Figure 7 outlines these critical areas within the Silver Creek subwatershed: 


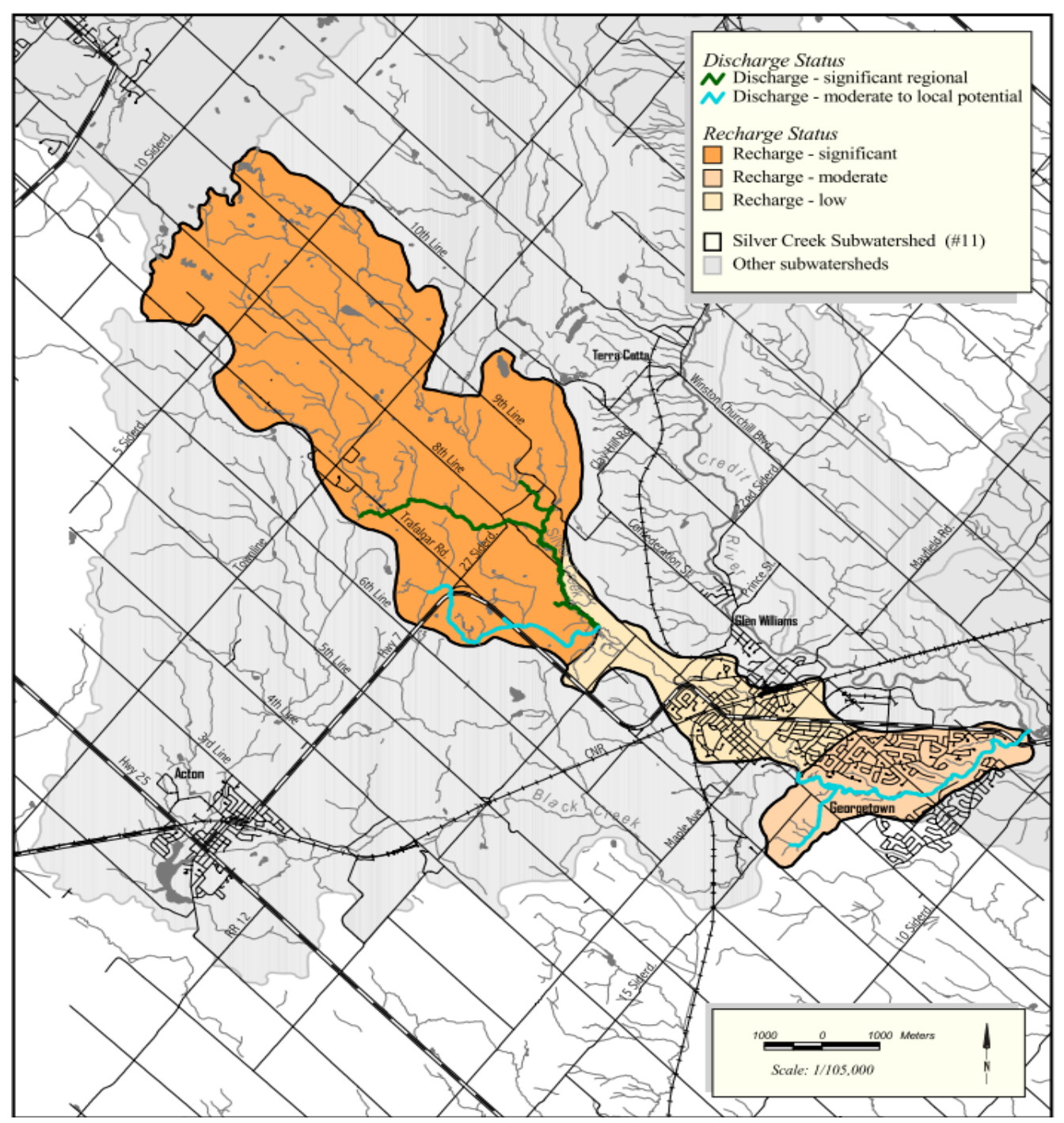

Figure 7: Recharge Status Silver Creek (Credit Valley Conservation; Schroeter \& Associates; Environmental Water Resources Group; Aquafor Beech Limited; Jacques Whitford Environmental Limited; Waterloo Hydrogeologic Inc. 2003a)

Streamflow averages were also examined during the subwatershed planning process for Silver Creek and were calculated based on a total potential water input from the entire watershed per year with the average ranging between 16,038,820 $\mathrm{m}^{3} /$ year $-26,640,712 \mathrm{~m}^{3} /$ year (Credit Valley Conservation; Schroeter \& Associates; Environmental Water Resources Group; Aquafor Beech Limited; Jacques Whitford Environmental Limited; Waterloo Hydrogeologic Inc. 2003a). Based on historical monitoring and analysis completed by the CVC current streamflow measurements are in line with historical trends. This information can be used for setting threshold limits within the multi-site ECA system. 


\subsubsection{Water Quality Objectives, Criteria, Targets, \& Monitoring}

Water quality within the Silver Creek subwatershed is considered an important objective to enhance as per the goals of the subwatershed. As part of the development of water quality monitoring in the Silver Creek subwatershed Parameters of Concern (POCs) were developed on the watershed scale by the CVC for use within the overall watershed and subwatersheds alike (Credit Valley Conservation; Schroeter \& Associates; Environmental Water Resources Group; Aquafor Beech Limited; Jacques Whitford Environmental Limited; Waterloo Hydrogeologic Inc. 2003a). These POCs are considered the targets for determining if the water quality objectives are met within the subwatershed. The targets for water quality include (Credit Valley Conservation; Schroeter \& Associates; Environmental Water Resources Group; Aquafor Beech Limited; Jacques Whitford Environmental Limited; Waterloo Hydrogeologic Inc. 2003a):

- Nutrients
○ Total phosphorus;
○ Nitrate;
- Nitrite; and,
- Ammonia.

- Oxygen related

○ Biological oxygen demand (BOD); and,

○ Dissolved oxygen (DO).

- Metals
○ Copper;
○ Zinc;
○ Nickel;
o Iron;
○ Aluminum; and,
- Manganese.

- Physical

- Suspended solids (SS); and,

- Water temperature. 
- Microbiological

O E. coli

- Other

- Chlorides

Although the Silver Creek subwatershed have explicit targets as they relate to water quality, specific subwatershed thresholds are not discussed however the Water Quality Index (WQI) as outlined by the Canadian Council of Ministers of the Environment and long-term averages are used to evaluate if the water quality criteria are being met (Credit Valley Conservation Authority n.d.). Silver Creek subwatershed use water quality monitoring data from two long-term PWQMN stations on Silver Creek (Credit Valley Conservation; Schroeter \& Associates; Environmental Water Resources Group; Aquafor Beech Limited; Jacques Whitford Environmental Limited; Waterloo Hydrogeologic Inc. 2003a). Currently water quality data for chemistry related parameters are collected on a monthly basis as well as four real-time water quality stations provide instantaneous information on changes to water quality (Credit Valley Conservation Authority n.d.). The real-time monitoring stations are capable of measuring water temperature, clarity, pH and oxygen in water (Credit Valley Conservation Authority n.d.).

\subsubsection{Stream Morphology Objectives, Criteria, Targets, \& Monitoring}

Maintaining stream morphology characteristics within the stream morphology object was considered a key criterion within the Silver Creek subwatershed study. The assessment of the health of stream morphology was determined through both qualitative and quantitative methods to diagnose stream behavior (Credit Valley Conservation; Schroeter \& Associates; Environmental Water Resources Group; Aquafor Beech Limited; Jacques Whitford Environmental Limited; Waterloo Hydrogeologic Inc. 2003a). Targets for stream morphology is governed by reach classifications which examine areas of the subwatershed with similar morphology, history of modification, adjustment type and surrounding land use (Credit Valley Conservation; Schroeter \& Associates; Environmental Water Resources Group; Aquafor Beech Limited; Jacques Whitford Environmental Limited; Waterloo Hydrogeologic Inc. 2003a). Targets for steam morphology is further defined through the following (Credit Valley Conservation; Schroeter \& 
Associates; Environmental Water Resources Group; Aquafor Beech Limited; Jacques Whitford Environmental Limited; Waterloo Hydrogeologic Inc. 2003a):

- Delineation of parameters such as slope, geology, soils, land use, hydrologic consistency, and planform;

- Collection of field data, and geomorphic analysis;

- Sediment transport modelling; and,

- Classifying channel morphology and type of adjustment.

Within the stream morphology objective and subsequent criteria and targets no specific thresholds are outlined within the subwatershed plan. Monitoring is the approach taken to understand change of stream morphology over time. Monitoring includes forms of field data capture, modelling, and GIS analysis (Credit Valley Conservation; Schroeter \& Associates; Environmental Water Resources Group; Aquafor Beech Limited; Jacques Whitford Environmental Limited; Waterloo Hydrogeologic Inc. 2003a).

\subsubsection{Terrestrial Objectives, Criteria, Targets, \& Monitoring}

Like other subwatershed studies a terrestrial objective was considered within the Silver Creek subwatershed study. Maintaining terrestrial characteristics of the Silver Creek subwatershed is a criteria to be governed by targets such as forest cover, wetland function and health, areas of natural and scientific interest, environmentally significant areas, cultural communities, watercourses, lakes and ponds, terrestrial corridors, and wildlife (Credit Valley Conservation; Schroeter \& Associates; Environmental Water Resources Group; Aquafor Beech Limited; Jacques Whitford Environmental Limited; Waterloo Hydrogeologic Inc. 2003a). Specific thresholds for the associated terrestrial objective are not mentioned however surveillance of the objective is carried out through GIS base mapping.

\subsubsection{Aquatic Objectives, Criteria, Targets, \& Monitoring}

Outlined within the Credit River Water Management Strategy protection and enhancement of aquatic habitat is considered an important criteria within the watershed and subwatersheds alike (Credit Valley Conservation; Schroeter \& Associates; Environmental Water Resources Group; Aquafor Beech Limited; Jacques Whitford Environmental Limited; Waterloo Hydrogeologic Inc. 2003a). For the aquatic objective fish health is considered another criteria for 
determining the status of the objective. Within the fish health criteria species diversity or biomass density is considered the target for which this criteria is monitored against (Credit Valley Conservation; Schroeter \& Associates; Environmental Water Resources Group; Aquafor Beech Limited; Jacques Whitford Environmental Limited; Waterloo Hydrogeologic Inc. 2003a). Quantitative fish measurements are captured from 30 monitoring stations on an annual basis throughout the Credit River watershed where fish density per square meter is calculated for analysis against the long term monitoring trend (Credit Valley Conservation; Schroeter \& Associates; Environmental Water Resources Group; Aquafor Beech Limited; Jacques Whitford Environmental Limited; Waterloo Hydrogeologic Inc. 2003a). Although the aquatic objective is clearly defined like other objectives within the Silver Creek subwatershed, specific thresholds are not identified. 


\subsection{Monitoring Technologies for the Stormwater Framework Parameters Monitoring}

of Objectives, Criteria, and Targets

Selection of framework parameters that can be appropriately monitored is crucial to implementing an effective multi-site ECA system. With the growth of the Internet of Things (IOT) environmental monitoring has become less expensive and more readily available for end users (Saravanan et al. 2018). Historically, monitoring was extremely labour intensive and in turn expensive to implement an effective monitoring program. Advancements associated with monitoring devices and cloud-based data access portals are required for a functional system. The following sections evaluate monitoring technologies that can monitor the objectives found to be important for watersheds across Ontario. These technologies were evaluated based on their ability to effectively monitoring targets and thresholds for compliance purposes within the multisite ECA system. Although there is variability between the subwatershed objectives from the three different regions as outlined in Sections 2.7 to 2.9 the following objectives were evaluated for monitoring applicability within the multi-site ECA system:

- Water Quality Objectives;

- Water Quantity Objectives;

- Stream Morphology Objectives;

- Terrestrial Objectives; and,

- Aquatic Objectives.

\subsubsection{Monitoring of Water Quality Objectives, Criteria, and Targets}

Given the importance for human health, ecological health, and general recreational activities preserving water quality is important for all citizens and therefore should be included as an objective for the multi-site ECA system. The Provincial Water Quality Objectives (PWQO) were developed by the Ministry of Environment and Climate Change to outline chemical and physical indicators for a satisfactory level of quality for surface waters, and where it discharges to the surface and groundwater. The PWQOs take into account human health, ecological health, recreational enjoyment, and aesthetics (Ontario Ministry of the Environment and Energy 1994). Watershed and subwatershed plans outline both chemical and physical criteria that are to be 
upheld and preserved as part of the plan. Effective monitoring of water quality parameters will be an important part for the proper governance of the permit. Real-time monitoring where feasible should be required for the permit areas. Cloete, Malekian, and Nair (2016) evaluated the design and development of real-time water quality monitoring systems. The research team selected $\mathrm{pH}$, temperature, conductivity, flow, and oxidation reduction potential (ORP) as their criteria to monitor in real-time. These parameters were selected because sensors were affordable, and they were proper indicators of water quality health. For example conductivity is an indication of impurities in the water which in turn reveal information such as how much total dissolved solids may be in the water (Cloete, Malekian, and Nair 2016). The water quality sensors were attached to a microcontroller which communicated with a wireless module capable of uploading data in real-time. In this example of real-time water quality monitoring the sensors were able to record real-time data however data logging capabilities were not introduced as part of this study.

While there are numerous examples of experimental real-time water quality monitoring sensors there are also refined and deployed monitoring systems. The Credit Valley Conservation (CVC) currently deploys a real-time water quality monitoring network at several locations throughout their watershed. The system is capable of measuring:

- Temperature (air and water)

- Dissolved oxygen

- $\mathrm{pH}$

- conductivity and chloride

- turbidity

- water level

- precipitation

Data is collected in real-time and uploaded to a web-based application and plotted every 15 minutes. Figure 8 outlines the basic principle for the system. 

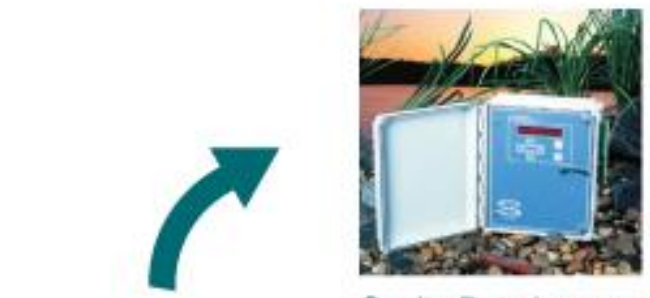

Onsite Data Logger and GSM Cellular Modem

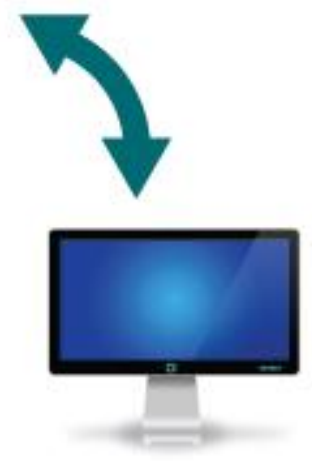

Water Quality Probe

Remotely Connected

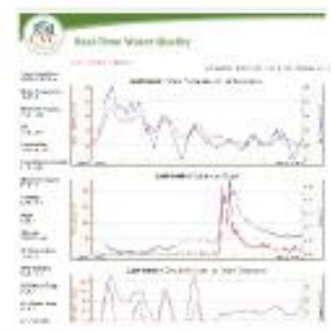

Automatically plotted after every $15 \mathrm{~min}$

Figure 8: CVC Real-Time Water Quality Network System Configuration (Credit Valley Conservation 2017)

The water quality probe used as part of this network is a Hydrolab DS5X which is capable of measuring temperature, conductivity, depth, $\mathrm{pH}, \mathrm{ORP}$, dissolved oxygen, turbidity, chlorophyll a, blue-green algae, rhodamine WT, ammonium, nitrate, chloride, total dissolved gas, and ambient light (HydroLab 2005)(Credit Valley Conservation 2014). The water probes data is collected by an Onsite Data Logger which is equipped with a GSM Modem that uploads and downloads information from office computers. Data is then displayed on graphs posted to the CVC website (Credit Valley Conservation 2017).

Several real-time monitoring water quality technologies exist and research relating to affordable technologies continues to grow. Basic monitoring systems can be easily designed and deployed using readily available hardware and software components. Myint, Gopal, and Aung (2017) carried out real-time monitoring of water quality parameters such as $\mathrm{pH}$, temperature, turbidity, and $\mathrm{CO}_{2}$ using off the shelf hardware components from a local electronic store. They 
were able to achieve reliable and cost effective monitoring using a single chip solution to interface the water quality sensors (Myint, Gopal, and Aung 2017). Arduino based water quality monitoring has also been taken a step further with the implementation of water quality monitoring with automation by measuring $\mathrm{pH}$ and $\mathrm{DO}$ with triggers set for aeration and water supply controls (Harun, Reda, and Hashim 2018). Other research teams have also further investigated the options of low cost real-time water quality monitoring networks however challenges with communications were found when monitoring in rural areas (Rahim et al. 2017).

\subsubsection{Monitoring of Water Quantity Objectives, Criteria, and Targets}

Water quantity objectives, criteria, targets, and thresholds should be considered for all multi-site ECA approvals. Measurement and monitoring of this objective has evolved over time which has resulted in more complex real-time monitoring networks used to calibrate hydrological modelling (Chacon-Hurtado, Alfonso, and Solomatine 2017). Local CAs partner with Environment Canada and the Ontario MECP for water quantity monitoring. Environment Canada's real-time monitoring network covers all of Canada with numerous monitoring stations in Ontario. These stations primarily measure water level in meters and calculate flow in cubic meters per second using the water level data and previously developed rating curves. The information is presented in real time and allows users of the data to plot these parameters graphically as shown in Figure 9. 


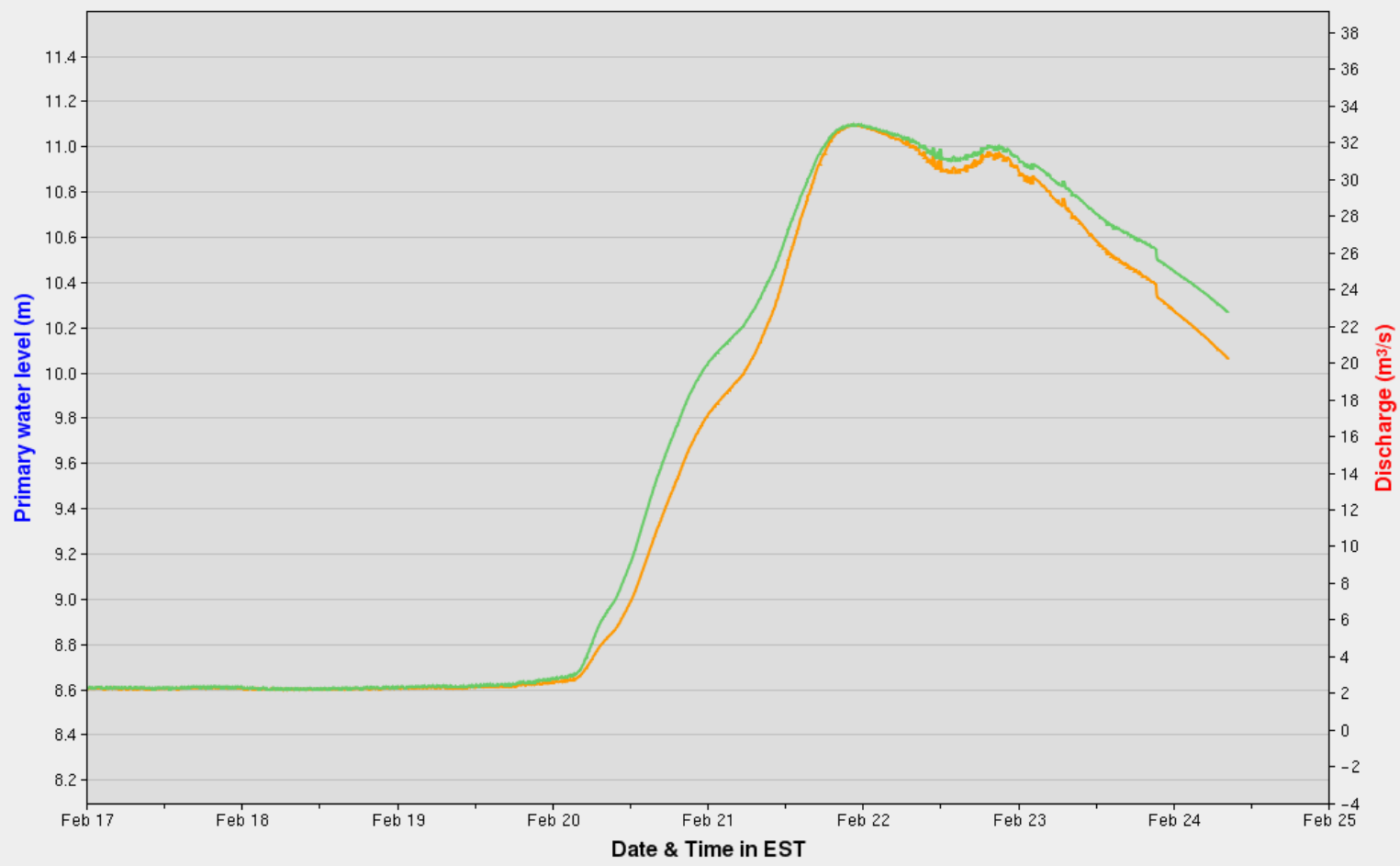

Figure 9: Real-Time Water Quantity for Black River LSRCA (Environment Canada 2018)

Flow monitoring stations are generally located close to operational and valid hydraulic control areas (Toronto and Region Conservation Authority 2000). These areas are considered to be representative of where water levels upstream of the control and not dependent on water levels downstream of the control (Toronto and Region Conservation Authority 2000). The streamflow monitoring process is generally carried out in one of two ways, either through mathematical modeling or by field measurements in order to develop a stage versus discharge curve or a rating curve (Toronto and Region Conservation Authority 2000). Water level measurements are then gathered either in real-time or manually upstream of the control and the aforementioned rating curve is applied to estimate the flow at that specific location (Toronto and Region Conservation Authority 2000).

Water level monitoring for support of streamflow estimates can be carried out using a wide range of established sensors. Instrument manufacturers such as Campbell Science offer bubble sensor water level monitors, radar level sensors, or pressure level sensors that can be 
connected to a GSM dataloggers. These sensors are capable of measuring and reporting back to a web-based application as outlined in Section 2.9.1 of this document. Although off the shelf instruments are readily available some of the set ups can be economically prohibitive for large scale deployment (Gopavanitha and Scholar 2017). The TRCA estimated that construction of a gauge costs between $\$ 7,000$ and $\$ 10,000$ with operational and maintenance costs between $\$ 2,500$ and $\$ 8,000$ for a three year period (Toronto and Region Conservation Authority 2000). The operational and maintenance costs will need to be decreased for the multi-site ECA system to properly function. The use of open source instruments could be utilized to reduce costs and allow for greater deployment throughout a subwatershed.

Advancements in open source monitoring technologies may provide multi-site ECAs with cost-effective options for greater monitoring deployment. Companies such as Adafruit and Arduino offer low cost open source data loggers and water level monitoring devices that could be considered for filling data gaps in monitoring networks throughout subwatersheds. Although these sensors would need modification or improvements, they could be a viable option in the future. One such level sensor produced by Adafruit is the eTape Liquid

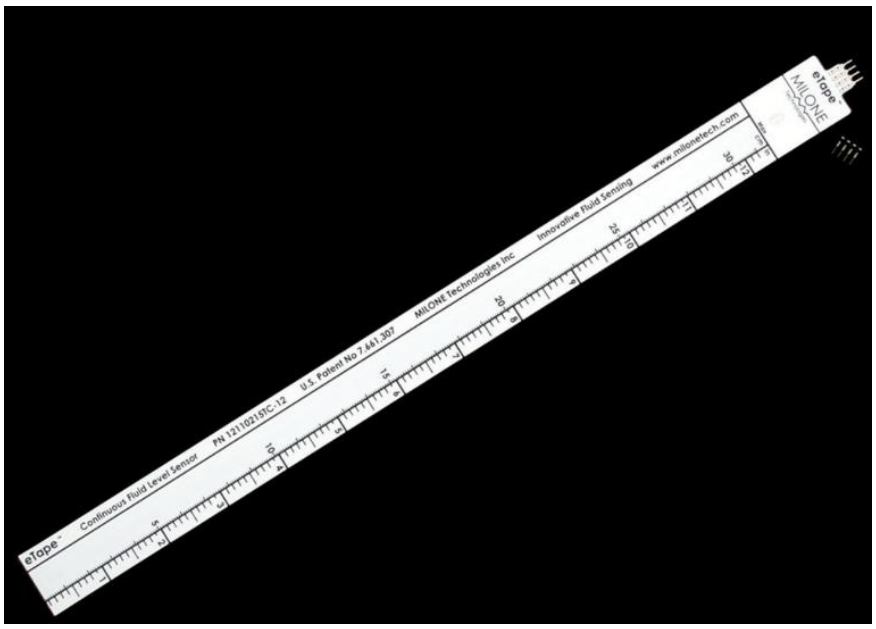
Figure 10: Adafruit eTape Liquid Level Sensor (Adafruit 2018) Level Sensor shown in Figure 10 and is a solid-state sensor with resistive output that varies with the level of liquid currently available for approximately $\$ 40$ USD. Although this sensor is currently only available in $360 \mathrm{~mm}$ lengths and would need to be larger for stream level measurement it outlines that sensor technology is evolving in favour of lower cost options. Other open source water level sensors such as the Adafruit Optomax Digital Liquid Level Sensor could be used to measure streamflow using an optical sensor for measuring water levels. These types open source optical sensors can be purchased for approximately \$25 USD. Connecting these instruments to off the shelf data loggers or micro-controllers has become increasingly easy with open source coding options available for 
all Adafruit sensors. The level sensors can interface with open source micro-controllers such as the Arduino GSM Shield 2 for approximately \$72 USD. Like real-time water quality monitoring citing of the stations for cellular coverage is required.

\subsubsection{Monitoring of Stream Morphology Objectives, Criteria, and Targets}

Selection and implementation of stream morphology monitoring presents different challenges than water quality or water quantity monitoring. In general stream morphology criteria relate to flooding, erosion, and slope stability. The primary focus is generally soil erosion which is the process of soil movement primarily by water and air (Toronto Regional Conservation Authority 2018). Erosion can cause changes in channel morphology, floodplains, and habitats (Wright, Marcus, and Aspinall 2000)(Jamieson et al. 2013). Surveying and monitoring of channels typically involve manually surveying the stream channel and surrounding floodplain or using aerial photography to document changes over time which can cause long periods between surveys due to the associated costs for capturing this data (Wright, Marcus, and Aspinall 2000).

Given the labour intensive nature of collecting manual field observations or aerial photography advanced remote sensing with multispectral imagery using hyperspatial satellites can provide more complete information on a regular basis when paired with a digital database for low order streams (Wright, Marcus, and Aspinall 2000). The use of hyperspatial satellites which can provide greater detail on low order streams would be applicable to multi-site ECA's since several subwatersheds are comprised of low order streams which can be greatly affected by erosion.

Empirical models based on geomorphological parameters have been used for assessing soil erosion from the watershed (Chen et al. 2011). The Universal Soil Loss Equation and the Revised Universal Soil Loss Equation (RUSLE) are the most commonly used models for predicting soil erosion loss (Chen et al. 2011) and require information from the field. Using remote sensing and GIS techniques to provide information for the RUSLE can make soil erosion estimates feasible in a cost effective way (Chen et al. 2011).

Although stream morphology information may be difficult to monitor in real-time advancements in remote sensing and GIS technologies can be used to gather information more 
regularly and less labour intensive than traditional in field investigations. Integrating remote sensing or GIS information into empirical models can allow for effective monitoring stream morphology within the multi-site ECA system.

For areas within a subwatershed where satellite imagery cannot provide the level of detail required to take accurate measurements other technologies could be used to supplement monitoring information. For measuring first order stream changes, where vegetative cover would limit the effectiveness of satellite information, drone or unmanned aerial vehicles (UAV) could be utilized. UAV technology can provide greater resolution for hydromorphological features at a greater cost efficiency (Casado et al. 2015) (Afshari et al. 2016)(Casado et al. 2016)(Woodget et al. 2017). Casado et al. 2016 used a UAV to capture aerial imagery at three resolutions including $2.5 \mathrm{~cm}, 5 \mathrm{~cm}$, and $10 \mathrm{~cm}$ along a $1.4 \mathrm{~km}$ stream. The results of the study indicated that for sensitive areas that require greater detail in the hydromorphological assessment resolutions less than $10 \mathrm{~cm}$ is required which GIS frameworks cannot accurately achieve. For regional river assessments automated identification using UAV integrated into GIS databases could be used (Casado et al. 2016). The enhanced detail of UAV measurement is shown in Figure 11 which compares traditional $80 \mathrm{~cm}$ satellite imagery to a $5 \mathrm{~cm}$ UAV image (Afshari et al. 2016).
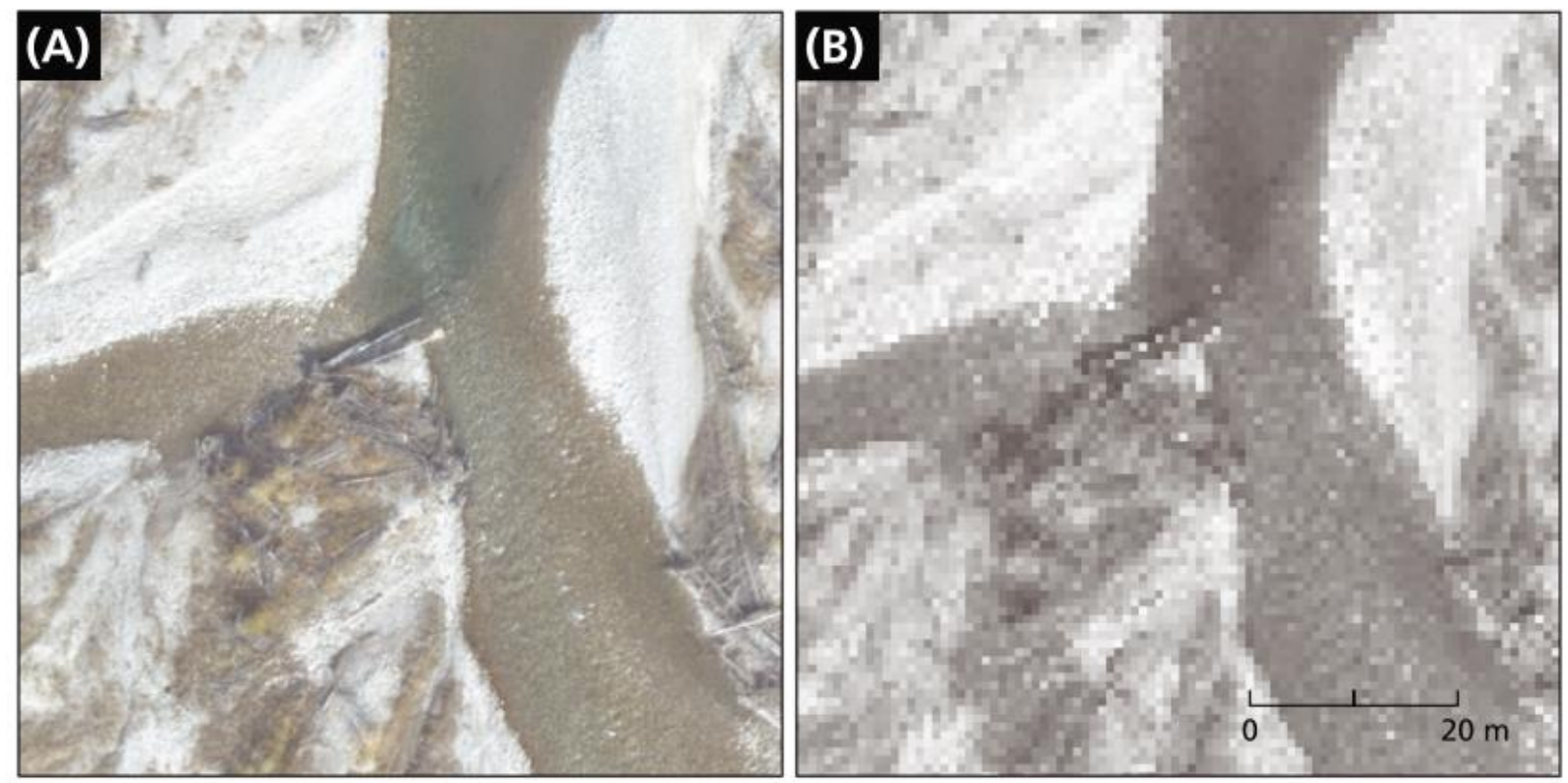

Figure 11: UAV (A) $5 \mathrm{~cm}$ Resolution vs Sattelite (B) $80 \mathrm{~cm}$ Resolution (Afshari et al. 2016) 


\subsubsection{Monitoring of Terrestrial Objectives, Criteria, and Targets}

Terrestrial monitoring presents similar challenges as stream morphology monitoring given the wide range of criteria and sheer landmass size associated with terrestrial objectives. For the purposes of this research terrestrial objectives are ones that deal with biology living or growing on land or on the ground. In general criteria relating to terrestrial objectives include (Upper Thames River Conservation Authority 2012)(Ministry of Environment, Ministry of Natural Resources 2009)(Credit Valley Conservation Authority 2005):

- Preservation or restoration of shoreline;

- Maintain or improve natural vegetative and woodlot cover;

- Achieve naturalized riparian areas;

- Preserve or restore wetlands;

- Preservation or restoration of natural areas or features; and,

- Achieve ecological health;

In most cases Conservation Authorities monitor their terrestrial objectives by establishing monitoring stations in the forest and wetland ecosystems representative of the different physiological areas and land uses (Credit Valley Conservation Authority 2005). These stations are set up to monitor change over time with the results published in the watershed or subwatershed report cards produced by the Conservation Authority for the given area.

For the multi-site ECA system these monitoring stations could still be useful for

monitoring changes over time however several advancements in remote sensing and GIS technologies could assist with monitoring change over time from a macro scale (Pratihast et al. 2016)(Sun and Li 2016)(Gunawardena et al. 2018)(Neukom, Müller Arisona, and Schubiger 2018). Pratihast et al. (2016) explored an interactive web-based near real-time (NRT) forest monitoring system that used various types of GIS services. Figure 12 outlines a diagram of the forest monitoring system that provided near real-time data for forest change based on remote sensing. 
The system implemented was based on open-source data in effort to support forest management and reduce illegal activities in other areas of the world. The system allows for the upload of field observations which can be used to verify the remote sensing data provided in near real-time. A hybrid system that includes monitoring stations and the integration of multi-sensor remote sensing data streams like Landsat, Sentinel 1 and Sentinel 2 could improve accuracy (Pratihast et al. 2016).

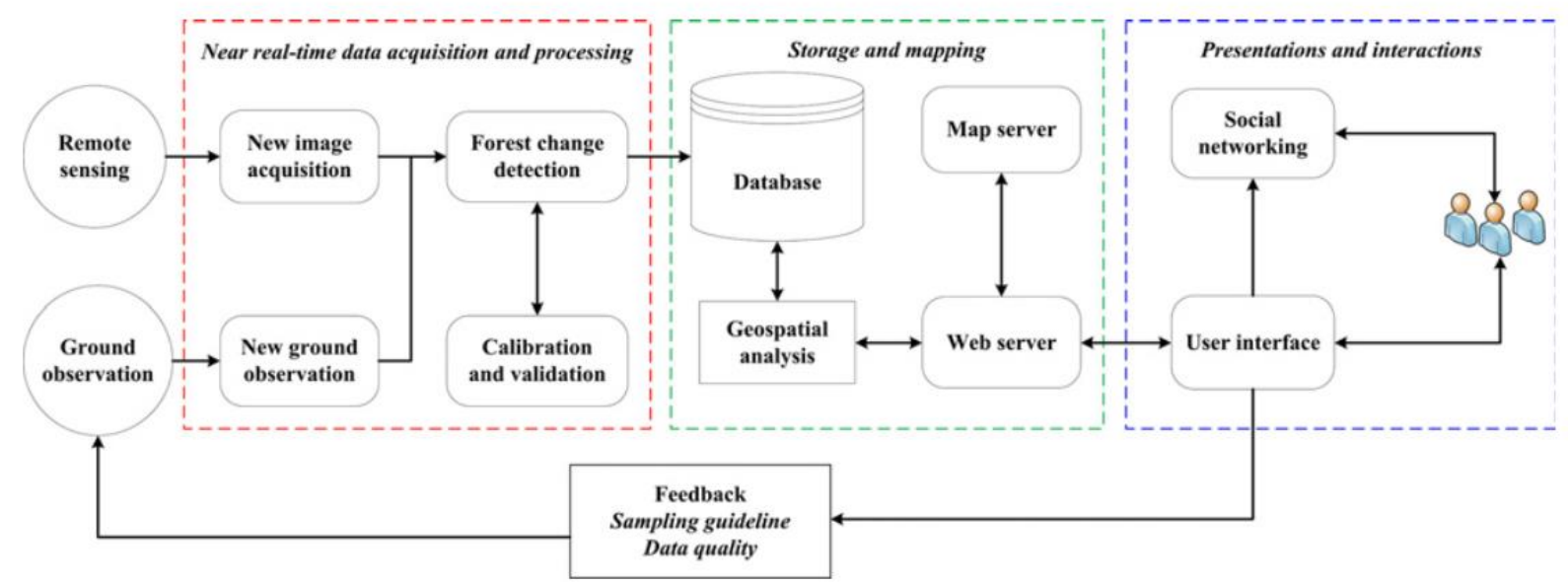

Figure 12: Near Real-Time Forest Monitoring Diagram (Pratihast et al. 2016)

ESRI offers a proprietary NRT GIS based platform that integrates live feed satellite data with ArcGIS a commonly used GIS software application (Dodd 2009). Through this platform data scrips can run every 5 minutes to update the data feed in attempt to provide greater frequency of GIS data (Dodd 2009). Non-proprietary systems have also been tested whereby publicly available GIS data is integrated for NRT visualization (Resch et al. 2009). These types of systems have been used to evaluate environmental change at a greater frequency and capture seasonal variation (Neukom, Müller Arisona, and Schubiger 2018). The greater frequency of information from NRT GIS systems can assist with evaluating land use change more accurately while limiting field resources (Neukom, Müller Arisona, and Schubiger 2018).

\subsubsection{Monitoring of Aquatic Objectives, Criteria, and Targets}

Monitoring of aquatic objectives and subsequent criteria presents a unique opportunity to use cutting edge technology under the multi-site ECA system. In general criteria relating to aquatic objectives include (Upper Thames River Conservation Authority 2012)(Ministry of Environment, Ministry of Natural Resources 2009)(Credit Valley Conservation Authority 2005): 
- Prevention of invasive species;

- Dissolved oxygen concentrations;

- Species diversity or biomass density (benthic macroinvertebrates); and,

- Aquatic habitat health.

For some areas like the Lake Simcoe region aquatic health is tied to dissolved oxygen concentration which is related to the health of their cold water fishery (Ministry of Environment, Ministry of Natural Resources 2009). If water quality can be related to aquatic criteria than the monitoring network set up for water quality can be used for some aquatic criteria as well under the multi-site ECA system. Other criteria if they are to be included as part of the multi-site ECA criteria such as invasive species prevention, species diversity, biomass density, and aquatic habitat health may require traditional monitoring or the use of developing technologies to monitor this aspect of the permit.

Traditional monitoring of invasive species, species diversity, biomass density, and aquatic habitat health are carried out through manual monitoring methods usually at pre-defined monitoring stations throughout the watershed or subwatershed (Credit Valley Conservation Authority 2005). Information collected as part of these investigations could be used to monitor and govern the multi-site ECA permit area.

Alternative and developing methods for monitoring aquatic health present a unique option for monitoring under a multi-site ECA system. Environmental DNA (eDNA) is a growing field that attempts to improve biodiversity monitoring for aquatic species (Nevers et al. 2018)(Barnes et al. 2014). eDNA can provide occupancy estimates, quantification of endangered species, and provide real-time detection of invasive species and their spread throughout an ecosystem (Nevers et al. 2018)(Barnes et al. 2014). The research and development of eDNA is attempting to remove the need for visually detection of species with a high priority application being the detection of invasive species (Nevers et al. 2018). Nervers et al. 2018 evaluated the eDNA detection of the round goby an invasive benthic fishing within the Great Lakes with a large presence in Lake Simcoe. The study routinely detected goby eDNA in areas known to have round goby's however eDNA was not detected upstream of an artificial fish barrier (Nevers et al. 2018). 
While additional research is required eDNA represents a potential solution for an aquatic criteria of invasive species prevention. eDNA can also provide greater detection vs. traditional methods allowing for a more sensitive method for detecting difficult to observe species (Rees et al. 2014). As per Rees et al. 2014 "environmental DNA analysis could be used as a relatively quick, inexpensive tool for collecting species presence and distribution data."

\subsubsection{Solutions for Data Management}

Advancement with IOT data and database management systems for web-based applications present a unique opportunity for a data management solution for a multi-site ECA system. Fang et al. 2014 looked at an integrated system for regional environmental monitoring and management based on IOT which covers similar data management issues that the multi-site ECA system would exhibit. The study evaluated integrating geographic information systems (GIS), remote sensing, global positioning systems, data acquisition technologies, and sensor technologies to create a decision support system for environmental monitoring and management (Fang et al. 2014). The four main components of the IIS include; the perception layer, the network layer, the middle layer, and the application layer. Figure 13 outlines the general architecture of an Integrated Information System (IIS) that can be deployed for the data management solutions.

The perception layer includes the physical world and the devises and sensors that could be deployed as part of the multi-site ECA system (Fang et al. 2014). Under the multi-site ECA system the perception layer would include; water quality sensors, water quantity sensors (water level sensors, streamflow sensors, etc.), remote sensing for stream morphology and terrestrial targets, as well as aquatic data collection for the aquatic targets.

The network layer includes the access and transport networks which is how the information from the physical world and sensors are relayed to a given network (Fang et al. 2014). These could include GSM data loggers such as the Arduino systems mentioned in Section 2.9.3. Essentially the information is transported from the physical world through sensors to cloud based database within the network layer of the IIS. 


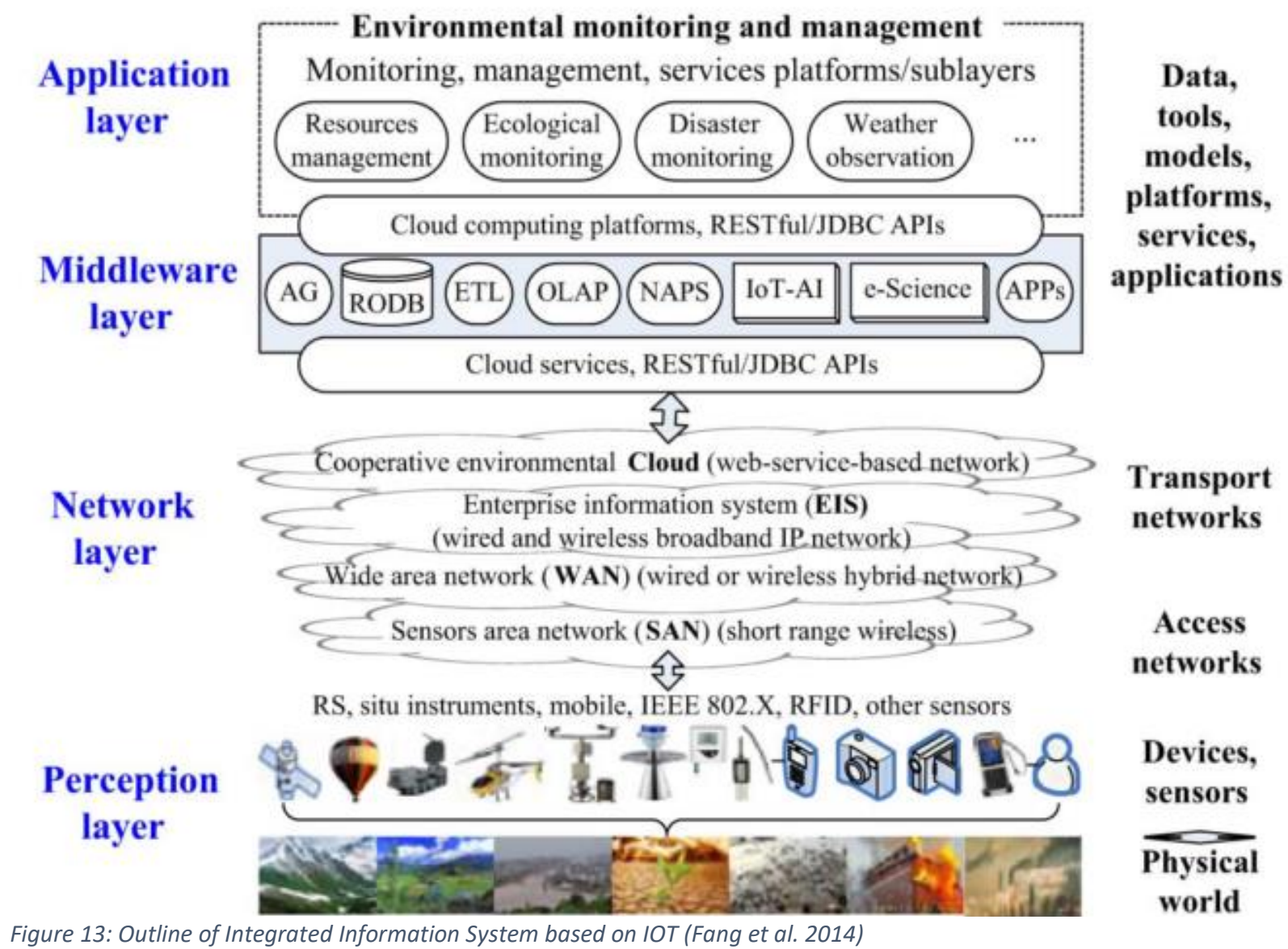

The middle layer is used to manipulate the data captured from the physical work into a usable format for the final application layer which includes the data, visualization tools, and webbased applications (Fang et al. 2014). It is within this middle and final application layer that the administrative burden is reduced for the MECP. This layer can include automatic reporting, data visualization, alerts for when targets are exceeded, among others. Utilizing IIS and IOT data within the multi-site ECA system provides a unique opportunity to effectively monitor and manage the approvals in a greater capacity than in under current ECA system.

\subsubsection{Sensor Data Networks}

Several options exist for IOT specialized networks for sensor data within Ontario. Traditional service providers such as Rogers and Bell Canada offer IOT specific data networks. In 2018 Rogers released the LTE-M network that replaced existing 2G network connections for IOT data (Rogers Communications Canada n.d.). Outside of the traditional service providers 
specialized network providers such as eleven-x host IOT networks for sensor deployment. The eleven-x platform uses LoRaWAN ${ }^{\mathrm{TM}}$ technology that enables sensor connectivity (eleven-x 2018).

\subsection{Literature Review Summary and Conclusions}

Utilizing some of the lesson learned from other watershed-based governance could support the implementation of Ontario's multi-site ECA system. The WFD and NPDES MS4 permitting system have reported and documented implementation measures, successes, and shortcomings that could support Ontario's multi-site ECA development. An important aspect of these two systems is the involvement of several key stakeholders such as conservation authorities, local government, volunteer groups, and private partnerships who can all take an active role in the implementation and success of the proposed system. WFD permits are evaluated at different intervals throughout the permit lifecycle to evaluate the permits performance. A 5-year review feature is also included as part of the LSPP and could be implemented as part of the multi-site ECA system. Baseline data and historical watershed information is important to the enactment of the system. Where watersheds and subwatersheds lack funding for plans and baseline studies additional resources will be required to support implementation of the multi-site ECA system.

The successful implementation of the framework is tied to the setting of appropriate objectives, criteria, targets, and thresholds that can be effectively monitored. The gathering of the common parameters into one framework can be achieved through the review of existing watershed and subwatershed plans. Once the targets and thresholds have been set, selecting monitoring systems that can be deployed on mass is crucial. Monitoring data from existing stations could be utilized if a multi-site ECA approval system is adopted. For a multi-site ECA system to function properly, remote monitoring networks like the CVC's network are required to remotely evaluate trends over time. Additional monitoring stations installed in each subwatershed would be required to properly assess the function and compliance of a given multisite ECA permit. Using alternative monitoring technologies integrated using IOT could present a unique and mass deployment option. Although there are limitations related to cellular network coverage monitoring stations installed for multi-site ECA purposes would need to consider coverage limitations when siting monitoring stations. Whether off the shelf or customized 
continuous water quality and water quantity monitoring solutions are employed for multi-site ECA monitoring it is apparent that the current state of technology could allow for the effective monitoring of these parameters within a subwatershed.

For the multi-site ECA system monitoring of terrestrial objectives, criteria, targets, and thresholds can be carried out using traditional methods however, integration of an NRT GIS based monitoring system with onsite verification could be included into the overall monitoring approach. Open source and proprietary NRT GIS systems exist but would require adaptation to satisfy the framework parameters relating to the terrestrial environment.

Given that multi-site ECA's are not intended to replace watershed monitoring from an ecological perspective, eDNA presents an interesting option that should be considered for the implementation of multi-site ECA's. Traditional methods of monitoring aquatic health may be required in the short term but as science advances relating to alternative methods for monitoring, they should be considered for implementation within the multi-site ECA system.

Data storage, management, and visualization of monitoring data is another key aspect to the successful implementation of a multi-site ECA system. Reduction of the administrative burden is key for the proper function of the system and if monitoring data cannot be stored, managed, and visualized in a usable format for the MECP the benefit of real-time monitoring data and streamlined ECA process will not be realized. Ideally each multi-site ECA would report their data in the same format as defined by the multi-site ECA process where the MECP could easily access and report on the permits compliance within a primary database. Alerts and warnings could be deployed by the web-based application to notify the appropriate authorities of concentrations approaching or exceeding the targets. This early warning or alert function could be used to implement mitigation measures to reduce the number of exceedances observed by the subwatershed.

\subsection{Gaps}

Under the current system, ECAs are issued for the specific stormwater control regardless of geographic location. Substantial administrative burden exists for ensuring compliance of these controls due to the volume of stormwater controls that exist throughout Ontario. As a result of 
the sheer number of required approvals, stormwater controls go unpermitted, unmaintained, and not effectively monitored, limiting the controls effectiveness (Ministry of the Environment and Climate Change 2014).

Increased urban sprawl causes changes to the hydrological cycle, alters stream response to storm events, changes to stream morphology, degrades water quality, and affects aquatic habitat and ecology (Zimmer et al. 2007) (Ministry of the Environment 2003). The environmental problem with the current ECA system is that the administrative burden relating to approvals, enforcement, and monitoring, which is already substantial, will continue to increase along with Ontario's development. With Ontario's population expected to grow by approximately 31 percent over the next 28 years (Ministry of the Finance 2014), it is important that stormwater controls are effectively regulated to limit urbanization's impact on receiving water bodies. This complex issue requires substantial analysis and evaluation to determine the specific mechanisms required to effectively implement and monitor a multi-site subwatershed based ECA system. Setting objectives, criteria, targets, thresholds, and how to effectively monitor these variables are essential for the successful implementation of a multi-site ECA system.

The use of traditional real time monitoring methods for water quality and water quantity can be used to support the multi-site ECA system however coverage of these networks needs to be evaluated to ensure representative data can be collected for the given permit area. Recent advancements in sensor technology could provide a low-cost solution for mass deployment of sensors within a permit area. Similarly, traditional monitoring methods for stream morphology, terrestrial, and aquatic objectives could be a viable option for governing the multi-site ECA system however advancements and ongoing research and development could be implemented to provide detailed information in real time to the MECP who will be responsible for governing the multi-site ECA system. Using an IIS architecture and IOT technology presents a unique opportunity for stormwater management through the multi-site ECA system. 


\section{Methods}

As previously discussed in Section 2.10, the current stormwater ECA system enables stormwater controls to go unpermitted, unmaintained, and not effectively monitored, limiting the controls effectiveness for protecting and managing Ontario's watersheds. Without evaluating alternative approaches to the existing ECA system, protection of Ontario's receiving waters will continue to diminish. Implementation of a multi-site ECA stormwater permitting system could achieve the original intent of the ECA system which is to govern and monitor stormwater controls to protect Ontario's watersheds.

The objective of this research is to develop a framework for multi-site ECA permits. The framework parameters will include stormwater objectives, criteria, targets, and thresholds that can be effectively monitored using either traditional or alternative monitoring technologies. As part of this research an extensive literature review of academic, institutional, professional opinions, and open source information was conducted to identify and compile background information for the framework.

The research objective was fulfilled through the following scoped items:

1) Identify and select for inclusion in a multi-site ECA system:
a. Stormwater Objectives;
b. Stormwater Criteria;
c. Stormwater Targets; and,
d. Stormwater Thresholds.

2) Evaluate and propose traditional or alternative monitoring solutions for the framework based on their ability to provide representative data for permit compliance.

3) Provide a summary table and recommendations for a multi-site ECA framework and proposed monitoring methods.

4) Simulate a multi-site ECA implementation using the framework parameters for Lovers Creek subwatershed in the Lake Simcoe watershed 
The first scoped item was supported by the information gathered from examples of watershed-based regulations that are currently being implemented for stormwater management. This information was then used to gather common themes relating to watershed governance and preservation from an Ontario multi-site ECA perspective. Framework parameters were also gathered and evaluated from the current watershed and subwatershed plans. These common framework parameters were assessed based on their ability to be monitored in a way that will provide continuous data or greater frequency of data that would allow for greater governance relating to permit compliance. Through the identification of common themes and parameters while apply logic and reasoning relating to their applicability within a multi-site ECA system supported the completion of the first scope.

Evaluation and selection of traditional and alternative monitoring technologies relating to water quality and quantity was carried out by identifying traditional monitoring technologies, their current deployment, specifications, and associated costs while comparing this to alternative technologies. Evaluation of alterative sensors was achieved through the development and implementation of evaluation criteria. This criterion was used to screen alternative sensors based on their specifications and similarities with traditional monitoring sensors as well as their cost, availability, and compatibility with open source microcontrollers and dataloggers. If the acceptance criteria were satisfied the sensors have the potential for deployment within the multi-site ECA monitoring system. Monitoring for non-sensor related objectives such as stream morphology, terrestrial and aquatic habitat monitoring were evaluated based on the ability to limit the requirements for onsite measurements and labour intensive data collection methods while providing greater frequency of data, where required. By using logic and reasoning and evaluating technologies against evaluation criteria recommendations for proposed monitoring methods were achieved.

The results of the framework development were gathered from the two previous scoped items. Logic and reasoning were used for the associated recommendations relating to the multisite ECA framework development and execution. 
The fourth scope item was carried out to simulate and test the framework parameters. Lovers Creek subwatershed within the Lake Simcoe watershed was selected based on the amount of background information, and the availability of a comprehensive subwatershed plan. The framework parameters were applied to the subwatershed and the thresholds were set and gathered based on readily available information. Hypothetical monitoring stations were outlined on a figure to visually depict the volume of potential monitoring stations that could be deployed in a multi-site monitoring network.

Figure 14 presents a visual representation of the steps to support the methods discussed as part of this section.

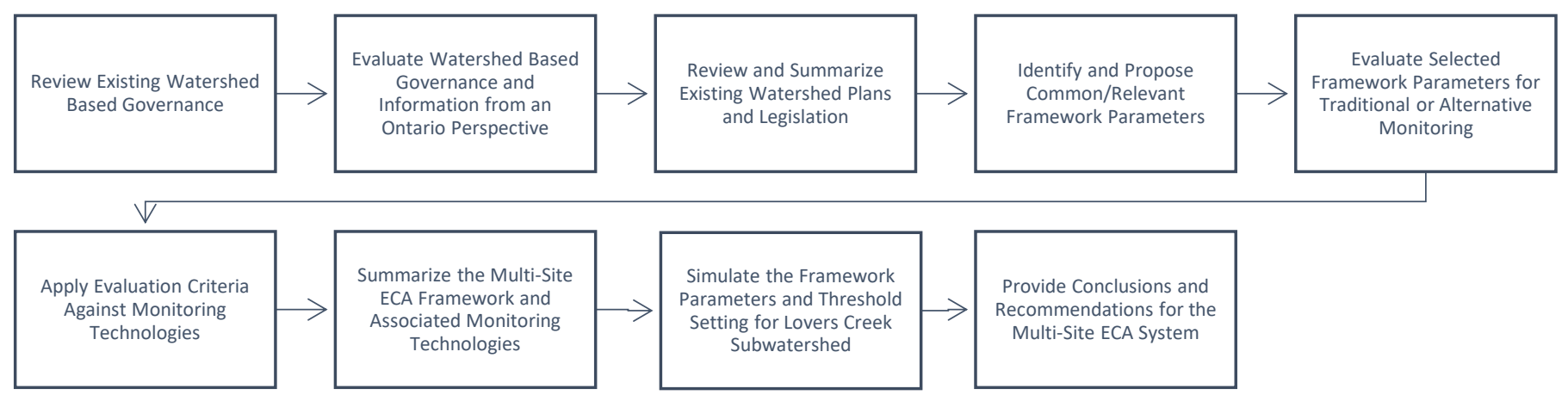

Figure 14: Method Flowchart 


\section{Selection of Stormwater Objectives, Criteria, and Targets}

Objectives, criteria, targets, and thresholds were compiled throughout the literature review process and were evaluated based on their applicability to a multi-site ECA system and if associated criteria and targets could be monitored in a way to provide relevant data while reducing the administrative burden on the MECP. In order for the multi-site ECA system to be effective the objectives, criteria, targets, and thresholds should set with the intention of prioritizing common goals for the health of Ontario's receiving waters, provide relevant information in a timely fashion, and have the ability to incorporate new technology, all while streamlining governance for a multi-site stormwater ECA system.

Based on the literature review, logic, reasoning, and evaluation of commonalities was used to select the following objectives for inclusion in the multi-site ECA system:

- Water Quality;

- Water Quantity;

- Stream Morphology;

- Terrestrial Environment; and,

- Aquatic Environment.

In the subsequent sections each of the five objectives will be discussed further with criteria, targets, and threshold considerations are evaluated.

\subsection{Water Quality}

Based on a review of the literature review relating to stormwater policy, planning, governance, and environmental effects water quality objectives are warranted with the multisite ECA system. Within water quality objectives the criteria for this objective is associated with improving water quality. With Ontario's current and projected population growth water quality issues are ever present and requires that land use planning incorporate watershed-based approaches to deal with cumulative impact from upstream sources on receiving water bodies (Shrubsole 2004). Although the pollutants associated with stormwater runoff are variable between watershed areas there are common contaminants that are persistently associated with stormwater runoff (Burton and Pitt 2001). 
Water quality contaminants that are associated with stormwater runoff within Ontario are consistent within watershed planning documents. Based on a review of three watershed regions in southern Ontario (Lake Simcoe Watershed, Thames River Watershed, and Credit River Watershed) the common water quality contaminants that have targets associated with them include the following (Upper Thames River Conservation Authority 2012)(Ministry of Environment, Ministry of Natural Resources 2009)(Credit Valley Conservation Authority 2005):

- Total Phosphorous;

- Nitrate;

- Ammonia;

- BOD;

- DO;

- Metals;

- TSS;

- Temperature;

- E.coli;

- Chloride; and,

- $\mathrm{pH}$.

Controlling these common water quality targets is achieved by implementing stormwater control measures as found in the MOE Stormwater Management Planning and Design Manual as released in 2003 as well as the Toronto Regional Conservation Authority and Credit Valley Conservation Low Impact Development Manual as released in 2010 (Ministry of the Environment 2003)(Credit Valley Conservation Authority and Toronto Region Conservation Authority 2010). To control water quality and meet objectives, criteria, targets, and thresholds common stormwater management practices include (Toronto and Region Conservation Authority 2012):

- $\quad$ wet ponds (stormwater management ponds);

- wetlands;

- infiltration facilities;

- low impact development practices; and, 
- $\quad$ oil grit separators.

Under a multi-site ECA system these individual controls would not require individual approvals. They would still require implementation and proper construction under the new system, however water quality compliance would be governed at the subwatershed level and monitored at various water quality monitoring stations installed within the subwatershed. Proper construction and implementation of stormwater controls can be a challenging based on the administrative burden on the MECP as well as the lack of defined design standards. The administrative burden for the MECP is an identified issue that one solution may be through the transfer of review process. This process transfers the initial ECA review process to the local municipality or conservation authority prior to final submission to the MECP (Prudhomme 2016)(Ministry of the Environment and Climate Change 2017).

Design manuals and guidelines exist however without a design standards the actual construction and implementation could vary (Credit Valley Conservation Authority and Toronto Region Conservation Authority 2010) (City of Edmonton 2014)(City of Barrie 2017). Implementing design standards for the proper implementation and construction can be achieved through using local knowledge as well as information from other regions. The Low Impact Development An Integrated Design Approach from Prince George's County, Maryland provides significant detail into design standards for LIDs (Department of Environmental Resources 1999). Using the already available information from both academic research and guidance documents to develop an Ontario based designed standard should be implemented to ensure the proper implementation and construction of stormwater controls which will support the multi-sit ECA system.

Selecting water quality targets to fulfill both the watershed objectives and multi-site ECA compliance should be derived from the Provincial Water Quality Objectives (PWQO) that are generally referenced within existing watershed management plans. In certain permits it may be necessary to include other contaminants of concern based on specific contaminant concerns associated with a given watershed. This approach is similar to the NPDES requirements for watershed specific studies to be completed and evaluate watershed specific water quality 
contaminants of concern for inclusion in permit compliance (Minan 2005). For the purpose of this research watershed common contaminants of concern for receiving waters were included.

Under the multi-site ECA system the water quality objective within each approval should be structured as outlined in Table 1. The targets selected for the multi-site objectives have associated PWQO's except for nitrate and BOD which will need to have approval specific thresholds set without the reliance on the PWQO's. Although the Clean Water Act protects against source pathogens and acts as a mechanism for Ontario wide protection, monitoring is still important to assist with source identification should an e.coli exceedance be detected. Metals thresholds are compound specific and would require speciation for the metals of concern in the specific watershed. For example, Lead may be a common contaminant of concern which will require a Lead specific threshold to be set. Other parameters such as turbidity and temperature will require supplemental information to set a specific threshold associated with the target for a given subwatershed. Targets such as nitrate, BOD, metals, turbidity, and temperature will need supplemental information prior to setting a specific threshold for a multi-site ECA approval. Setting thresholds for these targets can be achieved through review of historical monitoring results or collection of baseline data to understand existing conditions. The method setting associated thresholds is similar to the WFD which examines historical and baseline data to set thresholds within a specific permit area (Kaika 2003)(European Commission 2003).

Reconciling sources of water quality pollution is a challenge when dealing with monitoring of water quality parameters related to stormwater. Point source pollution such as accidental or intentional spills will need to be differentiated from stormwater water quality impact within the multi-site ECA system. In order to address this issue, increasing the amount of water quality monitoring stations and relating precipitation events to fluctuations in water quality concentrations can assist in isolating stormwater impact and non-stormwater impacts. 
Table 1: Multi-Site ECA Water Quality Objective, Criteria, Targets, and Thresholds

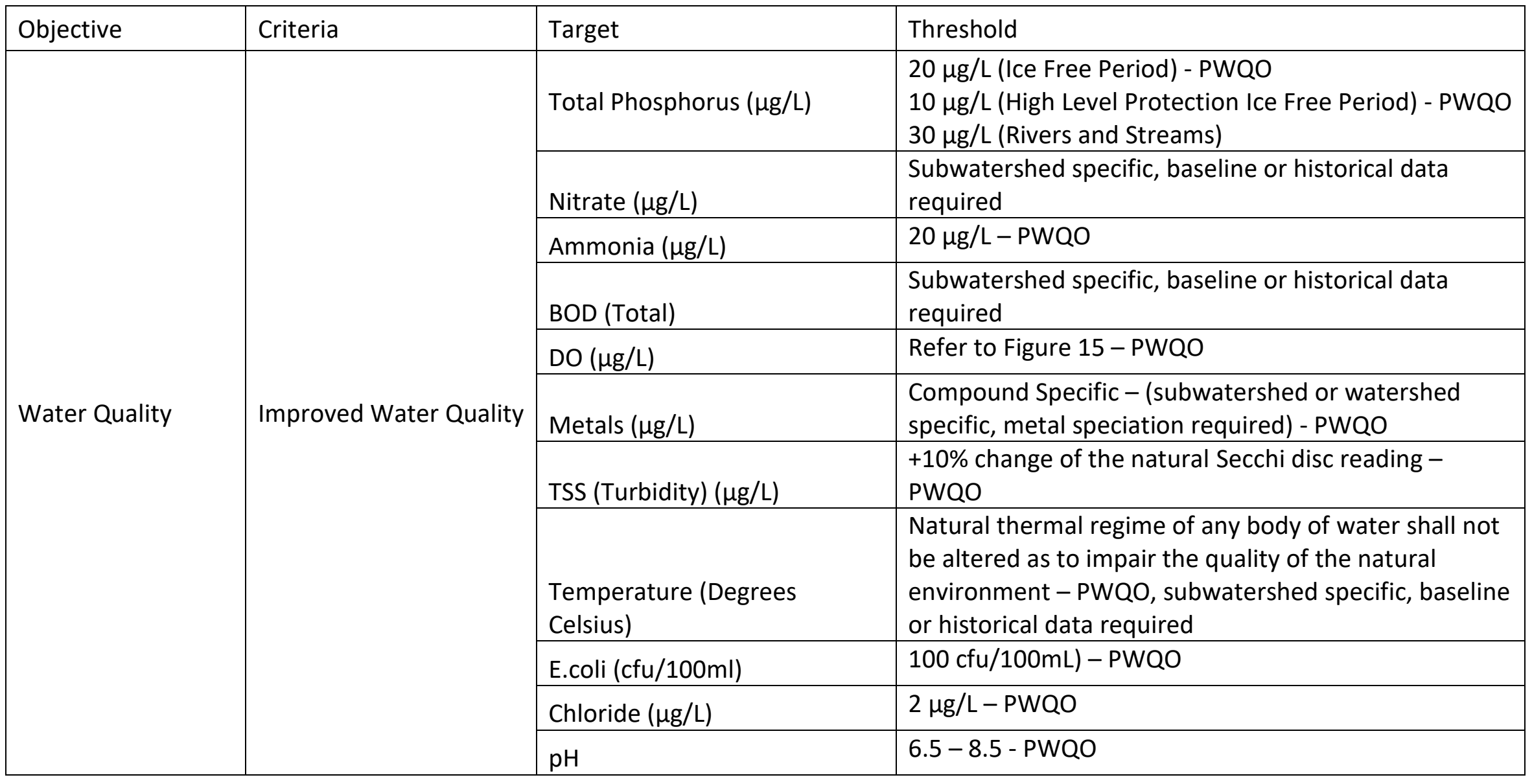


Dissolved oxygen targets under the PWQO are specific to temperature, cold water biota percent saturation, and water biota percent saturation (Ontario Ministry of the Environment and Energy 1994) (Ministry of Environment and Climate Change 2016). Figure 15 outlines the targets associated with dissolved oxygen under the PWQO's.

\begin{tabular}{|c|c|c|c|c|}
\hline Temperature ${ }^{\circ} \mathrm{C} \mathrm{C}$ & $\begin{array}{l}\text { Cold Water Biota: \% } \\
\text { Saturation }\end{array}$ & $\begin{array}{l}\text { Cold Water } \\
\text { Biota: } \mathbf{m g / L}\end{array}$ & $\begin{array}{l}\text { Warm Water Biota: \% } \\
\text { Saturation }\end{array}$ & $\begin{array}{l}\text { Warm Water } \\
\text { Biota: } \mathrm{mg} / \mathrm{h}\end{array}$ \\
\hline 0 & 54 & 8 & 47 & 7 \\
\hline 5 & 54 & 7 & 47 & 6 \\
\hline 10 & 54 & 6 & 47 & 5 \\
\hline 15 & 54 & 6 & 47 & 5 \\
\hline 20 & 57 & 5 & 47 & 4 \\
\hline 25 & 63 & 5 & 48 & 4 \\
\hline
\end{tabular}

Figure 15: PWQO Dissolved Oxygen Guideline (Ministry of Environment and Climate Change 2016)

Where possible the PWQO's should be used for setting the thresholds. Since the water quality criteria is associated with improved water quality where historical concentrations of the targets is less than the PWQO guideline the lesser of the two concentrations should be set for the approval. For parameters such as Metals additional information for a specific permit area is required to determine the specific metals that should be associated with the approval. Where possible the PWQO's for speciated metals should be used for setting thresholds within the permit. Nitrate, BOD, turbidity, and temperature all require either supplementary information from historical monitoring results within the subwatershed or watershed. Where historical monitoring information is not available baseline monitoring is required to understand existing concentrations prior to setting the threshold within the permit.

One challenge with setting water quality targets and thresholds is the potential for nonstormwater related exceedances. Unregulated discharges from industrial processes, illegal dumping, or uncontrolled spills can cause exceedances of the proposed targets. While the 
PWQO's can serve as the main guideline for setting thresholds, follow up investigations in the event of an exceedance will be required. The investigations need to include potential source identification and the proposed mitigation and control measures to be implemented to rectify the exceedance. An additional guidance document for follow up investigations will be required to assist permit owners in determine if exceedances are related to stormwater or not.

Ensuring a consistent approach to the water quality objective within the multi-site ECA system is important for the overall evaluation of watershed health within Ontario. With a unified approach relating to the water quality objective, it allows the MECP to carry out a consistent approach to governance and compliance within the multi-site ECA system. Watershed and subwatershed specific contaminants should be included as additional targets within multi-site ECA approvals however this will require a case by case evaluation and outside of the scope of this research.

\subsection{Water Quantity}

The water quantity criteria under the multi-site ECA system is related to maintaining instreamflow regimes to control flood events as well to maintain groundwater recharge. This objective serves as a way to not only protect the natural environment as well as protecting downstream properties from flooding as a result of upstream development (Toronto and Region Conservation Authority 2012).

The first criteria of maintaining in-streamflow regimes through controlling water quantity is important to other objectives within the multi-site ECA system including; water quality, stream morphology, terrestrial environment, and aquatic environment objectives. The interconnectivity of the water quantity objective on the overall compliance and health of a multi-site ECA approval makes this objective one of the most important objective to effectively implement and monitor. Within the multi-site ECA system the criteria of maintaining in-streamflow regimes will be governed by the target of streamflow. Streamflow for the purposes of the permitting system is the movement of water through the channels within the subwatershed as adapted from Stormwater Management Planning and Design Manual 2003 (Ministry of the Environment 2003). 
The second criteria of maintaining groundwater recharge under the water quantity objective is another important criteria because it looks at groundwater recharge through a water balance perspective to protect drinking water, and to preserve the natural function of natural features such as woodlots, wetlands, and watercourses (Toronto and Region Conservation Authority 2012). Similar to maintaining in-streamflow regimes the preservation of groundwater recharge is interconnected to other objectives and criteria within the multi-site ECA system. Within the multi-site ECA system the criteria of maintaining groundwater recharge the associated targets should include baseflow, groundwater levels, and percent change in flood plain, wetlands, and woodlots. Baseflow for the purposes of a multi-site ECA approval is the volume of water which contributes to the subwatersheds streamflow and is an indication of groundwater recharge (Credit Valley Conservation Authority and Toronto Region Conservation Authority 2010). Groundwater level targets under the multi-site ECA permitting system are water level fluctuation in meters below ground surface within the subwatersheds aquifers. The percent change target for flood plain, wetlands, and woodlots looks at change over time of the land features. The change in these land use features can adversely change the natural hydrological cycle of the subwatershed therefore making it an important target to monitor under the multisite ECA system.

Controlling water quantity targets such as streamflow, baseflow, and groundwater level are achieved through similar control measures as noted in the previous water quality section. Control measures as found in the MOE Stormwater Management Planning and Design Manual as released in 2003 as well as the Toronto Regional Conservation Authority and Credit Valley Conservation Low Impact Development Manual as released in 2010 (Ministry of the Environment 2003)(Credit Valley Conservation Authority and Toronto Region Conservation Authority 2010).

Current stormwater controls are implemented to match pre-development flows with post-development flows for all storms up to 100 year storms which in theory will limit the flood potential (Toronto and Region Conservation Authority 2012). Under a multi-site ECA system these individual controls would not require individual approvals. They would still require implementation and proper construction under the new system however water quantity compliance would be governed at the subwatershed level and monitored at various streamflow, 
baseflow, groundwater level monitoring stations installed within the subwatershed. As previously mentioned, to ensure proper construction of stormwater controls design and maintenance standards will require development as part of the overall multi-site ECA system. Although there are guidelines for controls such as LIDs, design standards may be required to avoid insufficient implementation of stormwater controls. Currently conservation authorities host working groups and workshops related to the planning, design, construction and operation and maintenance for LIDs.

Controlling the water quantity target of percent change of flood plain, wetlands, and woodlots can be achieved through proper land use planning. Effective land use planning will look to limit impervious surfaces, limit development on flood plains, protect natural wetlands, explore constructed wetlands, and preserve the natural canopy in woodlots in effort to maintain the natural hydrological cycle within the subwatershed.

Under the multi-site ECA system the water quality objective within each approval should be structured as outlined in Table 2 .

\begin{tabular}{|l|l|l|l|}
\hline Objective & Criteria & Target & Threshold \\
\hline & $\begin{array}{l}\text { Maintain In- } \\
\text { Streamflow Regimes }\end{array}$ & Streamflow $\left(\mathrm{m}^{3} / \mathrm{sec}\right)$ & $\begin{array}{l}\text { Subwatershed specific, } \\
\text { baseline or historical data } \\
\text { required }\end{array}$ \\
\cline { 2 - 4 } Water Quantity & $\begin{array}{l}\text { Maintain } \\
\text { Groundwater } \\
\text { Recharge }\end{array}$ & Baseflow $\left(\mathrm{m}^{3} / \mathrm{sec}\right)$ & $\begin{array}{l}\text { Subwatershed specific, } \\
\text { baseline or historical data } \\
\text { required }\end{array}$ \\
\cline { 2 - 4 } & Groundwater Level $(\mathrm{m})$ & $\begin{array}{l}\text { Subwatershed specific, } \\
\text { baseline or historical data } \\
\text { required }\end{array}$ \\
\cline { 2 - 4 } & $\begin{array}{l}\text { \% Change in Flood Plain, } \\
\text { Wetlands, Woodlots }\end{array}$ & $\begin{array}{l}\text { Watershed specific } \\
\text { supplementary studies } \\
\text { required }\end{array}$ \\
\hline
\end{tabular}

Table 2: Multi-Site ECA Water Quantity Objective, Criteria, Targets, and Thresholds

Streamflow, baseflow, and groundwater level thresholds will be subwatershed or watershed specific given the nature of these parameters. It is impractical to set specific thresholds for these parameters to be included for all multi-site ECA approvals. Streamflow will be dependent on where the subwatershed is located within the watershed. Upstream 
subwatersheds will have different natural streamflow rates than downstream subwatersheds. Thresholds for baseflow and groundwater level will also vary between subwatersheds. For example, baseflow rates in heavily developed areas will be much different than baseflow rates in rural communities with limited development (Maunder \& Hindley 2005). Streamflow, baseflow, and groundwater level will be subwatershed specific and will require supplementary information during the approval stage to set the specific threshold for the multi-site ECA permit area. Baseline monitoring and/or historical data can be used to set the thresholds for streamflow, baseflow, and groundwater level for a given permit area. Thresholds for percent change in flood plain, wetlands, and woodlots will also require supplementary studies to understand an existing percent coverage. Thresholds can be $+/$ - percent changes in coverage depending on the current health of the subwatershed.

\subsection{Stream Morphology}

Stormwater runoff can cause a loss of channel structure if not properly controlled. Degradation such as stream straightening alters the natural sequence of pools and riffles within a stream network which puts pressure on aquatic habitat (Credit Valley Conservation Authority and Toronto Region Conservation Authority 2010). In addition to the changes in the natural sequence of pools and riffles modifying stream morphology can also increase sediment yields, and has be found to cause greater flood frequency (Burton and Pitt 2001).

Under a stream morphology objective three primary criteria should be considered under the multi-site ECA system and are as follows:

- Limit stream erosion;

- Preserve natural stream morphology; and,

- Maintain and preserve flood plains.

Limiting stream erosion and preserving natural stream morphology enable streams and rivers to naturally evolve over time without impacting aquatic habitat while limiting any increase in sediment yields within the system. Preserving flood plains allow for proper infiltration limiting increases in peak flow within the stream and river networks which will protect the natural stream 
morphology. These criteria are interconnected with other proposed objectives within the multisite ECA which make them important to implement.

Limiting stream erosion, preserving natural stream morphology, maintaining and preserving floor plains can be achieved can be achieved through proper municipal and provincial planning policy. Under the 2014 Provincial Policy Planning Statement planning related to stormwater should "promote stormwater management best practices, including stormwater attenuation and re-use, and low impact development (Government of Ontario 2014). In addition to this, under the 2014 Provincial Policy Planning Statement development should be located outside areas such as flood plains (Government of Ontario 2014). Limited developed within flood plains is a common mitigation measure for the protection and preservation of flood plains. In line with the 2014 Provincial Policy Planning statement where flood plains have been over developed restoration activities and implementation of private and municipal LIDs to facilitate greater stormwater infiltration play an important role in achieving this criterion. Some common LIDs that improve infiltration include (Credit Valley Conservation Authority and Toronto Region Conservation Authority 2010):

- Rainwater harvesting;

- Green roofs;

- Roof downspout disconnection;

- Soakaways, infiltration trenches and chambers;

- Bioretention;

- Vegetated filter strips;

- Permeable pavement;

- Enhanced grass swales;

- Dry swales; and,

- Perforated pipe systems.

Targets associated with the three main proposed criteria include; percent change in flood plain coverage, percent change in stream cross-sections, and percent change in channelization. As previously mentioned, proper planning and implementation of effective stormwater controls 
can help a subwatershed achieve their approval targets. In the cases where subwatersheds may have future development plans the thresholds for percent change should look to preserve the pre-development natural state. Under the multi-site ECA system the stream morphology objective should be structed as outlined in Table 3.

\begin{tabular}{|l|l|l|l|}
\hline Objective & Criteria & Target & Threshold \\
\hline \multirow{3}{*}{$\begin{array}{l}\text { Stream } \\
\text { Morphology }\end{array}$} & $\begin{array}{l}\text { Limit Stream Erosion and } \\
\text { Preserve Stream } \\
\text { Morphology }\end{array}$ & $\begin{array}{l}\text { \% Change in Stream Cross- } \\
\text { Sections }\end{array}$ & $\begin{array}{l}\text { Review of Existing Data } \\
\text { /Watershed specific } \\
\text { supplementary studies } \\
\text { required }\end{array}$ \\
\cline { 2 - 4 } & $\begin{array}{l}\text { Maintain and Preserve } \\
\text { Flood Plains }\end{array}$ & \% Change in Channelization & $\begin{array}{l}\text { Review of Existing Data } \\
\text { /Watershed specific } \\
\text { supplementary studies } \\
\text { required }\end{array}$ \\
\cline { 2 - 4 } & \% Flood Plain Coverage & $\begin{array}{l}\text { Review of Existing Data } \\
\text { /Watershed specific } \\
\text { supplementary studies } \\
\text { required }\end{array}$ \\
\hline
\end{tabular}

Table 3: Multi-Site ECA Stream Morphology Objective, Criteria, Targets, and Thresholds

Historical information gathered from Watershed Report Cards as well as aerial photography could be used to determine thresholds for stream morphology. This supplementary information can be used to evaluate baseline conditions for the purposes of setting a threshold.

\subsection{Terrestrial Environment}

The terrestrial environment plays an important role for stormwater management. Under the multi-site ECA approval system terrestrial environment criteria, targets, and thresholds will need to be established. Terrestrial environment features such as wetlands and woodlots benefit a number of key areas relating to stormwater management including; maintain water balance, peak flow, baseflow, stream morphology characteristics, water quality, and aquatic habitats (Ministry of the Environment 2003). Without restoration and preservation of the terrestrial environment within a subwatershed could result in adverse effects to other stormwater objectives within the multi-site ECA system.

Within the terrestrial environment objective, two primary criteria are proposed for the multi-site ECA system. These criteria were selected based on their applicability to the objective 
as well as their ability to be effectively monitored as discussed in Section 6 . The two primary criteria include the following:

- Preserve and restore wetlands; and,

- Preserve and restore woodlots.

Preserving and restoring woodlots and wetlands will benefit the other proposed stormwater objectives within the multi-site ECA system. Preserving and restoring of woodlots and wetlands can be achieved through the development of subwatershed plans as well as proper municipal and provincial planning policy. The 2014 Provincial Policy Planning Statement identifies that "the diversity and connectivity of natural features in an area, and the long-term ecological function and biodiversity of natural heritage systems, should be maintained, restored or, where possible improved, recognizing linkages between and among natural heritage features and areas, surface water features and groundwater features (Government of Ontario 2014)." Furthermore the commitment under the 2014 Provincial Policy Planning Statement looks at permitting development in significant wetlands and woodlots (Government of Ontario 2014). Achieving preservation should be done through planning while restoration activities can be initiated by local municipalities, conservation authorities, and other stakeholders within the subwatershed. Constructed wetlands can play a supporting role in achieving the terrestrial environment objective.

Targets associated with preserving and restoring wetlands include the following:

- Percent change in naturalized riparian areas;

- Percent change in wetland area; and,

- Percent change in shoreline.

Targets associated with preserving and restoring woodlots include the following:

- Percent change in naturalized riparian areas; and,

- Percent change in natural vegetative and woodlot cover.

Percent change in naturalized riparian areas is included in both the wetland and woodlot criteria because of the interconnectivity between the two land features. Thresholds associated with 
these targets are subwatershed specific therefore requiring supplementary studies. These supplementary studies will look to evaluate current baseline conditions for percent change in naturalized riparian areas, wetland area, shoreline, natural vegetative and woodlot cover. Similar to other thresholds associated with a percent change in land feature over time historic coverage should be compared to existing coverage to evaluate the degree of change over time. Thresholds for a given multi-site ECA in developed areas should be set with restoration as a key consideration while areas that may be primed for development should include preservation and protection as the key consideration. Under the multi-site ECA system the stream morphology objective should be structed as outlined in Table 4.

\begin{tabular}{|c|c|c|c|}
\hline Objective & Criteria & Target & Threshold \\
\hline \multirow{5}{*}{$\begin{array}{l}\text { Terrestrial } \\
\text { Environment }\end{array}$} & \multirow{2}{*}{$\begin{array}{l}\text { Preserve and Restore } \\
\text { Woodlots }\end{array}$} & $\begin{array}{l}\% \text { Change Natural } \\
\text { Vegetative \& Woodlot } \\
\text { Cover }\end{array}$ & $\begin{array}{l}\text { Review of Existing Data } \\
\text { /Watershed specific } \\
\text { supplementary studies } \\
\text { required }\end{array}$ \\
\hline & & $\begin{array}{l}\text { \% Change in Naturalized } \\
\text { Riparian Areas }\end{array}$ & $\begin{array}{l}\text { Review of Existing Data } \\
\text { /Watershed specific } \\
\text { supplementary studies } \\
\text { required }\end{array}$ \\
\hline & \multirow{3}{*}{$\begin{array}{l}\text { Preserve and Restore } \\
\text { Wetlands }\end{array}$} & $\begin{array}{l}\text { \% Change in Naturalized } \\
\text { Riparian Areas }\end{array}$ & $\begin{array}{l}\text { Review of Existing Data } \\
\text { /Watershed specific } \\
\text { supplementary studies } \\
\text { required }\end{array}$ \\
\hline & & $\%$ Change in Wetland Area & $\begin{array}{l}\text { Review of Existing Data } \\
\text { Watershed specific } \\
\text { supplementary studies } \\
\text { required }\end{array}$ \\
\hline & & $\%$ Change in Shoreline & $\begin{array}{l}\text { Review of Existing Data } \\
\text { /Watershed specific } \\
\text { supplementary studies } \\
\text { required }\end{array}$ \\
\hline
\end{tabular}

Table 4: Multi-Site ECA Terrestrial Environment Objective, Criteria, Targets, and Thresholds

Watershed specific thresholds can be set using legacy GIS data or aerial photography to establish baseline conditions. Watershed Report Cards can also be used to support threshold setting as well provide field calibration of monitoring within the multi-site ECA system. 


\subsection{Aquatic Environment}

Stormwater impacts on aquatic environment should also be governed under the multisite ECA permitting system. The aquatic environment can be impacted though failure to effectively implement and govern the other objectives within the multi-site ECA system. Each objective including water quality, water quantity, stream morphology, and terrestrial environment all interconnect with the preservation and protection of the aquatic environment. For example slight changes in water quality, terrestrial environment, and stream morphology can impact sensitive fish species and result in a loss of key fish habitat (Evans et al. 1996). The degradation of the aquatic environment has both environmental and social impacts that should be mitigated under the multi-site ECA system.

Within the aquatic environment objective two primary criteria are proposed for the multisite ECA system. These criteria were selected based on their applicability to the objective as well as their ability to be effectively monitored. The two primary aquatic environment criteria include the following:

- Improve water quality; and,

- Maintain and promote natural species biodiversity and biomass density.

The improvement of water quality for aquatic environments for the multi-site ECA system should reference the water quality section of the permit. Targets and thresholds are defined in Section 4.1 Water Quality of this thesis.

Maintaining and promoting natural species biodiversity and biomass density is an indicator of subwatershed aquatic health. Since stormwater can impact the aquatic environment, understanding the species biodiversity and biomass density within a given permit area is required to effectively monitor the aquatic environment objective within the multi-site ECA system. Maintaining and promoting of natural species biodiversity and biomass density can be initiated by local municipalities, conservation authorities, and other stakeholders within the subwatershed. One such ongoing initiative is the Bring Back the Atlantic Salmon Lake Ontario initiative which involves the Ontario Federation of Anglers and Hunters and the Ontario Ministry of Natural Resources supported by Ontario Power Generation to restore a once thriving Atlantic 
salmon population in Lake Ontario (Ontario Federation of Anglers and Hunters 2017). The program carries out fish stocking, habitat restoration, and water quality enhancement. is should be done through planning while restoration activities can be initiated by local municipalities, conservation authorities, and other stakeholders within the subwatershed.

Targets associated with maintaining and promoting natural species biodiversity and biomass density include the percent change in biodiversity and density. Thresholds associated with these targets will be subwatershed and watershed specific depending on the natural aquatic composition. Supplementary investigations and review of historical aquatic surveys will be required to set specific thresholds for this target. Under the multi-site ECA system the aquatic environment objective should be structed as outlined in Table 5.

\begin{tabular}{|l|l|l|l|}
\hline Objective & Criteria & Target & Threshold \\
\hline \multirow{2}{*}{$\begin{array}{l}\text { Aquatic } \\
\text { Environment }\end{array}$} & Improve Water Quality & $\begin{array}{l}\text { Refer to Water Quality } \\
\text { Targets (Table 1) }\end{array}$ & $\begin{array}{l}\text { Refer to Water Quality } \\
\text { Targets (Table 1) }\end{array}$ \\
\cline { 2 - 4 } & $\begin{array}{l}\text { Maintain and Promote } \\
\text { Species Biodiversity and } \\
\text { Biomass Density }\end{array}$ & $\begin{array}{l}\text { \% Change in Biodiversity } \\
\text { and Biomass Density }\end{array}$ & $\begin{array}{l}\text { Review of Existing Data } \\
\text { /Watershed specific } \\
\text { supplementary studies } \\
\text { required }\end{array}$ \\
\hline
\end{tabular}

Table 5: Multi-Site ECA Aquatic Environment Objective, Criteria, Targets, and Thresholds

Thresholds for the aquatic environment will be gathered from the water quality targets as well as background information relating to biodiversity and biomass density. Watershed report cards represent one source of supplementary data that could be used to set thresholds and could be used to calibrated multi-site ECA monitoring (Credit Valley Conservation Authority 2005)(Upper Thames River Conservation Authority 2012). Additional information can also be gathered from local stakeholder and volunteer groups one such example is information reported and gathered from Atlantic Salmon Restoration Program. 


\section{Monitoring of Selected Objectives, Criteria, and Targets}

Effective monitoring of selected targets is essential to a proper functioning multi-site ECA system. In Section 4 of this thesis the selected multi-site ECA objectives, criteria, targets, and thresholds were discussed. These parameters have a function relating to stormwater management but can also be effectively monitored as part of the multi-site ECA system. Monitoring within the multi-site permitting system needs to be carried out in an economically feasible way that allows for effective stormwater management with less reliance of government resources. With ongoing advancements in sensor technologies, IOT, and integrated information systems (IIS) the implementation of an effective monitoring system for multi-site ECA's becomes a tangible possibility.

Effective stormwater management and effective governance are two primary goals within the proposed multi-site ECA systems. To achieve these goals, monitoring of multi-site ECAs need to be carried out in a way that incorporates advancements in sensor technology, data collection, storage, and visualization. The evaluation of traditional monitoring techniques and a comparison to alternative technologies is outlined in the following subsections. These technologies were evaluated based on potential implementation within the multi-site ECA permitting system.

Open source monitoring options and non-industry standard measurement methods were evaluated as alternative monitoring solutions. Open source is considered nonproprietary software that is publicly available where source code can be freely used and modified for a specific purpose. Open source sensors are sensors that can be easily installed and interfaced with IOT open source microcontrollers available from manufacturers such as Arduino ${ }^{\circledR}$, SparkFun Electronics ${ }^{\circledR}$, and Raspberry $\mathrm{Pi}^{\mathrm{TM}}$.

Traditional monitoring techniques are considered to be industry standard ways of monitoring using established proprietary sensors and software to carry out data collection and reporting.

\subsection{Water Quality Monitoring}

Ongoing advancements in water quality sensor technology and IOT data present a unique opportunity for water quality monitoring within a multi-site ECA permitting system. Traditional 
water quality monitoring instruments are well developed and deployed for several environmental monitoring purposes. In some cases, these water quality sensors are currently monitoring real-time water quality parameters in Ontario. The Ontario Provincial Water Quality Monitoring Network (PWQMN) operated by the MECP provides both chemical and physical data for Ontario watersheds (Loomer and Cooke 2003). Supplementary monitoring through the local CAs are also deployed to fill in data gaps or further characterize a specific watershed (Loomer and Cooke 2003). Open source sensor technology and IOT data could allow for greater deployment of water quality monitoring stations in totality or for specific contaminants of concern within a multi-site ECA. Increasing sensor deployment and integrating sensor data in a common platform can assist in isolating stormwater impact from non-stormwater impact by relating precipitation events to water quality monitoring data.

Although existing water quality monitoring networks are tested and readily deployed throughout Ontario, open-source sensors present an alternative monitoring method that could allow for greater deployment throughout the permit area. Regardless of selecting traditional or alternative monitoring technologies for monitoring within the multi-site ECA system, continuous remote access for monitoring data is required and can be readily deployed within a subwatershed. In the case where real-time data is easily deployed and available it can take precedence over basic remote data access since real-time data allows for easier interpretation of data during active stormwater events.

Development of total maximum daily loads (TMDLs) and water quality modelling may be required prior to setting subwatershed specific thresholds. A TMDL is calculated by determining the maximum amount of a pollutant that can enter a waterbody. This information is used to determine a contaminant reduction amount which can achieve better water quality results at the receiving water (United States Environmental Protection Agency 2018). Development of TMDL's for water quality parameters that could significantly impact a subwatershed could be developed and implemented within the multi-site ECA system. Developing TMDL's can be carried out by simple mass balance calculations or more complex water quality modelling methods (Chapra 2003) (Camacho et al. 2019). 
Table 6 outlines the traditional versus alternative monitoring techniques as well as the proposed monitoring frequency within a multi-site ECA permitting system. The following subsections evaluate, compare, and contrast traditional water quality monitoring techniques versus alterative water quality monitoring techniques.

\subsubsection{Traditional Water Quality Monitoring Techniques}

Certain water quality parameters are reported in real-time by various CAs using readily available monitoring equipment that can be purchased through local instrument suppliers. CVC operates and maintains a real-time water quality monitoring network where the data is publicly available in real-time. These real-time monitoring stations provide data for parameters such as water temperature, dissolved oxygen, turbidity, specific conductivity, chloride, and $\mathrm{pH}$ (Credit Valley Conservation 2014). The water quality parameters are collected using a Hydrolab DS5K instrument which is capable of measuring of number of different water quality parameters in real-time (HydroLab 2005). The HydroLab DS5K is a readily used water quality monitoring instrument that is often linked to a real-time datalogger that uploads information to database operated by a local Conservation Authority. Within the multi-site ECA system the monitoring data collected as part of the network should be structured within a similar IIS to the system outlined by Fang et al. 2014 and further discussed in Section 2.9.6 Solutions for Data Management.

In addition to real-time monitoring of water quality data, discrete sampling is also carried out within Ontario's watersheds and subwatersheds. Discrete sampling refers to water sampling at a specific point in time using consultants, CA employees, or stakeholder staffing resources. Water samples are either analyzed with handheld meters or submitted to certified laboratories for analytical analysis. Water quality sampling guidelines are developed by authorities such as the Canadian Council of Ministers of the Environment (CCME) who post guidance documents which outline the protocols for water quality sampling within Canada (Canadian Council of Ministers of the Environment 2011). In 2011 the CCME posted the Protocols Manual for Water Quality Sampling in Canada document which outlines water quality sampling safety protocols, quality assurance and quality control $(Q A / Q C)$, and sampling methods among other topics (Canadian Council of Ministers of the Environment 2011). Analytical techniques may vary depending on the analytical laboratory performing the analysis however only approved 
techniques and Canadian Council of Independent Laboratories (CCIL) should be used for analysis of water quality samples.

\subsubsection{Alternative Water Quality Monitoring Techniques}

Given that traditional sensors have been used for several years, this method of collecting water quality data is considered a viable option for the multi-site ECA permitting system provided proper station deployment throughout a permit area is available. Although these traditional proprietary monitoring systems are considered a viable option, they can be cost prohibitive for mass deployment across Ontario's subwatersheds. A recent report produced by the City of London estimated costs of $\$ 46,000$ for quantifying phosphorous loadings in the Thames River using continuous sampling (Norouzi and Rossum 2018). For the instrumentation and data logging capabilities the estimated cost was $\sim \$ 32,000$ (Norouzi and Rossum 2018).

As part of this research alternative water quality sensors were evaluate for their current or future applicability for monitoring the selected water quality targets. Alternative open source water quality monitoring techniques although in their infancy in development could reduce the construction, operational, and maintenance costs which could lead to greater deployment of sensors throughout a given multi-site permit area. Open source sensors for the purpose of this research include sensors where source code is made publicly and freely available to be distributed and used. The open source sensors need to be easily installed and interfaced with IOT open source microcontrollers available from manufacturers such as Arduino ${ }^{\circledR}$, SparkFun Electronics ${ }^{\circledR}$, and Raspberry $\mathrm{Pi}^{\mathrm{TM}}$.

The criteria for evaluating the applicability of open source water quality monitoring techniques (where available) are based off the readily used HydroLab DS5K, information gathered regarding traditional sensor costs, availability of sensors, and compatibility with open source microcontrollers. The acceptance criteria for alternative water quality sensors are as follows (HydroLab 2005):

- Operating temperature $\left(-5^{\circ} \mathrm{C}\right.$ to $\left.+50^{\circ} \mathrm{C}\right)$;

- Operating range (parameter specific, equal to or greater than HydroLab DS5K);

- Cost of sensor (less than traditional techniques); 
- Availability of sensor (available online); and,

- Compatibility with open source micro-controllers (Arduino ${ }^{\circledR}$, SparkFun Electronics $^{\circledR}$, and Raspberry $\left.\mathrm{Pi}^{\mathrm{TM}}\right)$;

It should be noted that operating accuracy was not included as an acceptance criterion. The accuracy of the open source sensors evaluated is dependent on the microcontroller's ability to measure input voltage generally on a scale of $0-5$ volts direct current.

\subsubsection{Alternative Total Phosphorus Monitoring Techniques}

Real-time monitoring of total phosphorus can be achieved using turbidity sensors (Marttila and Kløve 2012) (Stone, Graham, and Gatotho 2013). The calibration technique compares the particle size, colour, and organic matter content relationship (Marttila and Kløve 2012). Phosphorus concentrations have been found to correlate with "turbidity values as a fraction of nutrients occurs in particulate form or adsorbed to particles (Marttila and Kløve 2012)." Discrete phosphorus sampling is required to calibrate any real-time turbidity sensor deployed in a multi-site ECA permit area.

Since turbidity sensors can be used to measure total phosphorus open source, low cost

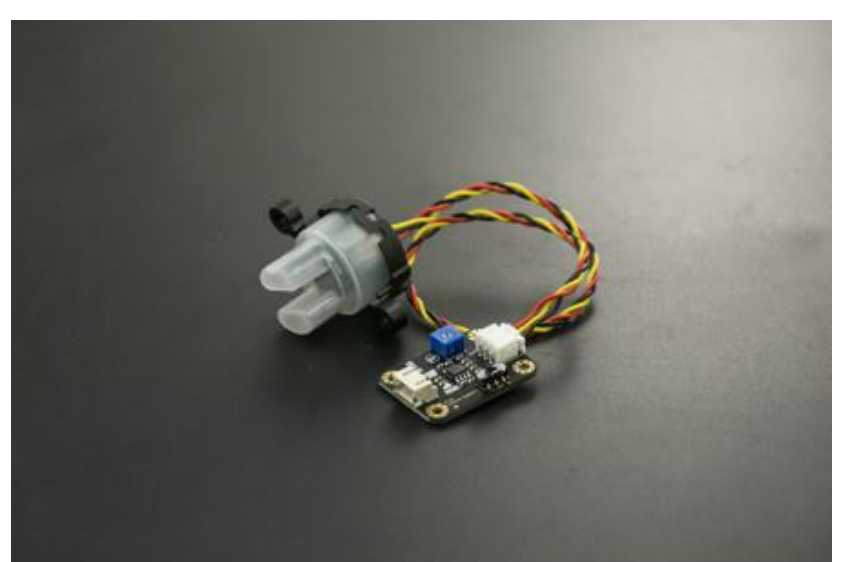

Figure 16: Open Source Turbidity Sensor (DFRobot 2017) sensors were evaluated for alternative monitoring techniques. Although the selected sensor does not satisfy all acceptance criteria the most viable open source, low cost turbidity sensor is outlined in Figure 16. Based on the required acceptance criteria the sensors evaluation against the acceptance criteria is as follows:

- Operating temperature: $5^{\circ} \mathrm{C}-90^{\circ} \mathrm{C}$ (outside acceptance criteria)

- Operating range: 0 - 3000 Nephelometric Turbidity Units (NTU) (within acceptance criteria)

- Cost of sensor: $\$ 9$ USD (within acceptance criteria)

- Availability of sensor: available online through DFRobot (within acceptance criteria) 
- Compatibility with open source microcontroller: compatible with Arduino ${ }^{\circledR}$ (within acceptance criteria)

This alternative sensor satisfies 4 of the 5 acceptance criteria however the critical criterial of operating temperature was outside of the acceptable range. Given Ontario's climate without an operating temperature of below zero degrees Celsius implementation of this alternative sensor would be difficult. Given the rapid development of open source technology new turbidity sensors could soon have the required operating temperature and accuracy. Testing of this open source technology would be required prior to implementation within the multi-site ECA system.

\subsubsection{Alternative Nitrate Monitoring Techniques}

Real-time nitrate monitoring can be achieved using ultraviolet (UV) photometers (Kröckel et al. 2011). Using UV photometers nitrate can be detected in the spectral range between 200 and $350 \mathrm{~nm}$ (Kröckel et al. 2011). Discrete sampling for nitrate is recommended to ensure a proper correlation between the photometer and actual nitrate concentrations.

Open source photometers were evaluated for alternative monitoring of nitrate. Based on the acceptance criteria the most appropriate open source sensor is the Adafruit TCS34725 RGB Sensor with infrared filter and white LED. The TCS34725 is outlined in Figure 17. Based on the acceptance criteria the sensors evaluation is as follows (TAOS 2012):

- Operating temperature: $-40^{\circ} \mathrm{C}-85^{\circ} \mathrm{C}$ (within acceptance criteria)

- Operating range: 3,800,000:1 Dynamic Range (within acceptance criteria)

- Cost of sensor: $~ \$ 8$ USD (within acceptance criteria)

- Availability of sensor: available online through Adafruit (within acceptance criteria)

- Compatibility with open source microcontroller: compatible with Arduino ${ }^{\circledR}$ and Raspberry $\mathrm{Pi}^{\mathrm{TM}}$ (within acceptance criteria) 


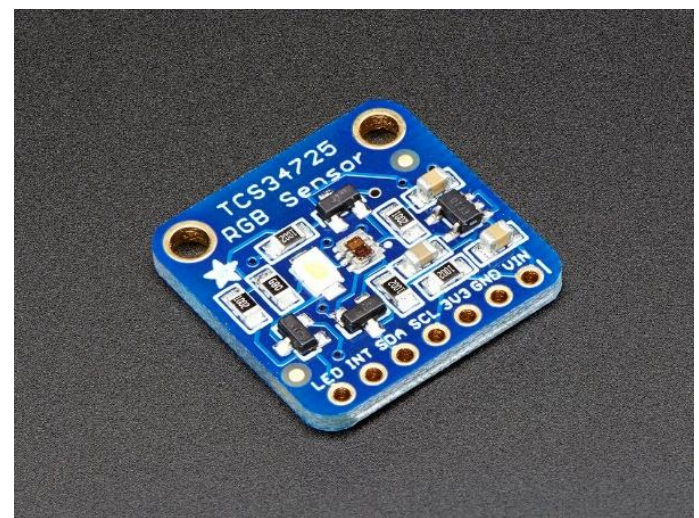

Figure 17: Open Source Adafruit TCS34725 (Adafruit 2013)

\subsubsection{Alternative Ammonia Monitoring Techniques}

Alternative open source ammonia water quality sensors are less available compared to other water quality parameters. Currently only open source ammonia sensors are available for air quality measurements. These instruments measure airborne ammonia concentrations in parts per million (ppm) and would not be applicable for measuring ammonia concentrations in water. Given the limited availability of open source water quality ammonia sensors, traditional instruments will be required for ammonia monitoring within the multi-site ECA system.

Traditional water quality sensors for real-time monitoring of ammonia include sensors available from established

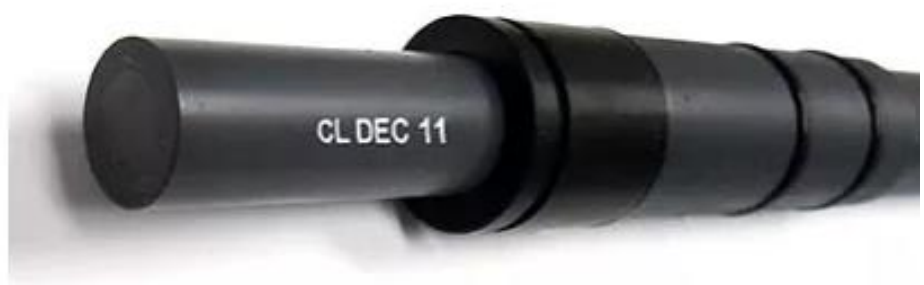

Figure 18: Eureka ${ }^{\circledR}$ Ammonia Sensor (Eureka 2017 manufacturers such as $\mathrm{YSI}^{\circledR}$ and Eureka ${ }^{\circledR}$. Eureka $^{\circledR}$ manufactures lon-Selective Electrode devices for measurement of water quality parameters such as ammonia. Figure 18 is an example of the Eureka $^{\circledR}$ device (Eureka 2017). These devices include real-time telemetry options which should be utilized within the multiple site ECA monitoring network. With the rapid development of open source instrumentation alternative ammonia sensors should be evaluated on a continual basis should an open source option become available. 


\subsubsection{Alternative BOD Monitoring Techniques}

Alternative open source BOD sensors have yet to be developed or available from the primary open source companies such as Adafruit, Arduino, or DF Robot. The lack of availability of open source BOD sensors may be a result of the measurement and technique for producing a $\mathrm{BOD}$ concentration. Traditional $\mathrm{BOD}_{5}$ measurement requires a discrete water quality sample where the lab collects two measurements which includes an initial dissolved oxygen sample followed by a subsequent dissolved oxygen sample 5 days later to determine the amount of oxygen consumed by microorganism during the 5 day incubation period (Liu and Mattiasson 2002)(Gotovtsev 2016).

Traditional water quality sensors for real-time monitoring of BOD are available from

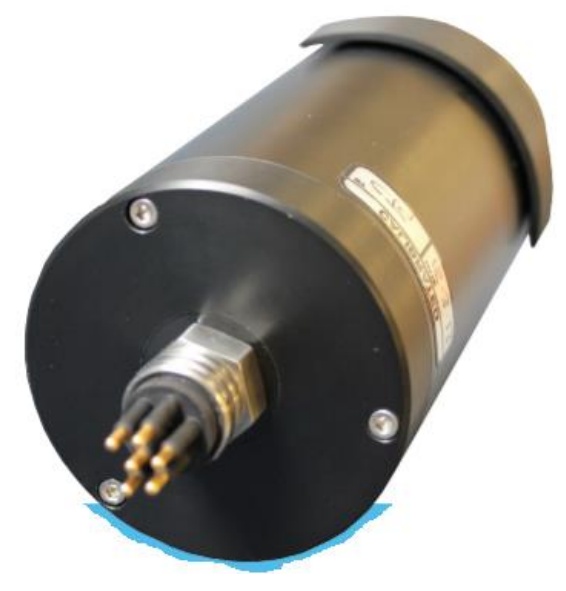

Figure 19: ModernWater BOD Sensor (ModernWater n.d.) reputable instrument manufactures such as Real Tech ${ }^{\circledR}$ and ModernWater ${ }^{\circledR}$ who produce water quality sensors capable of measuring BOD (ModernWater n.d.). An example of a ModernWater ${ }^{\circledR}$ BOD sensor is provided in Figure 19. These types of sensors measure short-term $\mathrm{BOD}$ and not $\mathrm{BOD}_{5}$. Short-term BOD in some cases may

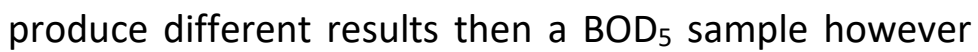
short-term BOD provides instantaneous results which would be beneficial to the effective monitoring of a multisite ECA permit area.

The availability of open source BOD sensors should be evaluated on a continual basis to identify if an open source option becomes available. Should one become available rigorous testing will be required prior to deployment.

\subsubsection{Alternative Dissolved Oxygen Monitoring Techniques}

Open source dissolved oxygen sensors are well established and available. The most common type of open source dissolved oxygen sensor is a galvanic probe which is the same technology used by traditional sensors developed and sold by established sensor manufacturers. A galvanic probe consists of a brass electrode and a carbon steel electrode that measures dissolved oxygen when current is run through the electrodes (Roxar Galvanic Probes 2015). 
Open source dissolved oxygen sensors were evaluated based on the acceptance criteria

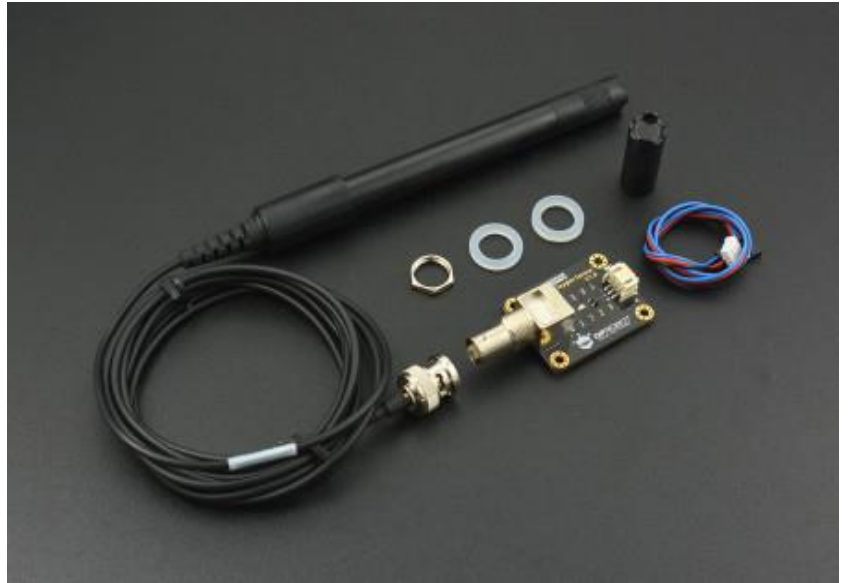

Figure 20: Open Source Dissolved Oxygen Sensor (3Peak 2018) established previously. The most applicable open source sensor is available from DFRobot which provides a Gravity: Analog dissolved oxygen sensor and meter kit. Figure 20 outlines the DFRobot dissolved oxygen sensor and associate components.

Based on the acceptance criteria the sensors evaluation is as follows (3Peak 2018):

- Operating temperature: $-40^{\circ} \mathrm{C}-125^{\circ} \mathrm{C}$ (within acceptance criteria)

- Operating range: 0-20 mg/L (outside acceptance criteria but within acceptance criteria for PWQO dissolved oxygen targets)

- Cost of sensor: $\$ 130$ USD (within acceptance criteria)

- Availability of sensor: available online through DFRobot (within acceptance criteria)

- Compatibility with open source microcontroller: compatible with Arduino ${ }^{\circledR}$, SparkFun Electronics ${ }^{\circledR}$, and Raspberry $\mathrm{Pi}^{\mathrm{TM}}$ );

The open source dissolved oxygen sensor satisfied all the criteria except for operating range. Although operating range was less than the traditional sensor it still provides enough range for measuring compliance against the PWQO's. The widest range for PWQO compliance is between 4 and $8 \mathrm{mg} / \mathrm{L}$ (Ontario Ministry of the Environment and Energy 1994).

Several tutorials and open source sensor connection diagrams exist which makes for easy bench testing and subsequent deployment. Like the other open source sensor options rigorous testing is required prior to distribution of this sensor technology for multi-site ECA permit monitoring.

\subsubsection{Alternative Metals Monitoring Techniques}

Alternative metals monitoring techniques are available however they are compound specific and require metals speciation. For real-time monitoring of metals within a multi-site ECA speciated metals based on subwatershed specific concerns will be required. For the purpose of 
this research lead was evaluated as a potential metal that would be monitored within multi-site ECA permits.

Lead concentrations in water can be measured using similar a similar method to nitrate monitors by using UV spectroscopy. Lead can be measured between detections between 247 and $300 \mathrm{~nm}$ (Frau et al. 2018). Calibration of the UV spectrometer is crucial for accurate measurements of lead concentrations using this method. Given the similarities to nitrate monitoring the same open source photometer was evaluated for lead monitoring. Figure 15 outlines the open source photometer that is compatible with the most common open source dataloggers. As previously mentioned, rigorous testing and calibration would be required prior to any large-scale monitoring deployments.

Due to accuracy issues it may be beneficial for traditional discrete sampling techniques to be employed for the lead and specifically metals monitoring within a multi-site ECA system. Discrete water quality samples will also allow for metals speciation and a more accurate comparison to the PWQO's as well as any subwatershed specific thresholds.

\subsubsection{Alternative Total Suspended Solids Monitoring Techniques}

Open source TSS turbidity sensors are readily available in the market place. Common open source turbidity sensors use the same technology as well established traditional TSS sensors developed by established manufacturers. The sensor technology measures suspended particles in water by measuring light transmittance and scattering rate. Open source turbidity sensors and microcontrollers have been evaluated for a wide range of water quality monitoring applications. Saravanan et al. 2018 evaluated real-time turbidity monitoring using open source low cost sensors which sent data to an Arduino Atmega that was post processed for deployment and viewing as part of an Integrated Information System.

Turbidity sensors were evaluated for their applicability for measuring TSS. An example of the most viable open source, low cost turbidity sensor is outlined in Figure 15 of Section 5.1.2.1 Alternative Total Phosphorus Monitoring Techniques.

Based on the required acceptance criteria the sensors evaluation against the acceptance criteria is as follows: 
- Operating temperature: $5^{\circ} \mathrm{C}-90^{\circ} \mathrm{C}$ (outside acceptance criteria)

- Operating range: 0 - 3000 Nephelometric Turbidity Units (NTU) (within acceptance criteria)

- $\quad$ Cost of sensor: $~ \$ 9$ USD (within acceptance criteria)

- Availability of sensor: available online through DFRobot (within acceptance criteria)

- Compatibility with open source microcontroller: compatible with Arduino ${ }^{\circledR}$ (within acceptance criteria)

This alternative sensor satisfies 4 of the 5 acceptance criteria however the critical criterial of operating temperature was outside of the acceptable range. Given Ontario's climate without an operating temperature of below zero degrees Celsius implementation of this alternative sensor would be difficult.

\subsubsection{Alternative Temperature Monitoring Techniques}

Alternative water temperature sensors are very common within the open source market.

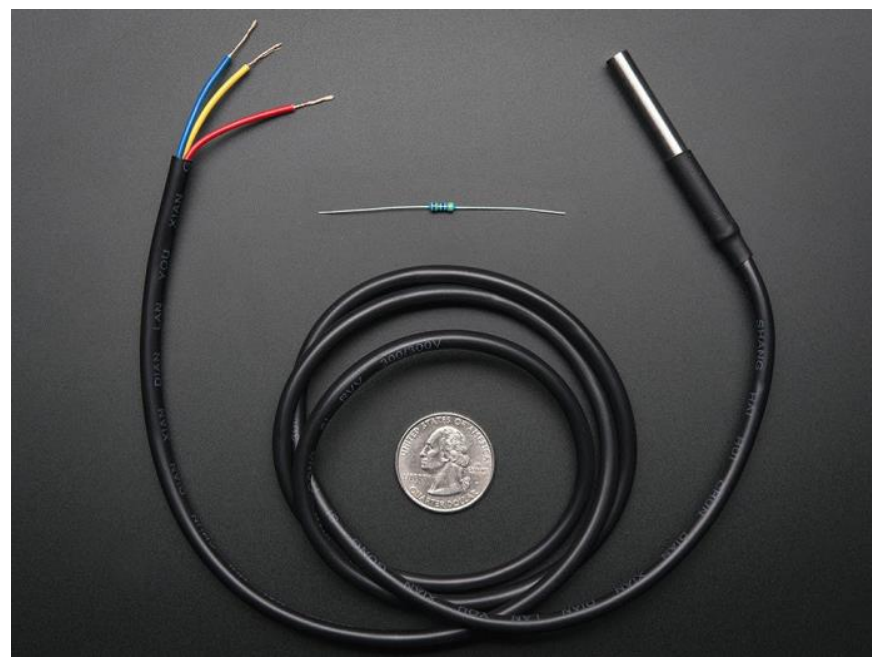

Figure 21: Open Source Temperature Sensor (Maxim 2008)
Several different sensors exist on the market that easily connect to microcontrollers for real-time monitoring. the waterproof Adafruit DS18B20 digital temperature sensor was selected as the most viable open source sensor that could be deployed for monitoring within a multisite ECA system based on the acceptance criteria. Figure 21 depicts the Adafruit DS18B20 digital temperature sensor.

The sensor evaluation based on the acceptance criteria is as follows (Maxim 2008):

- Operating temperature: $-55^{\circ} \mathrm{C}-125^{\circ} \mathrm{C}$ (within acceptance criteria)

- Operating range: $-10^{\circ} \mathrm{C}-85^{\circ} \mathrm{C}$ (within acceptance criteria)

- Cost of sensor: \$10 USD (within acceptance criteria)

- Availability of sensor: available online through adafruit (within acceptance criteria) 
- Compatibility with open source microcontroller: compatible with Arduino ${ }^{\circledR}$ and Raspberry $\mathrm{Pi}^{\mathrm{TM}}$ (within acceptance criteria)

Open source temperature sensors appear to be ready for mass deployment and could be a viable option for monitoring in multiple locations throughout a subwatershed. Out of all the water quality sensors evaluated as part of this thesis temperature sensors appear to be the readiest for scientific deployment. Prior to deployment, bench and pilot scale testing would be recommended to determine if in fact these sensors can produce reliable and accurate data.

\subsubsection{Alternative E.coli Monitoring Techniques}

Open source or traditional real-time E.coli sensors currently do not exist. E.coli concentrations in water are commonly measured through discrete sampling followed by laboratory analysis. Given the complexities of measuring E.coli real-time measurement is uncommon however some concepts exist which shows future potential for real-time measurement in water. Developments in electrochemical biosensors have advanced in the medical and food safety industry (Settu et al. 2013). In 2018, Parmiss Mojir Shaibani and Amirreza Sohrabi from the University of Calgary appeared to develop an electrochemical sensor that analyzes the metabolic activity of E.coli (Sherchan et al. 2018). These recent developments provide optimism that a real-time E.coli sensor will be available in the coming years. For the purpose of E.coli monitoring as part of a multi-site ECA approval traditional discrete sampling techniques are required until sensor technology advances. Once sensor technology advances the greater deployment of a e.coli sensor could assist with the source identification of e.coli contamination.

\subsubsection{Alternative Chloride Monitoring Techniques}

Chloride specific open source instrumentation currently does not exist as an alternative monitoring technology. Electrical conductivity can be used to determine chloride concentrations in water using linear, polynomial, and power regression models (Zare Abyaneh et al. 2005)(Windsor et al. 2011). A number of open source electrical conductivity sensors exist and were evaluated based on the acceptance criteria. 


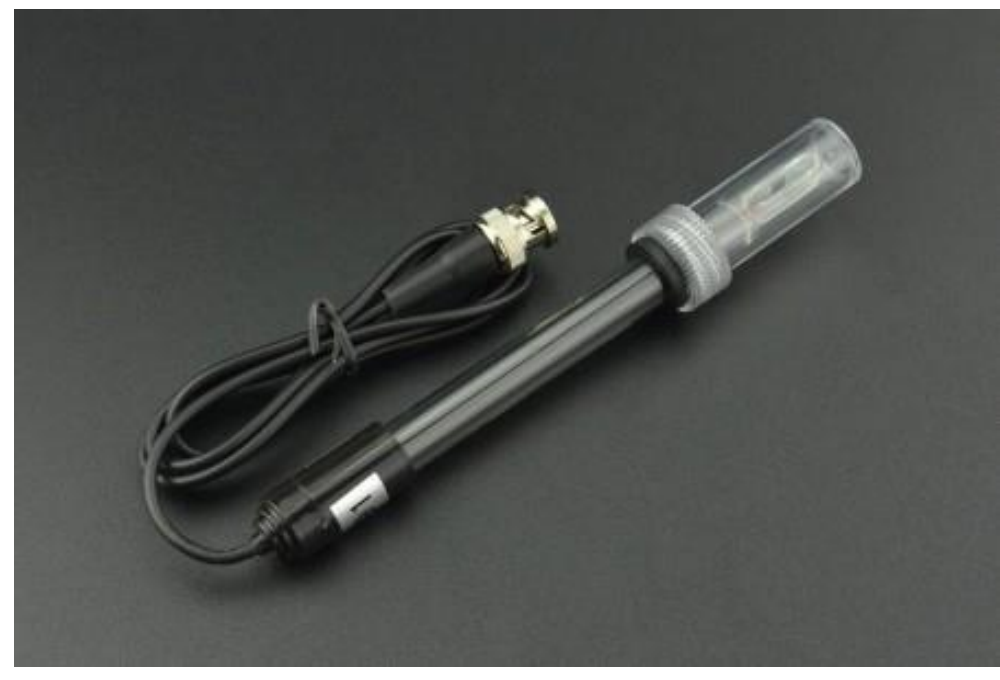

Figure 22: Open Source Electrical Conductivity Sensor (DFRobot 2018)
The most applicable open source electrical conductivity sensor is available from DFRobot and is shown in Figure 22. The sensor evaluation based on the acceptance criteria is as follows (DFRobot 2018):

- Operating temperature: $-0^{\circ} \mathrm{C}-40^{\circ} \mathrm{C}$ (outside acceptance criteria)

- Operating range: $0-20 \mathrm{~ms} / \mathrm{cm}$ (outside acceptance criteria)

- Cost of sensor: $~ \$ 70$ USD (within acceptance criteria)

- Availability of sensor: available online through Sparkfun (within acceptance criteria)

- Compatibility with open source microcontroller: compatible with Arduino ${ }^{\circledR}$ and Raspberry $\mathrm{Pi}^{\mathrm{TM}}$ (within acceptance criteria).

One additional consideration for this probe is the anticipated life expectancy of 0.5 years. For the probe to be viable in the multi-site ECA system a longer life expectancy would be required. The probe satisfied 3 of the 5 acceptance criteria and given the operating temperature and operating range of the instrument does not satisfy the criteria this probe could not be deployed. As technology advances greater operating temperatures and measurement range should improve which could then result in these types of electrical conductivity sensors being deployed within a multi-site ECA system. Traditional real-time monitoring using sensors like the commonly deployed Hydrolab DS5X will still be required for monitoring within a multi-site ECA permitting system.

\subsubsection{Alternative $\mathrm{pH}$ Monitoring Techniques}

Real-time monitoring of $\mathrm{pH}$ can be achieved using both open source and traditional realtime monitoring techniques and sensors. Real-time monitoring of $\mathrm{pH}$ has been deployed and studied using open source and alternative datalogging technology for integration within an IIS (Fan et al. 2012)(Qin et al. 2018). Sensors commonly measure pH levels using potentiometric 
technology which is a well-established method. Given the availability of this technology low cost open source $\mathrm{pH}$ sensors are readily available.

$\mathrm{pH}$ sensors were evaluated based on the acceptance criteria with the most applicable being a

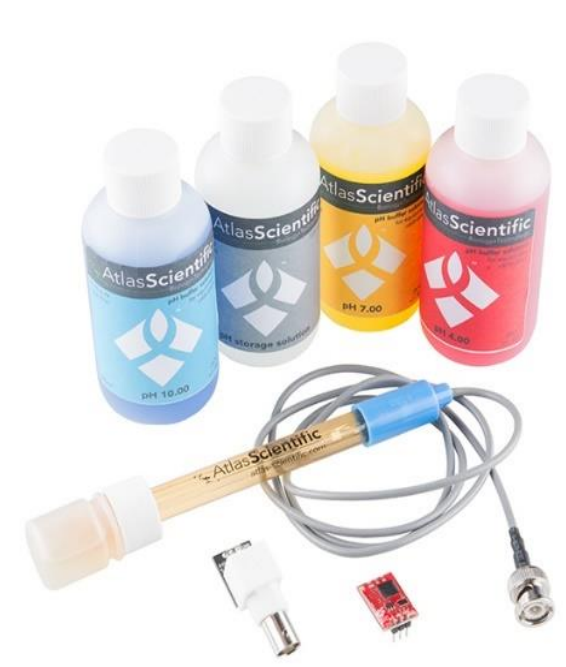

Figure 23: Open Source pH Sensor (AtlasScientific 2018) low cost laboratory grade $\mathrm{pH}$ sensor distributed produced by AtlasScientific Environmental Robotics. Figure 23 outlines the $\mathrm{pH}$ sensor produced by AltlasScientific Environmental Robotics.

The sensor evaluation based on the acceptance criteria is as follows(AtlasScientific 2018):

- Operating temperature: $-40^{\circ} \mathrm{C}-85^{\circ} \mathrm{C}$ (within acceptance criteria)

- Operating range: $0.001-14.000$ (within acceptance criteria)

- Cost of sensor: $\$ 150$ USD (within acceptance criteria)

- Availability of sensor: available online through Sparkfun (within acceptance criteria)

- Compatibility with open source microcontroller: compatible with Arduino ${ }^{\circledR}$ and Raspberry $\mathrm{Pi}^{\mathrm{TM}}$ (within acceptance criteria).

Open source $\mathrm{pH}$ sensors may be ready for mass deployment and could be a viable option for monitoring in multiple locations throughout a subwatershed. The sensor selected for evaluation satisfies all the acceptance criteria. Although traditional $\mathrm{pH}$ sensors such as the Hydrolab DS5X would provide greater confidence, open source $\mathrm{pH}$ sensors may be ready for deployment in the immediate future.

\subsubsection{Water Quality Sampling Interval}

Setting an appropriate sampling interval for water quality monitoring can assist in properly characterizing stormwater impacts on water quality. Through the use of in-situ sensors set at appropriate sampling intervals can support well defined chemographs during and after rainfall events (Chappell, Jones, and Tych 2017). Developing a minimum monitoring rate that does not impact the effectiveness of data quality while not impacting the data storage and 
transfer requirements is required to properly harness the power of in-situ monitoring (Ahmed and Durucan 2007)(Chappell, Jones, and Tych 2017). Where streams are impact by rainfall frequently a high frequency of measurement for water quality parameters between $1-15$ minutes yields greater results (Ahmed and Durucan 2007)(Chappell, Jones, and Tych 2017). For sensor based monitoring of water quality parameters the proposed sampling interval is 5 minutes which is a common interval for open source microcontrollers and will achieve greater results for evaluating contaminant concentrations during and after rainfall events (Chappell, Jones, and Tych 2017).

\subsubsection{Instrument Robustness and Environmental Enclosure Considerations}

Instrument robustness and environmental enclosure considerations for alternative monitoring technologies requires careful consideration prior to deployment. There are current deployments in the field for research purposes using open source sensors controlled by microcontrollers (Jo and Baloch 2017)(Harun, Reda, and Hashim 2018). Other testing has been carried out in a lab setting to determine the sensor accuracy for specific applications (Myint, Gopal, and Aung 2017)(Rahim et al. 2017). One concern with open source sensors is their perceived robustness given the price points associated with the various sensors. In order to determine their robustness additional field testing would be required. Efforts to compare traditional and open source sensors have been carried out with variable results with some being able to withstand different clients and report reliable data and others being unable to perform based on their posted specifications (Rabault et al. 2017)(Gunawardena et al. 2018). Weatherproof enclosures for the microcontroller component of these systems are readily available but would require customizable weather proof connects.

\subsubsection{Selection of Preferred Water Quality Monitoring Method}

Monitoring the targets as part of the water quality objective can be carried out with a combination of open source and traditional water quality sensors. As open source sensors continue to improve there may be a possibility to retrofit monitoring stations with less expensive sensor options. Based on the acceptance criteria and for the purpose of monitoring within the multi-site ECA system, the following lists the preferred monitoring method for water quality targets: 
- Total Phosphorus Monitoring: Hydrolab DS5X (Traditional)

- Nitrate Monitoring: Adafruit TCS34725 (Alternative)

- Ammonia Monitoring: Hydrolab DS5X (Traditional)

- BOD Monitoring: Hydrolab D5SX (Traditional)

- Dissolved Oxygen Monitoring: Gravity Analog Dissolved Oxygen Sensor DFRobot (Alternative)

- Metals: Discrete Sampling (Traditional)

- Total Suspended Solids: Gravity Analog Turbidity Sensor DFRobot (Alternative)

- Temperature: Adafruit DS18B20 Digital Temperature Sensor (Alternative)

- E.coli: Discrete Sampling (Traditional)

- Chloride: Hydrolab DS5X (Traditional)pH: AtlasScientific Environmental Robotics EZO ${ }^{\text {TM }} \mathrm{pH}$ Sensor (Alternative)

The Hydrolab DS5X is a common sensor deployed throughout Ontario's watersheds and should still be used for measuring water quality parameters where open source instrumentation is still developing. Other alternative open source sensors can be ready for deployment for monitoring within a multi-site ECA permit area. The low costs associated with some of these sensors should allow for numerous stations within the permit area. Open source sensors to be used will require bench scale and pilot scale testing to determine the accuracy of readings compared to more traditional calibrated instrumentation. Table 6 outlines the water quality monitoring traditional versus alternative techniques analyzed as part of this section. 
Table 6: Water Quality Monitoring Traditional vs. Alternative

\begin{tabular}{|c|c|c|c|c|c|}
\hline Objective & Criteria & Target & Traditional Monitoring Techniques & $\begin{array}{l}\text { Alternative Monitoring } \\
\text { Techniques }\end{array}$ & $\begin{array}{l}\text { Proposed } \\
\text { Monitoring } \\
\text { Frequency }\end{array}$ \\
\hline \multirow{11}{*}{ Water Quality } & \multirow{11}{*}{$\begin{array}{l}\text { Improved } \\
\text { Water Quality }\end{array}$} & $\begin{array}{l}\text { Total Phosphorus } \\
\text { (mg/L) }\end{array}$ & $\begin{array}{l}\text { Discrete Sampling } \\
\text { Continuous Turbidity Monitoring }\end{array}$ & $\begin{array}{l}\text { Open Source Turbidity } \\
\underline{\text { Sensor }}\end{array}$ & $\begin{array}{l}\text { Continuous } \\
\text { Remote Access }\end{array}$ \\
\hline & & Nitrate (mg/L) & $\begin{array}{l}\text { Discrete Sampling } \\
\text { Continuous Nitrate Monitoring }\end{array}$ & $\begin{array}{l}\text { Open Source Nitrate } \\
\text { Sensor }\end{array}$ & $\begin{array}{l}\text { Continuous } \\
\text { Remote Access }\end{array}$ \\
\hline & & Ammonia (mg/L) & $\begin{array}{l}\text { Discrete Sampling } \\
\text { Continuous Ammonia Monitoring }\end{array}$ & $N / A$ & $\begin{array}{l}\text { Continuous } \\
\text { Remote Access }\end{array}$ \\
\hline & & BOD (Total) & $\begin{array}{l}\text { Discrete Sampling } \\
\text { Continuous BOD Monitoring }\end{array}$ & $N / A$ & $\begin{array}{l}\text { Continuous } \\
\text { Remote Access }\end{array}$ \\
\hline & & $\begin{array}{l}\text { Dissolved Oxygen } \\
(\mathrm{mg} / \mathrm{L})\end{array}$ & $\begin{array}{l}\text { Discrete Sampling } \\
\text { Continuous Dissolved Oxygen } \\
\text { Monitoring }\end{array}$ & $\begin{array}{l}\text { Open Source DO } \\
\underline{\text { Sensor }}\end{array}$ & $\begin{array}{l}\text { Continuous } \\
\text { Remote Access }\end{array}$ \\
\hline & & Metals (mg/L) & $\begin{array}{l}\text { Discrete Sampling } \\
\text { Compound Specific Continuous } \\
\text { Monitoring }\end{array}$ & $\begin{array}{l}\text { Open Source Lead } \\
\underline{\text { Sensor }}\end{array}$ & $\begin{array}{l}\text { Continuous } \\
\text { Remote Access } \\
\text { for Select } \\
\text { Parameters }\end{array}$ \\
\hline & & TSS (Turbidity) (mg/L) & $\begin{array}{l}\text { Discrete Sampling } \\
\text { Continuous Turbidity Monitoring }\end{array}$ & $\begin{array}{l}\text { Open Source Turbidity } \\
\text { Sensor }\end{array}$ & $\begin{array}{l}\text { Continuous } \\
\text { Remote Access }\end{array}$ \\
\hline & & $\begin{array}{l}\text { Temperature (Degrees } \\
\text { Celsius) }\end{array}$ & $\begin{array}{l}\text { Discrete Sampling } \\
\text { Continuous Temperature } \\
\text { Monitoring }\end{array}$ & $\begin{array}{l}\frac{\text { Open Source }}{\text { Temperature Sensor }} \\
\underline{ }\end{array}$ & $\begin{array}{l}\text { Continuous } \\
\text { Remote Access }\end{array}$ \\
\hline & & E.coli (cfu/100ml) & Discrete Sampling & $\underline{\text { E.coli Sensor }}$ & Discrete Sampling \\
\hline & & Chloride $(\mu \mathrm{g} / \mathrm{L})$ & $\begin{array}{l}\text { Discrete Sampling } \\
\text { Continuous Chloride Monitoring }\end{array}$ & $\begin{array}{l}\text { Open Source Electrical } \\
\text { Conductivity }\end{array}$ & $\begin{array}{l}\text { Continuous } \\
\text { Remote Access }\end{array}$ \\
\hline & & $\mathrm{pH}$ & $\begin{array}{l}\text { Discrete Sampling } \\
\text { Continuous pH Monitoring }\end{array}$ & Open Source pH Sensor & $\begin{array}{l}\text { Continuous } \\
\text { Remote Access }\end{array}$ \\
\hline
\end{tabular}




\subsection{Water Quantity Monitoring}

Water quantity measurement and sensor technology is well established within the environmental monitoring field. Flow gauges and water level sensors have been developed over several decades and improved to the point where some Conservation Authorities are measuring water quantity targets in real-time. Currently the Government of Canada under the Water Survey of Canada operates the water quantity monitoring network across the country which provides real-time data for water level and flow (Government of Canada n.d.). The network is a partnership between various stakeholders and government organizations across the country in effort to operate, maintain, and expand the active hydrometric gauges currently deployed throughout Canada (Government of Canada n.d.). Although there are 2800 stations currently deployed nationally, for the multi-site ECA permitting system to function additional monitoring stations would be required. The advancement of open source sensor technology may allow for deployment of stations where the existing network does not cover. It should be noted that these stations would be able to support monitoring for the criteria of maintaining in-streamflow regimes, except for the target of baseflow which can be calculated using algorithms related to stream discharge. To support the other water quantity criteria of maintaining groundwater recharge and water balance, monitoring needs to be carried out in a way to satisfy the targets of groundwater level and percent change in flood plain, wetlands, and woodlots.

Traditional monitoring techniques for water quantity have been well developed and deployed throughout Ontario's watersheds, however, open source water quantity sensors could be used to supplement existing data for monitoring of multi-site ECA's. In the following subsections traditional methods and alternative methods for monitoring water quantity targets are evaluated for their applicability within a multi-site ECA system. Table 7 outlines the traditional versus alternative monitoring techniques as well as the proposed monitoring frequency with a multi-site ECA permitting system. 
Table 7: Water Quantity Monitoring Traditional vs. Alternative

\begin{tabular}{|c|c|c|c|c|c|}
\hline Objective & Criteria & Target & $\begin{array}{l}\text { Traditional Monitoring } \\
\text { Techniques }\end{array}$ & $\begin{array}{l}\text { Alternative } \\
\text { Monitoring } \\
\text { Techniques }\end{array}$ & $\begin{array}{l}\text { Proposed } \\
\text { Monitoring } \\
\text { Frequency }\end{array}$ \\
\hline \multirow{4}{*}{$\begin{array}{l}\text { Water } \\
\text { Quantity }\end{array}$} & $\begin{array}{l}\text { Maintain In- } \\
\text { Streamflow } \\
\text { Regimes }\end{array}$ & $\begin{array}{l}\text { Streamflow } \\
(\mathrm{m} 3 / \mathrm{sec})\end{array}$ & $\begin{array}{l}\text { Discrete Measurement, } \\
\text { Continuous Streamflow } \\
\text { Monitoring }\end{array}$ & $\frac{\text { Open Source }}{\underline{\text { Level Sensor }}}$ & $\begin{array}{l}\text { Continuous } \\
\text { Remote } \\
\text { Access }\end{array}$ \\
\hline & \multirow{3}{*}{$\begin{array}{l}\text { Maintain } \\
\text { Groundwater } \\
\text { Recharge \& } \\
\text { Water Balance }\end{array}$} & $\begin{array}{l}\text { Baseflow } \\
\text { (m3/sec) }\end{array}$ & $\begin{array}{l}\text { Discrete Measurement, } \\
\text { Continuous Baseflow } \\
\text { Monitoring }\end{array}$ & $\frac{\text { Open Source }}{\underline{\text { Level Sensor }}}$ & $\begin{array}{l}\text { Continuous } \\
\text { Remote } \\
\text { Access }\end{array}$ \\
\hline & & $\begin{array}{l}\text { Groundwater } \\
\text { Level }(\mathrm{m})\end{array}$ & $\begin{array}{l}\text { Discrete Measurements, } \\
\text { Continuous Water Level } \\
\text { Monitoring }\end{array}$ & $\begin{array}{l}\text { Water Level } \\
\text { Sensor }\end{array}$ & $\begin{array}{l}\text { Continuous } \\
\text { Remote } \\
\text { Access }\end{array}$ \\
\hline & & $\begin{array}{l}\text { \% Change in } \\
\text { Flood Plain, } \\
\text { Wetlands, } \\
\text { Woodlots }\end{array}$ & $\begin{array}{l}\text { Field Measurement and } \\
\text { GIS Verification }\end{array}$ & $\begin{array}{l}\text { GIS Based } \\
\text { Near Real } \\
\text { Time }\end{array}$ & $\begin{array}{l}\text { Continuous } \\
\text { Remote } \\
\text { Access }\end{array}$ \\
\hline
\end{tabular}

\subsubsection{Traditional Water Quantity Monitoring Techniques}

Traditional water quantity monitoring techniques are a viable option for the majority of the monitoring data required for the multi-site ECA system. As discussed in Section 5.2, existing real-time networks could be used for multi-site ECA monitoring data with supplemental monitoring required to fill data gaps within various subwatersheds. Traditional streamflow monitoring is carried out by using well established water level sensors which reports water level data that is converted to streamflow using a stage-discharge model (Government of Canada n.d.). The stage-discharge model is calibrated by collecting site specific discharge and water level measurements. Complete real-time streamflow monitoring stations are available from several established manufacturers including Campbell Science ${ }^{\circledR}, \mathrm{YSI}^{\circledR}$, and Eijkelkan Soil and Water ${ }^{\circledR}$. Handheld measurement devices are also available for the same suppliers which are generally used for calibration of the real-time monitoring sensors.

For the maintenance of groundwater recharge and water balance criteria, traditional monitoring was evaluated for baseflow, groundwater level, and percent change in flood plain, wetland, and woodlots. Baseflow separation calculations can produce daily baseflow information 
through the use of hydrograph data that is already provided by Environment Canada (Miller et al. 2014). Traditional groundwater level sensors are well deployed throughout Ontario. The most common level sensors are available from Solinst ${ }^{\circledR}$ and Eijkelkan Soil and Water ${ }^{\circledR}$ The limitation with groundwater sensors is the availability of a robust and reliable IOT platform although there is research underway to alleviate this limitation. One research group is testing real-time automated data collection for water supply and monitoring wells in attempt to improve decision making ability related to water supply issues (Smart Cities Connect 2017). Real-time groundwater sensors exist however their deployed is limited throughout Ontario. Currently there are no Conservation Authorities or other stakeholder groups reporting groundwater levels in real time through an ISS platform.

Monitoring for the percent change in flood plain, wetland, and wood lot coverage is current achieved through a combination of field measurement and GIS verification. This traditional monitoring technique is labour intensive which needs to be evaluated for its inclusion within the multi-site ECA system.

\subsubsection{Alternative Water Quantity Monitoring Techniques}

Alternative open source sensors exist for measuring water quantity targets such as streamflow, and water level which could be used to support the monitoring requirements within a multi-site ECA system. With the deployment of water quantity monitoring stations throughout Ontario's watersheds the role of alterative sensors can be limited to filling in monitoring and data gaps where required a lower cost. The TRCA estimated that construction of a stream flow gauge costs between $\$ 7,000$ and $\$ 10,000$ with operational and maintenance costs between $\$ 2,500$ and $\$ 8,000$ for a three year period (Toronto and Region Conservation Authority 2000). The expense associated with these deployments promote the possibility of using alternative water quality monitoring techniques. A sampling interval of 5 minutes is proposed to follow the same frequency as the water quality sensors to capture flow data during rainfall events. The following subsections explore the alternative water quantity sensors which could be utilized as well as an alternative data collection technique for gather information on land use changes.

The criteria for evaluating the applicability of open source water quantity monitoring techniques (where available) are based off the readily used real-time streamflow monitoring stations 
available from several established manufacturers including Campbell Science ${ }^{\circledR}, \mathrm{YSI}^{\circledR}$, Solinst $^{\circledR}$, and Eijkelkan Soil and Water ${ }^{\circledR}$.

The acceptance criteria for alternative streamflow sensors are as follows (YSI, n.d.):

- $\quad$ Operating temperature $\left(0^{\circ} \mathrm{C}\right.$ to $\left.+40^{\circ} \mathrm{C}\right)$;

- Operating range $(0-70.3 \mathrm{~m})$

- Cost of sensor (less than traditional techniques);

- Availability of sensor (available online); and,

- Compatibility with open source micro-controllers (Arduino ${ }^{\circledR}$, SparkFun Electronics ${ }^{\circledR}$, and Raspberry $\left.\mathrm{Pi}^{\mathrm{TM}}\right)$;

\subsubsection{Alternative Streamflow/Baseflow Monitoring Techniques}

Alternative open source water level sensors could be used for measuring streamflow and subsequently baseflow monitoring. Open source sensors were evaluated for their suitability for monitoring water level for providing streamflow and baseflow data. Two types of open source technologies could be utilized for monitoring. The first type of open source water level sensor is

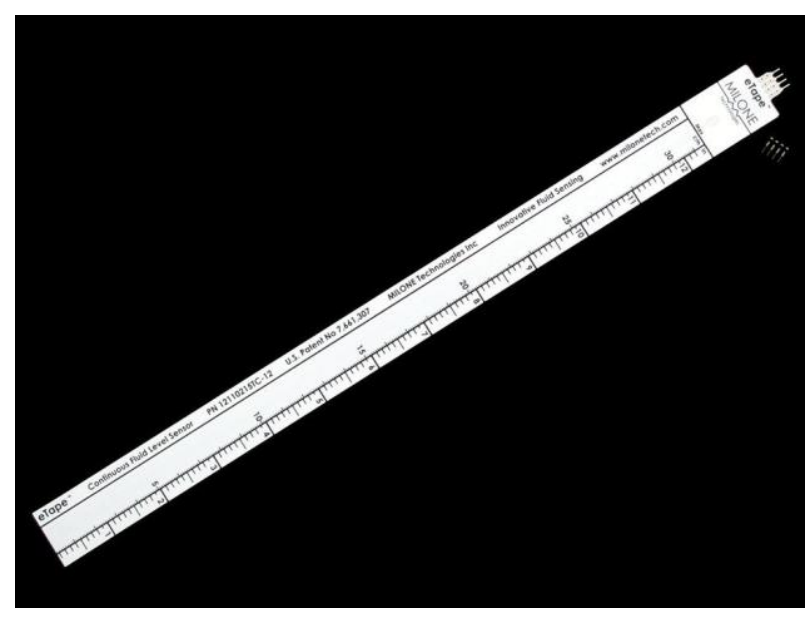

Figure 24: Open Source eTape Liquid Level Sensor (Adafruit 2018)
eTape Liquid Level Sensor technology which uses resistive output that changes with the level of the fluid passing the sensor. The eTape Liquid Level Sensor is shown in Figure 24. The sensor evaluation based on the acceptance criteria is as follows:

- Operating temperature: $-6^{\circ} \mathrm{C}$ to $+60^{\circ} \mathrm{C}$ (within acceptance criteria)

- Operating range: $0-30 \mathrm{~cm}$ (outside acceptance criteria

- Cost of sensor: $\$$ \$OUSD (within acceptance criteria)

- Availability of sensor: available from Adafruit (within acceptance criteria)

- Compatibility with open source micro-controllers: compatible with Arduino ${ }^{\circledR}$, SparkFun Electronics ${ }^{\circledR}$, and Raspberry $\mathrm{Pi}^{\mathrm{TM}}$ (within acceptance criteria) 
The eTape Liquid Level Sensor satisfied 4 of the 5 acceptance criteria with the exception of operating range. The range exhibited by traditional sensors is much greater than what is required for this application. Depending on the deployment the operating range could be acceptable in certain cases. However, the seasonal variability of water levels within Ontario watershed the range may restrict its applicability.

Another possible option for water level monitoring is a recently released Optomax Digital Liquid Level Sensor used for measuring liquid level. The sensor technology uses infrared light that is directed towards a liquid. This sensor is not affected by foam or small bubbles. Figure 25

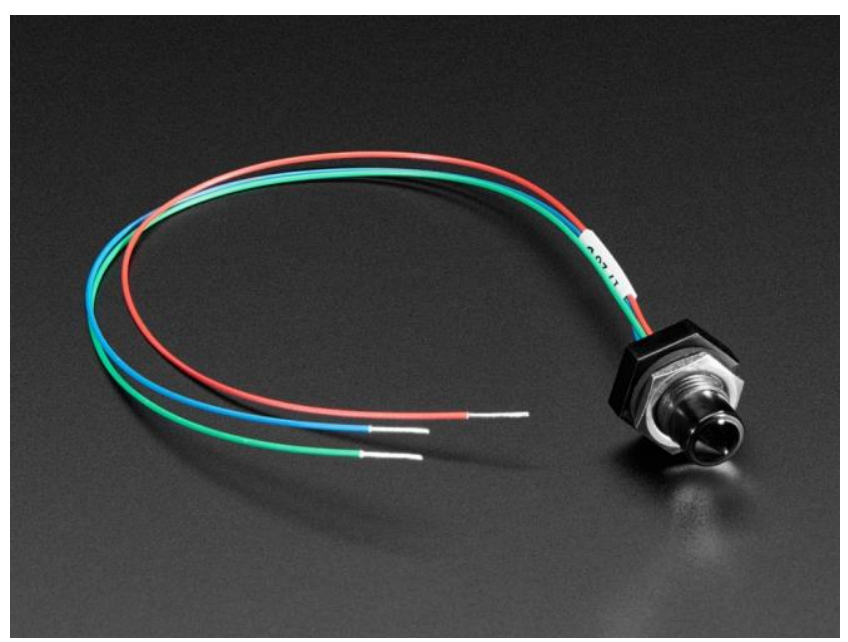

Figure 25: Open Source Optomax Digital Liquid Level Sensor (SST

Figure

(within acceptance criteria)

- Compatibility with open source micro-controllers: compatible with Arduino ${ }^{\circledR}$, SparkFun Electronics ${ }^{\circledR}$, and Raspberry $\mathrm{Pi}^{\mathrm{TM}}$ (within acceptance criteria)

The Optomax satisfied 4 of 5 acceptance criteria with the exception of range. The range of the sensor would need to be tested to determine if an accurate level measurement could be repeated.

Another potential technology for streamflow measurement is Large Scale Particle Image Velocimetry (LSPIV). The technology is a way to measure hydraulic and hydrological systems using thermal image based processing (Tauro, Piscopia, and Grimaldi 2017)(Legleiter, Kinzel, and 
Nelson 2017). In order to increase accuracy hybrid systems using LSPIV and passive optical data has been researched and although results correlate with field measurements additional research is still required to refine the accuracy (Legleiter, Kinzel, and Nelson 2017). The development of LSPIV could be used to supplement streamflow monitoring in the multi-site ECA system.

\subsubsection{Alternative Groundwater Level Monitoring Techniques}

Groundwater level monitoring presents challenges since the sensors are housed within a groundwater monitoring well. Standard groundwater monitoring wells include either flush mount or stick up casings with the well piping extending into the ground to a specific depth below ground surface depending on the aquifer intended for monitoring. Open source sensors were evaluated for their suitability to be enclosed in a groundwater monitoring well. The Optomax Digital Liquid Level Sensor described in the previous section is one viable option for measuring groundwater level within monitoring wells. The applicability will depend on the deviation of the monitoring well. If the monitoring well is drilled and installed straight enough for the infrared sensor to send a signal to the water level and have the signal returned it could be utilized for measuring groundwater levels.

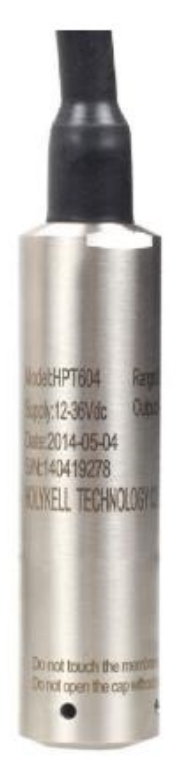

Figure 26: Open Source HolyKell Water Level Sensor (HolyKell 2018)

The other groundwater level monitoring sensor is an open source sensor that is designed to connect with an Arduino. The design is based on the traditional level logging sensors but at a lower cost and with compatibility with open source micro controller options. Figure 26 outlines the HolyKell Water Level Sensor. The sensor evaluation based on the acceptance criteria is as follows:

- Operating temperature: $-30^{\circ} \mathrm{C}$ to $+85^{\circ} \mathrm{C}$ (within acceptance criteria)

- $\quad$ Operating range: $0-500 \mathrm{~m}$ (within acceptance criteria)

- $\quad$ Cost of sensor: $~ \$ 70 U S D$ (within acceptance criteria)

- $\quad$ Availability of sensor: available from Alibaba (within acceptance criteria)

- $\quad$ Compatibility with open source micro-controllers: compatible with Arduino $^{\circledR}$ (within acceptance criteria) 
The Holykell water level sensor met all of the acceptance criteria and presents itself as a lower cost alternative than traditional options while having the capability of interfacing with an open source microcontroller.

\subsubsection{Alternative Percent Change in Flood Plain, Wetland, and Woodlot Coverage}

Alternative monitoring for the percent change in flood plain, wetland, and woodlot coverage is specific to using GIS based software and aerial imagery. Near real-time GIS based measurements are developing which consist of using continuous data streaming from satellite imagery (Pratihast et al. 2016). Hybrid systems also exist that include physical monitoring stations and the integration of multi-sensor remote sensing data streams like Landsat, MODIS Sentinel 1 and Sentinel 2 could improve accuracy (Pratihast et al. 2016). Additional research has been completed to determine deforestation rates using NRT GIS. A proof of concept was developed using Landsat NDVI and ALOS PALSAR imagery which was found to have an overall accuracy of 87.4\% (Reiche et al. 2015). Development of NRT GIS from companies such as ERSI could be used for the multi-site application. ERSI has developed an easy access for NRT GIS that aggregates publicly available satellite and GIS based data into an ArcGIS based server (Dodd 2009). Figure 27 outlines the ERSI process for producing NRT GIS data.

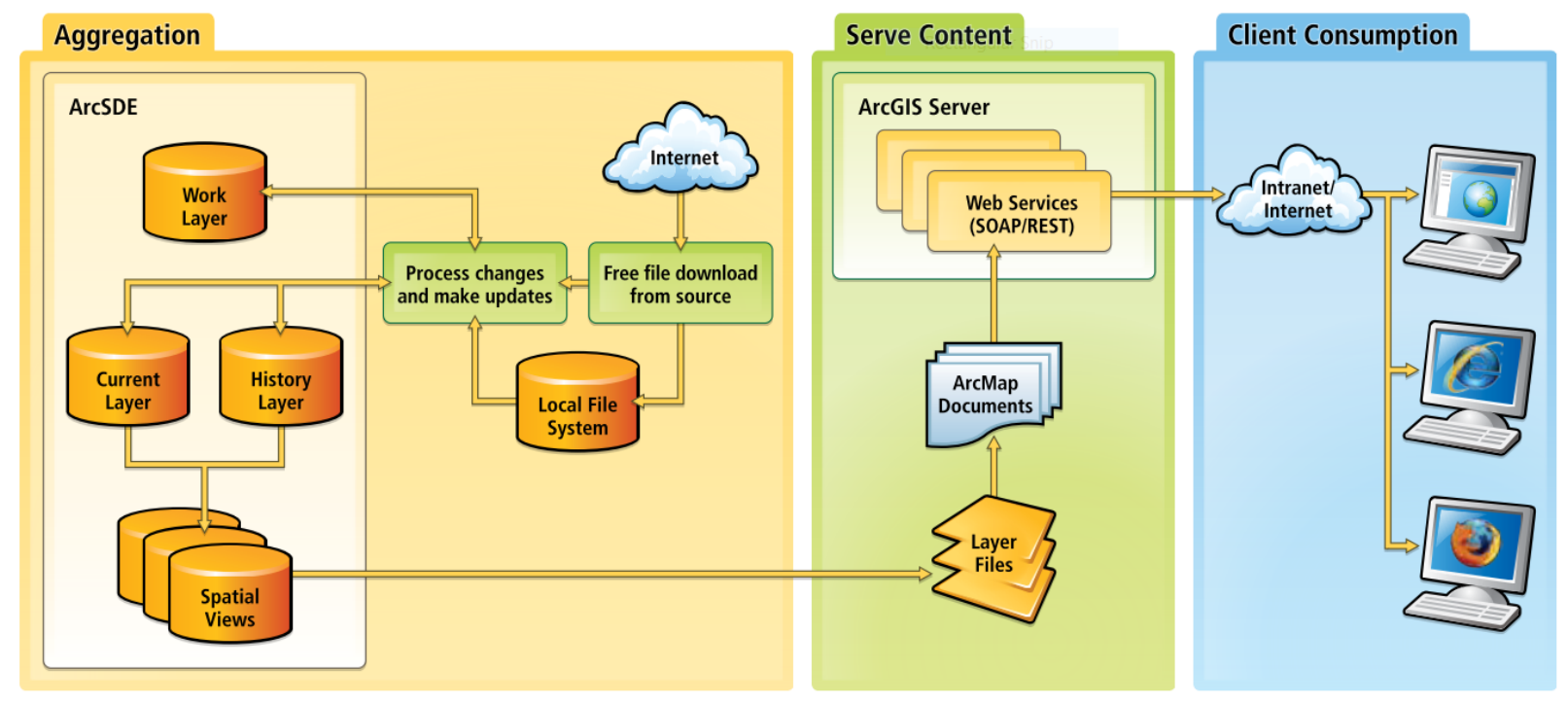

Figure 27: ERSI NRT Process (Dodd 2009)

These type of systems have been used to integrate sensor data within a live view platform for environmental data management (Resch et al. 2009)(Sun and Li 2016). Integrating field 
sensors with NRT GIS provides additional opportunities for environmental data management. Using field sensors in collaboration with mapping data near real time reporting of environmental data is possible (Gong, Geng, and Chen 2015)(Neukom, Müller Arisona, and Schubiger 2018).

Near real-time monitoring for percent change in land use should be considered for inclusion in the multi-site ECA system. Example NRT GIS systems exist however adaptation to satisfy the multi-site ECA monitoring requirements are required. Once the system has been developed and integrated into an IIS framework, limited resources would be required to monitor output because of the slow pace at which land coverage occurs. Field verification would be required in the event the system identifies a drastic change or if there is are specific areas of concern within the permit area.

\subsubsection{Selection of Preferred Water Quantity Monitoring Method}

With proper bench scale testing and pilot scale testing the water quantity objective can be monitored using alternative open source sensor technology. For measuring the percent change in flood plain, wetland, and woodlot coverage a specific NRT GIS system would need to be developed and tested prior to implementation. With the coverage of existing water quantity monitoring networks open sensors can be used to provide supplemental data where required. The preferred open source sensors and methods are as follows:

- Steam flow/Baseflow: Optomax Digital Liquid Level Sensor

- Groundwater Level: HolyKell Water Level Sensor/Optomax Digital Liquid Level Sensor

- Percent Change Flood Plain, Wetland, and Woodlot: Near Real-Time GIS

\subsection{Stream Morphology Monitoring Traditional \& Alternative Monitoring Techniques}

The selected criteria within the stream morphology objective includes the limiting of stream erosion and preservation of stream morphology as well as maintaining and preserving flood plain area. The targets which governs the criteria include the percent change in stream cross sections, the percent change in channelization, and the percent change in flood plain coverage. Vertical erosion or downcutting is caused by geological processes that causes the removal of material from the stream bed (Lyons et al. 2015). Although vertical erosion is a source of suspended sediment load in streams alternative monitoring techniques will not be able to 
effectively monitor this type of stream erosion (Lyons et al. 2015). The stream morphology objective differs from the water quality and water quantity objectives because it deals with land use change where field sensors are not applicable. Table 8 outlines the traditional versus alternative monitoring techniques as well as the proposed monitoring frequency with a multisite ECA permitting system.

Table 8: Stream Morphology Monitoring Traditional vs. Alternative

\begin{tabular}{|c|c|c|c|c|c|}
\hline Objective & Criteria & Target & $\begin{array}{l}\text { Traditional } \\
\text { Monitoring } \\
\text { Techniques } \\
\end{array}$ & $\begin{array}{l}\text { Alternative } \\
\text { Monitoring } \\
\text { Techniques } \\
\end{array}$ & $\begin{array}{l}\text { Proposed } \\
\text { Monitoring } \\
\text { Frequency }\end{array}$ \\
\hline \multirow{3}{*}{$\begin{array}{l}\text { Stream } \\
\text { Morphology }\end{array}$} & \multirow{2}{*}{$\begin{array}{l}\text { Limit Stream } \\
\text { Erosion and } \\
\text { Preserve } \\
\text { Stream } \\
\text { Morphology }\end{array}$} & $\begin{array}{l}\text { \% Change in } \\
\text { Stream Cross- } \\
\text { Sections }\end{array}$ & $\begin{array}{l}\text { Field Measurement } \\
\text { and Verification }\end{array}$ & NRT GIS/UAV & $\begin{array}{l}\text { GIS NRT \& } \\
\text { Annual Field } \\
\text { Verification }\end{array}$ \\
\hline & & $\begin{array}{l}\text { \% Change in } \\
\text { Channelization }\end{array}$ & $\begin{array}{l}\text { Field Measurement } \\
\text { and Verification }\end{array}$ & NRT GIS & $\begin{array}{l}\text { GIS NRT \& } \\
\text { Annual Field } \\
\text { Verification }\end{array}$ \\
\hline & $\begin{array}{l}\text { Maintain and } \\
\text { Preserve Flood } \\
\text { Plains }\end{array}$ & $\begin{array}{l}\text { \% Flood Plain } \\
\text { Coverage }\end{array}$ & $\begin{array}{l}\text { Field Measurement } \\
\text { and GIS Verification }\end{array}$ & NRT GIS & $\begin{array}{l}\text { GIS NRT \& } \\
\text { Annual Field } \\
\text { Verification }\end{array}$ \\
\hline
\end{tabular}

The traditional monitoring method for the percent change in land use coverage includes both field measurement and GIS verification. This method can be labour intensive and requires physical resources to collect and validate the data.

The alternative method involves the integration of multi-sensor remote sensing data streams to monitor percent change in land use over time (Pratihast et al. 2016). This near realtime method still requires field verification but once calibration could be a viable option for implementation within the multi-site ECA permitting system. For percent change in stream crosssection UAV technology should be used to classify and monitoring first order streams as well provide greater detail for high risk tributaries. Using resolutions less than $10 \mathrm{~cm}$ with UAV technologies has been found to provide greater hydro morphological classifications and monitoring accuracy (Casado et al. 2015)(Afshari et al. 2016)(Casado et al. 2016)(Woodget et al. 2017). 


\subsubsection{Selection of Preferred Stream Morphology Monitoring Method}

For measuring the percent change in land use coverage, a specific near real-time system would need to be developed and tested prior to implementation. The development the proposed near real-time GIS system would limit the amount of resources required to properly monitoring changes in land use. Annual field verification for sensitive or high priority areas is recommended to calibration the NRT GIS system. The proposed method for monitoring the stream morphology targets are as follows:

- Percent Change in Stream Cross-Section: Near Real-Time GIS

- Percent Change in Channelization: Near Real-Time GIS

- Percent Change in Flood Plain Coverage: Near Real-Time GIS

\subsection{Terrestrial Environment Monitoring Traditional \& Alternative Monitoring Techniques}

The selected criteria within the terrestrial objective includes the preservation and restoration of wood lots as well as the preservation and restoration of wetlands. The targets which governs the criteria include the percent change in natural vegetative cover and woodlot cover, percent change in naturalized riparian areas, percent change in wetland area, and percent change in shoreline. Like the stream morphology objective, the terrestrial environment is monitored through examining land use change over time and not with specific environmental sensors. Table 9 outlines the traditional versus alternative monitoring techniques as well as the proposed monitoring frequency with a multi-site ECA permitting system. 
Table 9: Terrestrial Environment Traditional vs. Alternative

\begin{tabular}{|c|c|c|c|c|c|}
\hline Objective & Criteria & Target & $\begin{array}{l}\text { Traditional } \\
\text { Monitoring } \\
\text { Techniques } \\
\end{array}$ & $\begin{array}{l}\text { Alternative } \\
\text { Monitoring } \\
\text { Techniques } \\
\end{array}$ & $\begin{array}{l}\text { Proposed } \\
\text { Monitoring } \\
\text { Frequency }\end{array}$ \\
\hline \multirow{5}{*}{$\begin{array}{l}\text { Terrestrial } \\
\text { Environment }\end{array}$} & \multirow{2}{*}{$\begin{array}{l}\text { Preserve and } \\
\text { Restore } \\
\text { Woodlots }\end{array}$} & $\begin{array}{l}\text { \% Change } \\
\text { Natural } \\
\text { Vegetative \& } \\
\text { Woodlot Cover }\end{array}$ & $\begin{array}{l}\text { Field Measurement } \\
\text { and GIS Verification }\end{array}$ & NRT GIS & $\begin{array}{l}\text { GIS NRT \& } \\
\text { Annual Field } \\
\text { Verification }\end{array}$ \\
\hline & & $\begin{array}{l}\text { \% Change in } \\
\text { Naturalized } \\
\text { Riparian Areas }\end{array}$ & $\begin{array}{l}\text { Field Measurement } \\
\text { and GIS Verification }\end{array}$ & NRT GIS & $\begin{array}{l}\text { GIS NRT \& } \\
\text { Annual Field } \\
\text { Verification }\end{array}$ \\
\hline & \multirow{3}{*}{$\begin{array}{l}\text { Preserve and } \\
\text { Restore } \\
\text { Wetlands }\end{array}$} & $\begin{array}{l}\text { \% Change in } \\
\text { Naturalized } \\
\text { Riparian Areas }\end{array}$ & $\begin{array}{l}\text { Field Measurement } \\
\text { and GIS Verification }\end{array}$ & NRT GIS & $\begin{array}{l}\text { GIS NRT \& } \\
\text { Annual Field } \\
\text { Verification }\end{array}$ \\
\hline & & $\begin{array}{l}\% \text { Change in } \\
\text { Wetland Area }\end{array}$ & $\begin{array}{l}\text { Field Measurement } \\
\text { and GIS Verification }\end{array}$ & NRT GIS & $\begin{array}{l}\text { GIS NRT \& } \\
\text { Annual Field } \\
\text { Verification }\end{array}$ \\
\hline & & $\begin{array}{l}\text { \% Change in } \\
\text { Shoreline }\end{array}$ & $\begin{array}{l}\text { Field Measurement } \\
\text { and GIS Verification }\end{array}$ & NRT GIS & $\begin{array}{l}\text { GIS NRT \& } \\
\text { Annual Field } \\
\text { Verification }\end{array}$ \\
\hline
\end{tabular}

Traditional terrestrial monitoring includes field measurements as well as GIS verification. As previously mentioned this method can be labour intensive and requires physical resources to collect and validate the collected data.

The alternative method for monitoring the percent change in land use was described in Section 5.2.2.3. Alternative Percent Change in Flood Plain, Wetland, and Woodlot Coverage. The uses of near real-time GIS based monitoring requires field verification. Field verification should be carried out for sensitive or high priority areas on an annual basis to calibrate the NRT GIS monitoring system.

\subsubsection{Selection of Preferred Terrestrial Environment Monitoring Method}

As described in Section 5.3.1 Selection of Preferred Stream Morphology Method development of a near real-time system would be required prior to implementation within the multi-site ECA system. The development the proposed near real-time GIS system would limit the 
amount of resources required to properly monitoring changes in land use. Annual field verification for high priority and sensitive areas is recommended. The field verification can also be used to calibrate the NRT GIS system. The proposed method for monitoring the terrestrial environment targets are as follows:

- Percent Change in Natural Vegetative and Woodlot Cover: NRT GIS

- Percent Change in Naturalized Riparian Areas: NRT GIS

- Percent Change in Wetland Area: NRT GIS

- Percent Change in Shoreline: NRT GIS

\subsection{Aquatic Environment Monitoring Traditional \& Alternative Monitoring Techniques} Within the aquatic environment objective two criteria are proposed for inclusion in the multi-site ECA permitting system. The two criteria include; improve water quality as well as maintain and promote species biodiversity and biomass density. The targets which support these two criteria include; water quality targets and percent change in biodiversity and biomass density. The water quality targets include the specific contaminants of concern as detailed in Section 5.2 Water Quality Monitoring of this report. The data collected as part of water quality objective can be used to support decision making and permit compliance relating to the aquatic environment. The percent change in biodiversity and biomass density requires aquatic specific monitoring to be carried out. Table 10 outlines the traditional versus alternative monitoring techniques as well as the proposed monitoring frequency with a multi-site ECA permitting system. 
Table 10: Aquatic Environment Traditional vs. Alternative

\begin{tabular}{|l|l|l|l|l|l|}
\hline Objective & Criteria & Target & $\begin{array}{l}\text { Traditional } \\
\text { Monitoring } \\
\text { Techniques }\end{array}$ & $\begin{array}{l}\text { Alternative } \\
\text { Monitoring } \\
\text { Techniques }\end{array}$ & $\begin{array}{l}\text { Proposed } \\
\text { Monitoring } \\
\text { Frequency }\end{array}$ \\
\hline \multirow{5}{*}{$\begin{array}{l}\text { Aquatic } \\
\text { Environment }\end{array}$} & $\begin{array}{l}\text { Improve Water } \\
\text { Quality }\end{array}$ & $\begin{array}{l}\text { Refer to Water } \\
\text { Quality } \\
\text { Targets } \\
\text { Refer to Water } \\
\text { Quality Targets }\end{array}$ & $\begin{array}{l}\text { Water } \\
\text { Quality } \\
\text { Monitoring }\end{array}$ & $\begin{array}{l}\text { Refer to Water } \\
\text { Quality } \\
\text { Monitoring }\end{array}$ \\
\cline { 2 - 6 } & $\begin{array}{l}\text { Promote } \\
\text { Species } \\
\text { Biodiversity and } \\
\text { Biomass Density }\end{array}$ & $\begin{array}{l}\text { \% Change in } \\
\text { Biodiversity \& } \\
\text { Biomass } \\
\text { Density }\end{array}$ & $\begin{array}{l}\text { Aquatic Field } \\
\text { Surveys }\end{array}$ & eDNA & $\begin{array}{l}\text { Aquatic Field } \\
\text { Surveys }\end{array}$ \\
\hline
\end{tabular}

Traditional water quality monitoring techniques are described in Section 5.2 Water Quality Monitoring. Traditional aquatic monitoring depends on the type of aquatic species being targeting. For example electro-fishing is still commonly used for fish surveys in streams (Scholten 2003). For other types of monitoring, large mesh and small mesh nets are used to capture fish, benthic macro invertebrates, and zooplankton (Ministry of Natural Resources 2015). Measuring benthic microalgae is commonly carried out through sediment sampling (Grinham et al. 2007). Regardless of the technique for sampling aquatic species it generally involves labour intensive methods for collection and analysis of the collected samples.

Advancements in Environmental DNA (eDNA) could present a unique opportunity for monitoring the aquatic environment within a multi-site ECA system. eDNA involves the identification of environmental species through DNA analysis (Rees et al. 2014). This type of aquatic detection technique uses DNA that is gathered from feces, saliva, urine, and skin cells of aquatic species which may in a given water body (Rees et al. 2014). eDNA has been used to identify hard to sample or trap aquatic species and because of the non-invasive nature of eDNA allows for endangered and threatened species to be identified without physical hard (Rees et al. 2014). Although this technique is developing and in its infancy it has also been used to study aquatic invasive species due to the fact it can detect DNA from aquatic species that have a low density within a given water body (Smart et al. 2015). As eDNA technology develops it could be 
used for monitoring permit compliance within the multi-site permitting system. Labour intensive field measurement will still be required until alternative methods are available.

\subsubsection{Selection of Preferred Aquatic Environment Monitoring Method}

Given that water quality targets are also associated with the aquatic environment the preferred monitoring methods are described in Section 5.1.3 Selection of Preferred Water Quality Monitoring Methods. For the percent change in biodiversity and biomass density advancements in eDNA technologies may eventually supplant field sampling methods however cannot be utilized at this present time for multi-site ECA monitoring. The proposed method for monitoring the aquatic environment targets are as follows:

- Water Quality (Refer to Section 5.1.3)

- Percent Change in Biodiversity and Biomass Density: Aquatic Field Surveys (Traditional)

\subsection{Integrated Information System Architecture}

The successful deployment and data management for the monitoring data collected as part of the multi-site ECA system will require a robust integrated information system. The IIS architecture is important for data collection, data storage, data manipulation, and data display. The architecture needs to be structure to reduce human input while producing useful information for the intended users. Fang et al. 2014 outlined an overall architecture of IIS based on an IOT platform. This IIS architecture outlined by Fang et al. 2014 should be used within the multi-site ECA system. The IIS includes a perception layer, network layer, middleware layer, and application layer.

For the targets that can be monitored using environmental sensors, IOT platforms are required to allow for real-time monitoring data from the physical world to be collected and sent to the network layer. The network layer will store the data collected from the field sensors on cloud-based servers and will allow access for the middleware layer where the data is manipulated and processed. Once the data is processed in the middleware layer, the application layer will visually depict the environmental data in a form that is usable for the user. The visual layer will likely take the form of a web-based application where the stakeholders can log in and view the monitoring data. An advanced version of a web-based application could allow for stakeholders 
to receive email alerts for targets that are measured outside of their threshold. This will allow for the owners of the permit to employ corrective and mitigative actions to ensure compliance with their multi-site ECA.

For the targets that do not include physical sensors such as the percent change in land use targets and integrated NRT GIS based application will need to be structured within the overall IIS. Using the Fang et al. 2014 IIS layout, the NRT GIS will need to follow the same process from the perception layer, network layer, and middleware layer, and finally displaying NRT GIS data through the application layer. Both sensor-based monitoring and GIS based monitoring will need to be integrated at the application layer to provide the users with all multi-site ECA monitoring data within one application layer.

For integration of existing real-time water quantity and water quality sensors an Application Program Interface (API) will be required to pull data from existing sources to be included in the multi-site ECA application layer. An API is used to commutate between two IIS's and sets out communication protocols between the two systems (Yamanoue, Oda, and Shimozono 2012). For targets that require field measurements or field calibrations an additional API will be required to allow stakeholders to upload monitoring data for their specific multi-site ECA area. The IIS will then translate the API information into the application layer for user viewing.

Several proprietary examples of IIS exist in the environmental monitoring market space which use a similar ISS architecture as the one previously mentioned. Teresa Systems Inc. offers an IIS for water quality monitoring at a watershed level (Tesera 2018). For water quantity monitoring Aquatic Informatics offers IIS solutions to integrate water quantity monitoring data in a usable web application platform (Aquatic Informatics 2017). Sensor manufacturers are also providing IIS solutions that work with specific proprietary sensors. For example, Solinst ${ }^{\circledR}$ offers a web based application for IOT level logging sensors (Solinst 2017). These proprietary examples show that IIS systems can work for environmental monitoring. Although these examples exist a customized IIS to encompass all monitoring data and sensors will be required for the multi-site ECA system. 
To effectively limit the governance and administrative burden associated with ECAs a well-defined and developed IIS is essential at the beginning of the multi-site ECA system roll out. Additional research related to IIS is required prior to developing the framework within the multisite ECA permitting system. 


\section{Multi-Site Framework Simulation for Lovers Creek Subwatershed}

\subsection{Lovers Creek Subwatershed Background}

Lovers Creek subwatershed located within the Lake Simcoe Watershed was selected for the theoretical multi-site permit framework simulation. The purpose of this simulation was to test the framework parameters and monitoring requirements for a theoretical multi-site permit area. The Lovers Creek subwatershed has an extensive subwatershed plan and various supplementary studies that support the health of the subwatershed. Within the subwatershed plan information is available relating to known stormwater controls. Figure 28 outlines the known stormwater control locations within the subwatershed.

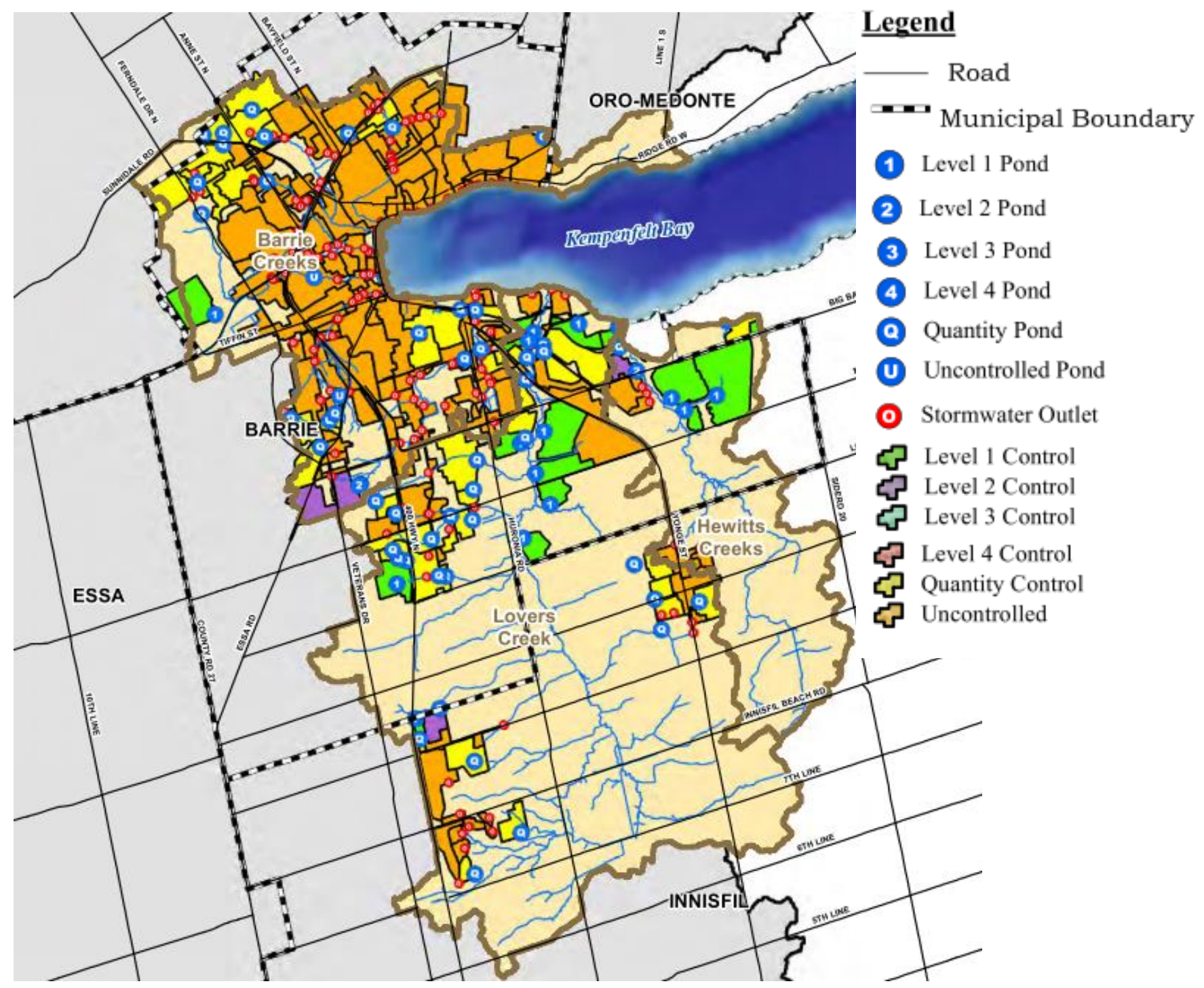

Figure 28: Lovers Creek Stormwater Control (Lake Simcoe Regional Conservation Authority 2012) 
In addition to an inventory of stormwater controls additional information on control stormwater, uncontrolled stormwater with retrofit opportunities, and uncontrolled with no retrofit opportunities is available. Figure 29 outlines the locations of these areas.

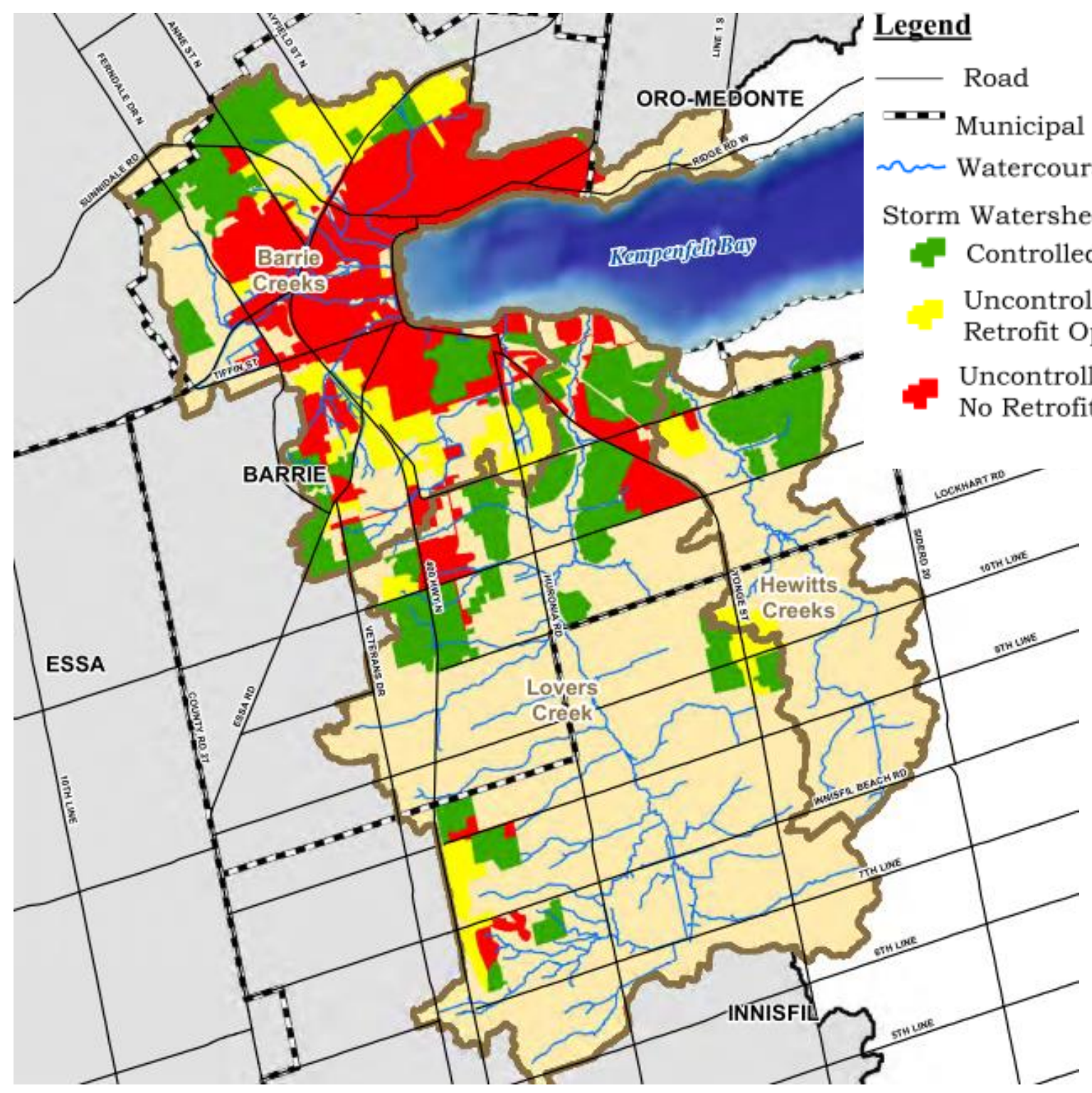

Figure 29: Lovers Creek Controlled \& Uncontrolled Areas (Lake Simcoe Regional Conservation Authority 2012)

The land uses within the Lovers Creek subwatershed consist of 35\% of natural heritage features, including forests, wetlands, and grasslands, 34\% agriculture and 21\% developed land (Lake Simcoe Region Conservation Authority 2012). Based on the 2012 subwatershed plan the Lovers Creek subwatershed met most water quality targets from a provincial standpoint however 
water quality degradation is occurring specifically relating to phosphorous concentrations (Lake Simcoe Region Conservation Authority 2012). From a water quantity perspective groundwater levels and stream flows have been increasing as a result of urbanization (Lake Simcoe Region Conservation Authority 2012)(Lake Simcoe Region Conservation Authority 2013). The aquatic environment includes a number of coldwater species such as mottled sculpin and brook trout with Lovers Creek considered one of the healthiest for sensitive aquatic species (Lake Simcoe Region Conservation Authority 2013).

\subsection{Lovers Creek Water Quality Targets \& Thresholds}

For the implementation of the water quality objective within the Lovers Creek subwatershed multi-site ECA targets were used from the developed framework parameters. The targets include; total phosphorous, nitrate, ammonia, BOD, dissolved oxygen, metals (iron, zinc, copper), turbidity, temperature, E.coli, chloride, and pH. For total phosphorous, nitrate, dissolved oxygen, turbidity, metals, temperature, and chloride thresholds, subwatershed specific baseline and threshold data was obtained from the Lovers Creek subwatershed plan, monitoring report cards, and the Lake Simcoe Protection Plan (Ministry of Environment, Ministry of Natural Resources 2009)(Lake Simcoe Region Conservation Authority 2012)(Lake Simcoe Region Conservation Authority 2013). For thresholds associated with ammonia, E.coli, and pH the Provincial Water Quality Objectives were selected. BOD was the only water quality parameter that would need additional baseline monitoring or supplementary monitoring to set the specific threshold.

A total of 25 monitoring stations were proposed throughout the Lovers Creek subwatershed and are shown in Figure 30. The monitoring stations were selected based on representative coverage of the subwatershed to collect data on the various streams within the subwatershed. The monitoring technologies for the various water quality targets are provided in Table 11 along with the monitoring frequency and sampling interval. 


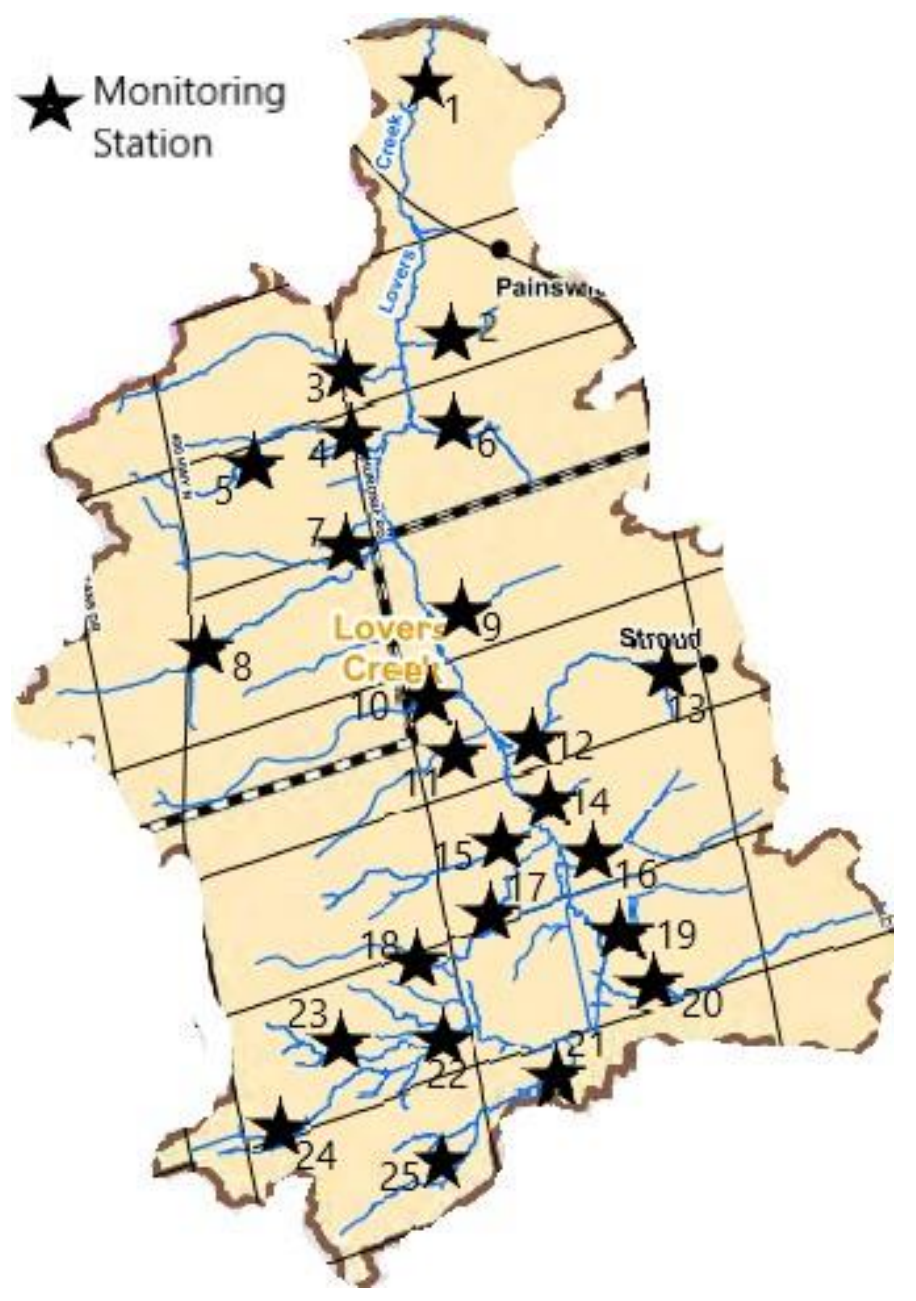

Figure 30: Lovers Creek Proposed Monitoring Station Locations

\subsection{Lovers Creek Water Quantity Targets and Thresholds}

The water quantity targets for the Lovers Creek multi-site ECA include; streamflow, baseflow, groundwater level, and percent change in flood plain, wetlands, and woodlots. A streamflow threshold of $0.712 \mathrm{~m}^{3} / \mathrm{sec}$ was selected based on the mean total flow from historical information provided within the subwatershed plan (Lake Simcoe Region Conservation Authority 2012). Baseflow thresholds ranged throughout the subwatershed. Baseflow information was gathered based on data available from the subwatershed plan. Figure 31 outlines the historical baseflow values throughout the subwatershed. The proposed monitoring stations from Figure 30 provide coverage for the various changes in baseflow. The groundwater level threshold of 222.2 mbgs represents the statics spring water level from the TW1/87 groundwater level observation well which is influenced by the Lovers Creek subwatershed (Lake Simcoe Region Conservation 
Authority 2012). As per the Lovers Creek Subwatershed Plan wetland coverage is currently at $16.8 \%$ (1009.3 ha) of the total subwatershed area (Lake Simcoe Region Conservation Authority 2012)(Lake Simcoe Region Conservation Authority 2013). Wetland and flood plain coverages were set at $0 \%$ change as the criteria for land use coverage is to maintain, preserve and restore. The current woodlot coverage for Lovers Creek is $26.7 \%$ (1601.6 ha) however the Lake Simcoe Conservation Authority maintains a threshold value of 25\% (Lake Simcoe Region Conservation Authority 2012). Currently Lovers Creek exhibits greater coverage than the proposed threshold with a $1.7 \%$ greater coverage of woodlot. Table 11 outlines the streamflow, baseflow, groundwater level, and percent change in flood plain, wetlands, and woodlot thresholds that will be set as part of the Lovers Creek multi-site permit.

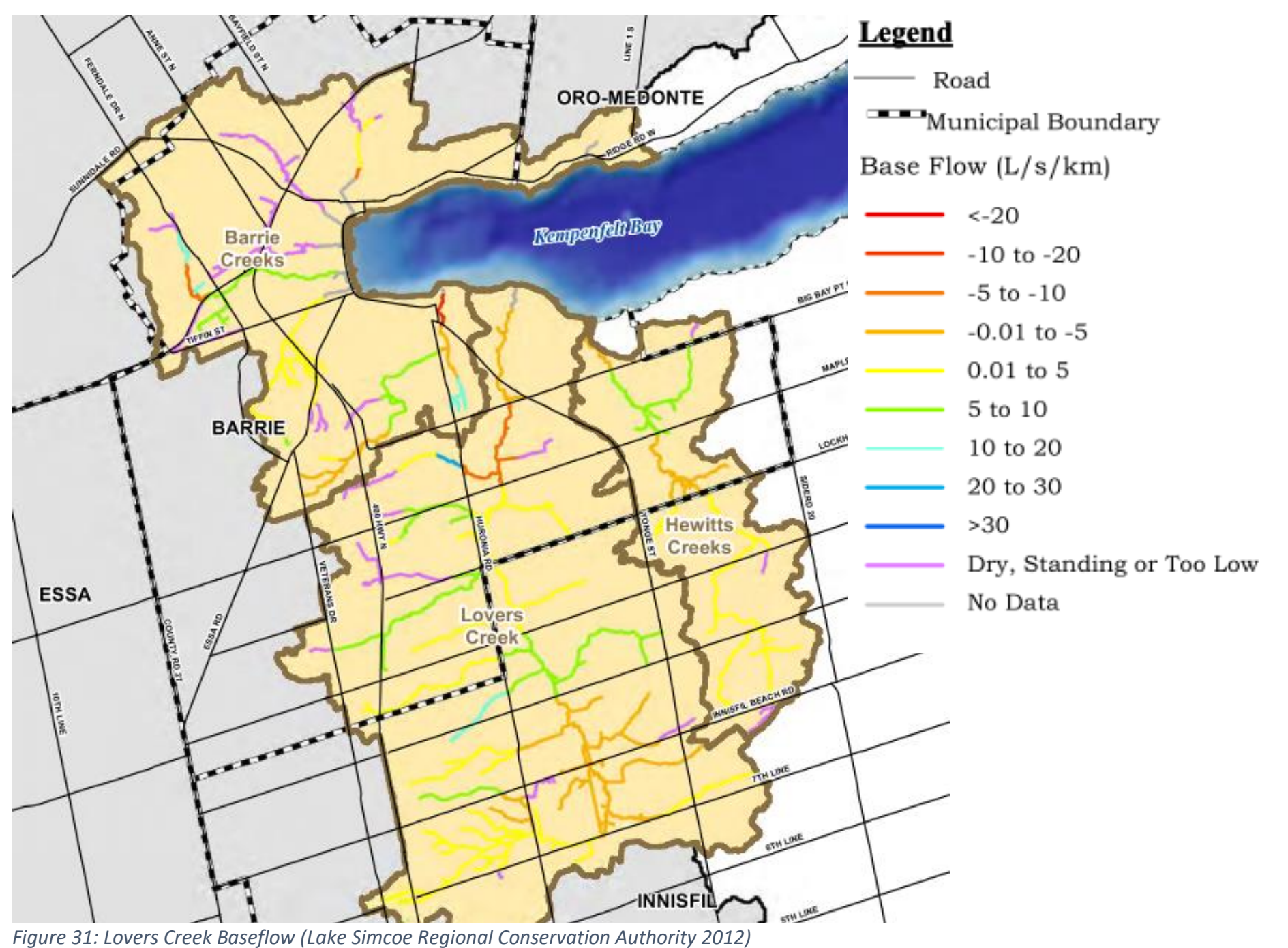




\subsection{Lovers Creek Stream Morphology Targets \& Thresholds}

The stream morphology targets for the Lovers Creek subwatershed include; percent change in stream-cross sections, number of channelized areas, and percent change in flood plain coverage. A lack of information relating to percent change in stream cross sections is available and will require an additional background study to set this threshold. For the channelized area target, there are currently 66 channelized areas in the Lovers Creek subwatershed. Development of additional channelized areas is restricted unless it is for flood relief, erosion control, fisheries protection, or the environmentally enhance the site (Lake Simcoe Region Conservation Authority 2012). Based on this information the threshold is set at 66 channelized areas for the Lovers Creek permit area. If additional areas are found a follow up investigation is required to ensure the conditions for adding channelized areas are met. A zero percent change in flood plain coverage is the set threshold for Lovers Creek. Near Real Time GIS and drone-based surveys are the proposed monitoring method for stream morphology monitoring. Table 11 includes the stream morphology targets and thresholds along with monitoring for the Lovers Creek permit area.

\subsection{Lovers Creek Terrestrial Environment Targets \& Thresholds}

The terrestrial environment targets for Lovers Creek include; percent change in natural vegetative and woodlot cover, percent change in naturalized riparian areas, percent change in wetland area, and percent change in shoreline. For the percent change in natural vegetative and wootlot cover Lovers Creek currently has $26.7 \%$ coverage with a Lake Simcoe Conservation Authority threshold of 25\% (Lake Simcoe Region Conservation Authority 2012). The threshold for this target will be set at $25 \%$ leaving a potential change of $1.7 \%$. Figure 32 outlines land use coverage for the Lovers Creek and surrounding area. Based on the baseline data available for the target of percent change in naturalized riparian areas and percent change in shoreline the threshold will be set at $71 \%$ of the $30 \mathrm{~m}$ Riparian Zone Buffer (Lake Simcoe Region Conservation Authority 2012). For the percent change in wetland cover the threshold will be set at $16.8 \%$ (1009.3 ha). These land use targets and thresholds will be monitored using near real time GIS and UAV technology where required. Table 11 includes the terrestrial environment targets and thresholds for the Lovers Creek permit areas 


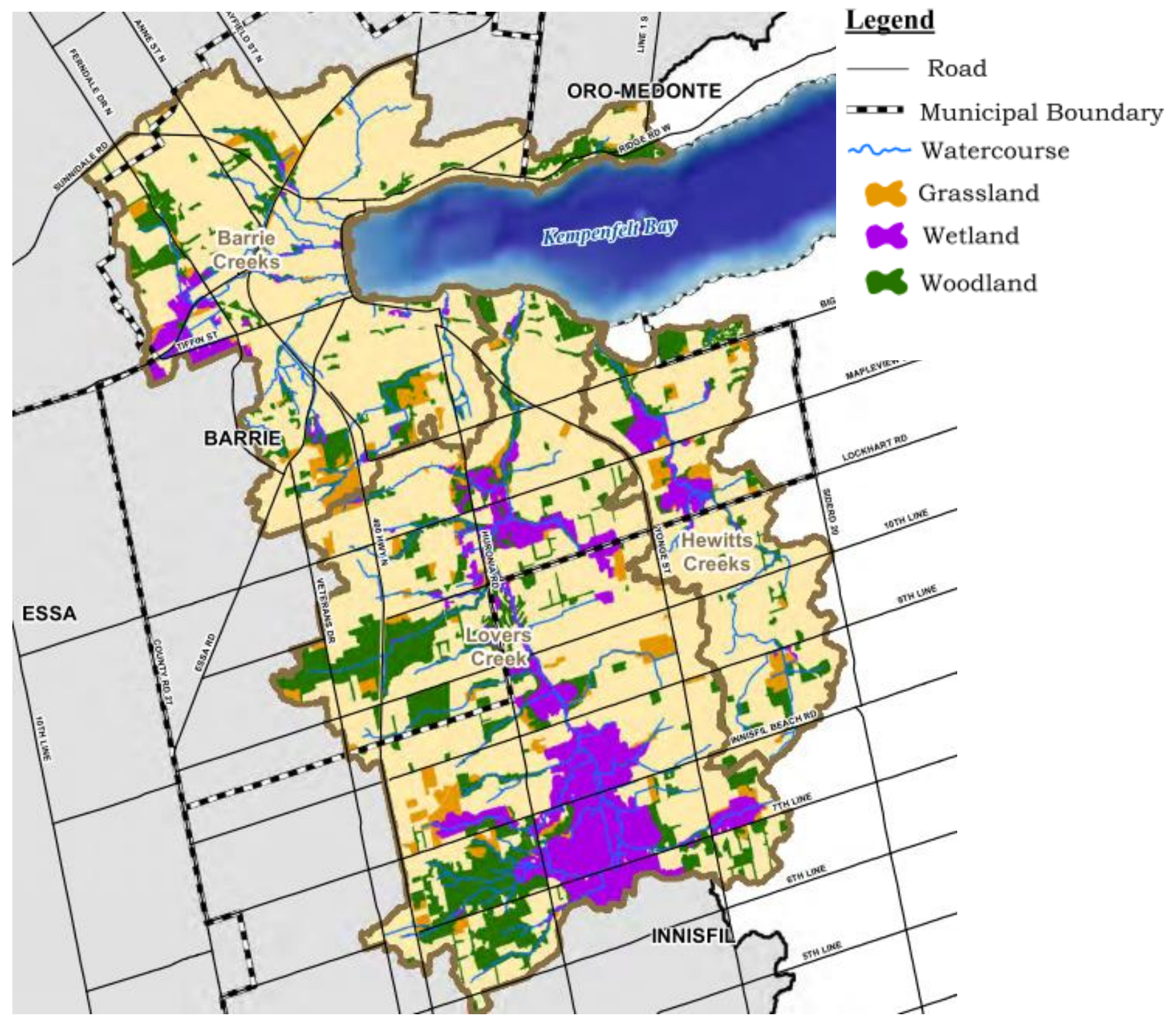

Figure 32: Lovers Creek Land Cover (Lake Simcoe Regional Conservation Authority 2012)

6.6. Lovers Creek Aquatic Environment Targets \& Thresholds

The aquatic environment targets for Lovers Creek include water quality targets as well as percent change in biodiversity and biomass density. Based on the Lovers Creek aquatic environment Brook Trout and Mottled Scuplin were the selected species for monitoring within the multi-site permit as they represent aquatic species that are highly sensitive to environmental changes within the subwatershed (Lake Simcoe Region Conservation Authority 2012). Currently monitoring for presence or absence of Brook Trout and Mottled Scuplin is carried out within the 
Lovers Creek subwatershed. Actual density numbers are not available but should be recorded within the monitoring carried out as part of the multi-site ECA. eDNA and aquatic field surveys are the preferred monitoring method for the aquatic environment targets and objectives. Figure 33 and 34 outline the historical and proposed monitoring locations for Brook Trout and Mottled Scuplin. Table 11 includes the aquatic environment targets and thresholds for the Lovers Creek permit area.

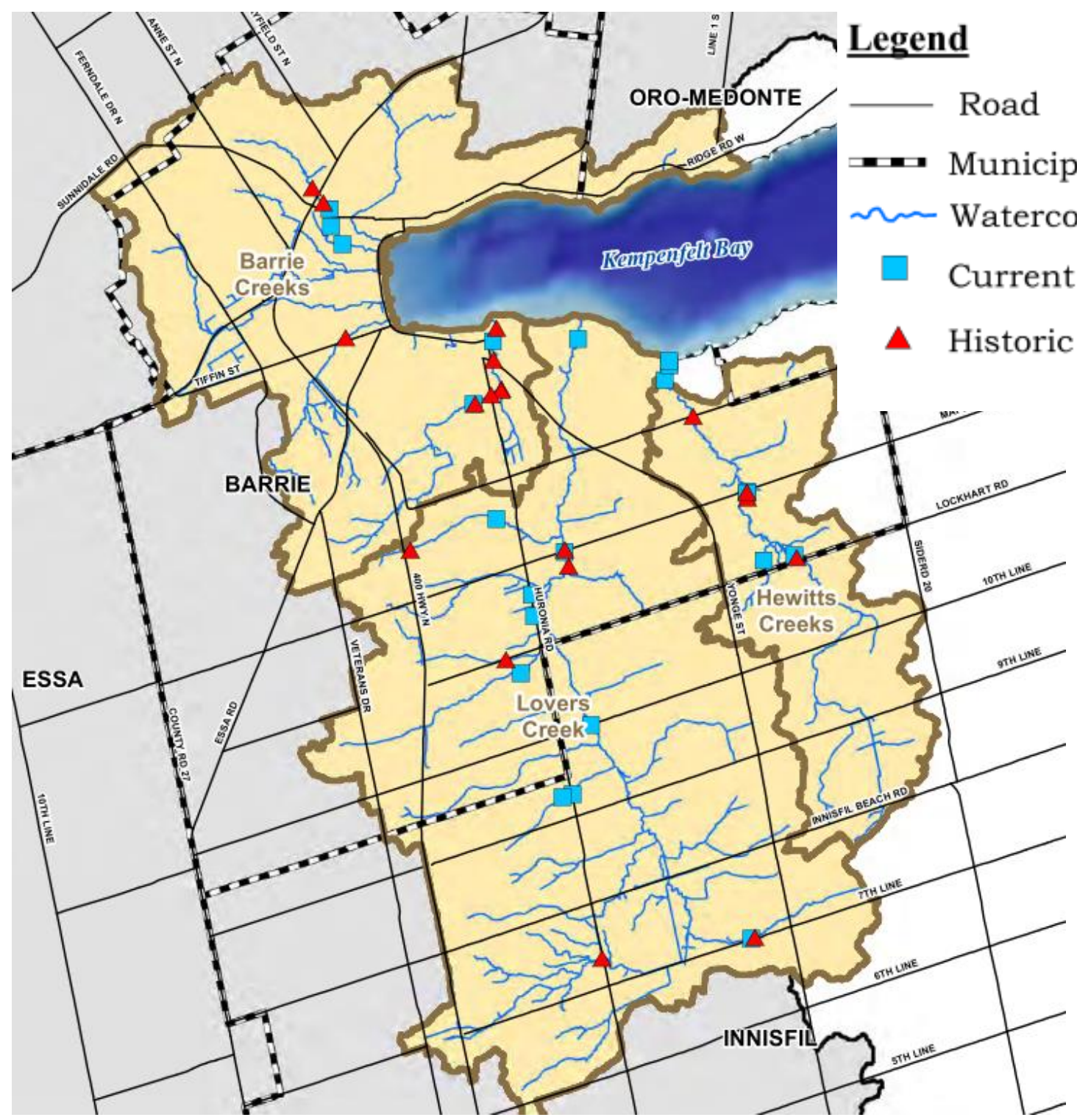

Figure 33: Historical and Proposed Brook Trout Monitoring Locations (Lake Simcoe Regional Conservation Authority 2012) 


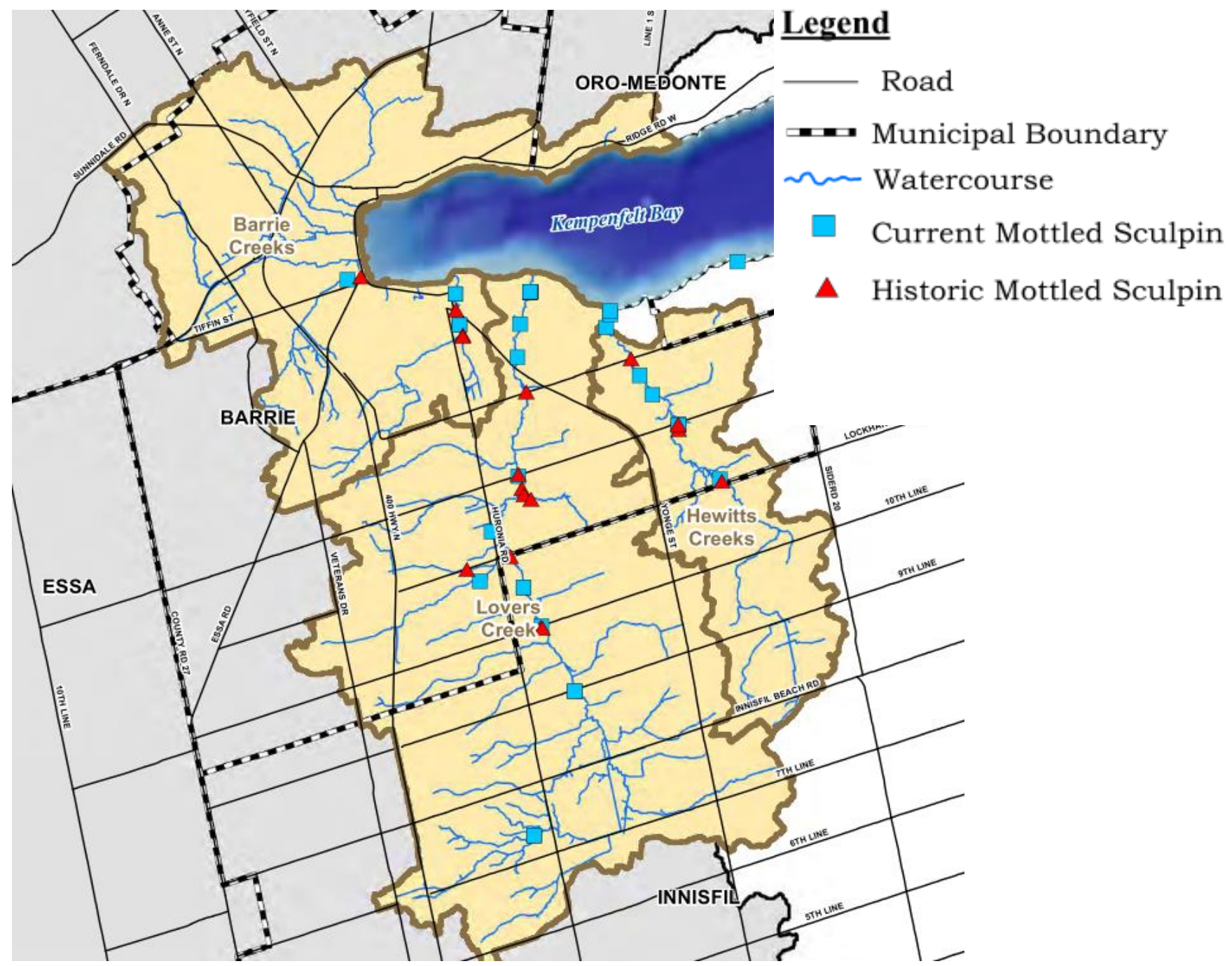

Figure 34: Historical and Proposed Mottled Sculpin Monitoring Locations (Lake Simcoe Regional Conservation Authority 2012) 
Lovers Creek Subwatershed Multi-Site ECA

\begin{tabular}{|c|c|c|c|c|c|c|}
\hline Objective & Criteria & Target & Threshold & Monitoring Technology & Monitoring Frequency & Monitoring/Sampling Interval \\
\hline \multirow{11}{*}{ Water Quality } & \multirow{11}{*}{$\begin{array}{l}\text { Improved Water } \\
\text { Quality }\end{array}$} & Total Phosphorus (mg/L) & $\begin{array}{l}\text { Historical } 65 \mathrm{mg} / \mathrm{L}(2006-2010) \\
\text { Proposed Threshold } 0.03 \mathrm{mg} / \mathrm{L}\end{array}$ & Hydrolab D5SX & Continuous/Remote Access & 5-minute Interval \\
\hline & & Nitrate $(\mathrm{mg} / \mathrm{L})$ & $\begin{array}{l}\text { Historical } 100 \mathrm{mg} / \mathrm{L}(2006-2010) \\
\text { Proposed Threshold } 2.9 \mathrm{mg} / \mathrm{L}\end{array}$ & Adafruit TCS34725 & Continuous/Remote Access & 5-minute Interval \\
\hline & & Ammonia (mg/L) & $20 \mu \mathrm{g} / \mathrm{L}-\mathrm{PWQO}$ & Hydrolab D5SX & Continuous/Remote Access & 5-minute Interval \\
\hline & & BOD (Total) & Additional Baseline Data Required & Hydrolab D5SX & \begin{tabular}{|l} 
Continuous/Remote Access \\
\end{tabular} & 5-minute Interval \\
\hline & & Dissolved Oxygen (mg/L) & $7 \mathrm{mg} / \mathrm{L}$ (LSPP) & $\begin{array}{l}\text { Gravity Analog Dissolved Oxygen } \\
\text { Sensor DFRobot }\end{array}$ & Continuous/Remote Access & 5-minute Interval \\
\hline & & Metals (mg/L) & $\begin{array}{l}\text { Historical Iron: } 65 \mathrm{ug} / \mathrm{L} \text { (2006 - 2010) } \\
\text { Proposed Threshold: } 300 \mathrm{ug} / \mathrm{L} \\
\text { Historical Zinc: } 100 \mathrm{ug} / \mathrm{L}(2006 \text { - 2010) } \\
\text { Proposed Threshold: } 20 \mathrm{ug} / \mathrm{L} \\
\text { Historical Copper: } 97 \mathrm{ug} / \mathrm{L}(2006 \text { - 2010) } \\
\text { Proposed Threshold: } 5 \mathrm{ug} / \mathrm{L}\end{array}$ & Discrete Sampling & Discrete Sampling & Quarterly \\
\hline & & TSS (Turbidity) (mg/L) & $\begin{array}{l}\text { Historical } 87 \mathrm{mg} / \mathrm{L}(2006-2010) \\
\text { Proposed Threshold } 30 \mathrm{mg} / \mathrm{L}\end{array}$ & $\begin{array}{l}\text { Gravity Analog Turbidity Sensor } \\
\text { DFRobot }\end{array}$ & Continuous/Remote Access & 5-minute Interval \\
\hline & & $\begin{array}{l}\text { Temperature (Degrees } \\
\text { Celsius) }\end{array}$ & $\begin{array}{l}\text { Cold water steam average maximum } \\
\text { water temperature } 14 \text { degrees celcius } \\
\text { (Monitoring Report 2013) }\end{array}$ & $\begin{array}{l}\text { Adafruit DS18B20 Digital } \\
\text { Temperature Sensor }\end{array}$ & Continuous/Remote Access & 5-minute Interval \\
\hline & & E.coli (cfu/100ml) & $100 \mathrm{cfu} / 100 \mathrm{~mL})-$ PWQO & Discrete Sampling & Discrete Sampling & Quarterly \\
\hline & & Chloride & $\begin{array}{l}\text { Historical } 67 \mathrm{mg} / \mathrm{L}(2006 \text { - 2010) } \\
\text { Threshold } 128 \mathrm{mg} / \mathrm{L}\end{array}$ & Hydrolab D5SX & Continuous/Remote Access & 5-minute Interval \\
\hline & & $\mathrm{pH}$ & $6.5-8.5-P W Q O$ & $\begin{array}{l}\text { AtlasScientific Environmental } \\
\text { Robotics EZO }{ }^{\mathrm{m}} \mathrm{pH} \text { Sensor }\end{array}$ & Continuous/Remote Access & 5-minute Interval \\
\hline \multirow{3}{*}{ Water Quantity } & $\begin{array}{l}\text { Maintain In-Stream } \\
\text { Flow Regimes }\end{array}$ & Stream Flow (m3/sec) & $0.712 \mathrm{~m} 3 / \mathrm{sec}$ & $\begin{array}{l}\text { Adafruit Optomax Digital Liquid } \\
\text { Level Sensor }\end{array}$ & Continuous/Remote Access & 5-minute Interval \\
\hline & \multirow[t]{2}{*}{$\begin{array}{l}\text { Maintain } \\
\text { Groundwater } \\
\text { Recharge \& Water } \\
\text { Balance }\end{array}$} & Base Flow $(\mathrm{L} / \mathrm{s} / \mathrm{km})$ & $\begin{array}{l}\text { Station } 1,14,15,16,17,19:-0.01--5 \\
\text { Station } 2,5: \text { Dry Standing } \\
\text { Station } 3,4:-10-20 \\
\text { Station } 6,7,9,18,20,21,22,24,25: 0.1- \\
5 \\
\text { Station } 8,10,11,12,13,23: 5-10\end{array}$ & $\begin{array}{l}\text { Adafruit Optomax Digital Liquid } \\
\text { Level Sensor }\end{array}$ & Continuous/Remote Access & 5-minute Interval \\
\hline & & Groundwater Level $(\mathrm{m})$ & 222.2 mbgs (Barrie City Centre Well) & $\begin{array}{l}\text { HolyKell Water Level Sensor/ } \\
\text { Adafruit Optomax Digital Liquid } \\
\text { Level Sensor }\end{array}$ & Continuous/Remote Access & Daily \\
\hline
\end{tabular}




\begin{tabular}{|c|c|c|c|c|c|c|}
\hline & & $\begin{array}{l}\text { \% Change in Flood Plain, } \\
\text { Wetlands, Woodlots }\end{array}$ & $\begin{array}{l}\text { Wetland: } 16.8 \% \text { (1009.3 ha) } \\
\text { Flood Plain: } 0 \% \text { change in flood plain } \\
\text { coverage } \\
\text { Woodlot: Current } 26.7 \% \text { (1601.6 ha) } \\
\text { 25\% (LSRCA Threshold) }\end{array}$ & NRT GIS & $\begin{array}{l}\text { NRT GIS \& Annual Field } \\
\text { Verification }\end{array}$ & As Available \\
\hline \multirow{3}{*}{$\begin{array}{l}\text { Stream } \\
\text { Morphology }\end{array}$} & \multirow[b]{2}{*}{$\begin{array}{l}\text { Limit Stream } \\
\text { Erosion and } \\
\text { Preserve Stream } \\
\text { Morphology }\end{array}$} & $\begin{array}{l}\% \text { Change in Stream } \\
\text { Cross-Sections }\end{array}$ & Additional Study Required & NRT GIS & $\begin{array}{l}\text { NRT/UAV \& Annual Field } \\
\text { Verification }\end{array}$ & $\begin{array}{l}\text { NRT: As Available } \\
\text { UAV: Annual }\end{array}$ \\
\hline & & \# of Channelized Areas & $\begin{array}{l}66 \text { Channelized Areas } \\
\text { Development Restricted (unless for flood } \\
\text { relief, erosion control, fisheries } \\
\text { protection, or to environmentally } \\
\text { enhance the site) }\end{array}$ & NRT GIS & $\begin{array}{l}\text { NRT GIS \& Annual Field } \\
\text { Verification }\end{array}$ & As Available \\
\hline & $\begin{array}{l}\text { Maintain and } \\
\text { Preserve Flood } \\
\text { Plains }\end{array}$ & \% Flood Plain Coverage & $0 \%$ change in flood plain coverage & NRT GIS & $\begin{array}{l}\text { NRT \& Annual Field } \\
\text { Verification }\end{array}$ & As Available \\
\hline \multirow{5}{*}{$\begin{array}{l}\text { Terrestrial } \\
\text { Environment }\end{array}$} & \multirow{2}{*}{$\begin{array}{l}\text { Preserve and } \\
\text { Restore Woodlots }\end{array}$} & $\begin{array}{l}\% \text { Change Natural } \\
\text { Vegetative \& Woodlot } \\
\text { Cover }\end{array}$ & $\begin{array}{l}\text { Current 26.7\% (1601.6 ha) } \\
\text { 25\% (LSRCA Threshold) }\end{array}$ & NRT GIS & $\begin{array}{l}\text { NRT \& Annual Field } \\
\text { Verification }\end{array}$ & As Available \\
\hline & & $\begin{array}{l}\text { \% Change in Naturalized } \\
\text { Riparian Areas }\end{array}$ & $71 \%$ of the $30 \mathrm{~m}$ Riparian Zone Buffer & NRT GIS & $\begin{array}{l}\text { NRT \& Annual Field } \\
\text { Verification } \\
\end{array}$ & As Available \\
\hline & \multirow{3}{*}{$\begin{array}{l}\text { Preserve and } \\
\text { Restore Wetlands }\end{array}$} & $\begin{array}{l}\text { \% Change in Naturalized } \\
\text { Riparian Areas }\end{array}$ & $71 \%$ of the $30 \mathrm{~m}$ Riparian Zone Buffer & NRT GIS & \begin{tabular}{|l} 
NRT \& Annual Field \\
Verification \\
\end{tabular} & As Available \\
\hline & & $\begin{array}{l}\% \text { Change in Wetland } \\
\text { Area }\end{array}$ & Wetland $16.8 \%$ (1009.3 ha) & NRT GIS & $\begin{array}{l}\text { NRT \& Annual Field } \\
\text { Verification } \\
\end{array}$ & As Available \\
\hline & & $\%$ Change in Shoreline & $\begin{array}{l}\text { 30m width along watercourses (71\% } \\
\text { currently unconvered) }\end{array}$ & NRT GIS & $\begin{array}{l}\text { NRT \& Annual Field } \\
\text { Verification } \\
\end{array}$ & As Available \\
\hline \multirow[b]{2}{*}{$\begin{array}{l}\text { Aquatic } \\
\text { Environment }\end{array}$} & $\begin{array}{l}\text { Improve Water } \\
\text { Quality }\end{array}$ & $\begin{array}{l}\text { Refer to Water Quality } \\
\text { Targets }\end{array}$ & Refer to Water Quality Targets & $\begin{array}{l}\text { Refer to Water Quality } \\
\text { Monitoring }\end{array}$ & $\begin{array}{l}\text { Refer to Water Quality } \\
\text { Monitoring }\end{array}$ & Refer to Water Quality Monitoring \\
\hline & $\begin{array}{l}\text { Maintain and } \\
\text { Promote Species } \\
\text { Biodiversity and } \\
\text { Biomass Density }\end{array}$ & $\begin{array}{l}\text { \% Change in Biodiversity } \\
\& \text { Biomass Density }\end{array}$ & $\begin{array}{l}\text { \% Density/Presence Absence of Brook } \\
\text { Trout } \\
\text { \% Density/Presence Absence of Mottled } \\
\text { Scuplin }\end{array}$ & Aquatic Field Surveys/eDNA & Aquatic Specie Specific & Annual \\
\hline
\end{tabular}




\section{Conclusions and Recommendations}

\subsection{Multi-Site ECA Framework and Monitoring Requirements}

Development of the multi-site ECA framework parameters was carried out based on their connection with stormwater management and their ability to be effectively monitored. The summary of the Framework for Multi-Site Stormwater Environmental Compliance Approvals is available in Table 12. The framework identifies the proposed objectives of water quality, water quantity, stream morphology, terrestrial environment, and aquatic environment. Within each objective are a subsect of criteria that have associated targets and thresholds that support the function of a multi-site ECA system. For setting thresholds specific to a given permit area, a comprehensive subwatershed plan is required. Background information such as monitoring reports, watershed report cards, or other supplementary information is required to set permit specific thresholds. In the Lovers Creek framework simulation, thresholds were gathered from the comprehensive subwatershed plan as well as background monitoring data. Where data gaps for threshold development still exist the methods for how the WFD determines reference conditions or thresholds should be used. In the multi-site ECA system the municipality would be responsible for developing and designing the monitoring plan in accordance with the framework parameters. The MECP would still be responsible for approving and issuing the multi-site ECA. The MECP would also be responsible for the enforcement and compliance of a multi-site permit.

While traditional monitoring techniques provide reliable data, they can also become logistically and cost prohibitive for inclusion within a multi-site ECA monitoring network. The proposed monitoring techniques were selected through an evaluation of traditional versus alternative monitoring techniques. Traditional monitoring techniques for sensor-based measurements were evaluated for their current deployment in the field for watershed monitoring. These sensors are proprietary in nature and considered industry standard sensors for monitoring environmental parameters. Alternative monitoring technologies were screened based on a developed evaluation criterion which screened the technologies for inclusion in the framework. 
Out of the 12 sensor-based targets, 4 traditional monitoring techniques were selected, with the primary sensor being the Hydrolab D5SX. The remaining 8 sensor-based parameters, alternative monitoring techniques are proposed. The open source sensors include a variety of sensors available from DFRobot ${ }^{\circledR}$, Adafruit $^{\circledR}$, AtlasScientific $^{\circledR}$, and HolyKell ${ }^{\circledR}$. These sensors have available open source code that can be installed on open source microcontrollers available from manufacturers such as Arduino ${ }^{\circledR}$, SparkFun Electronics ${ }^{\circledR}$, and Raspberry $\mathrm{Pi}^{\mathrm{TM}}$. Prior to the deployment of the alternative monitoring techniques extensive bench scale and pilot scale testing is required to determine accuracy and robustness for environmental field monitoring. A key consideration will be if the sensors can withstand Ontario's variable climate. As open source sensors continue to develop the 4 proposed traditional monitoring techniques could be converted to alternative open source monitoring options. Continual evaluation is required to identify and test new open source sensor options that are released to the open source market.

For framework parameters that do not rely on field sensors to collect information traditional and alternative monitoring techniques were evaluated. The primary difference between the traditional and alternative options is the possibility of converting GIS information into an NRT GIS system. An NRT GIS system presents the possibility of obtaining data related to land use change in near real time. Where GIS cannot provide the measurement accuracy UAV technologies should be implemented to supplement GIS data. eDNA was evaluated as part of the aquatic environment objective however given the status of the technology field surveys for monitoring this objective is still required. Similarly, to sensor-based monitoring, continual evaluation of eDNA is required understand if eDNA technology improves to a point where implementation is possible.

All monitoring data is proposed to be structured within an IIS. The IIS is to act as the single point of access for permit information. The IIS will help with compliance reporting and monitoring in effort to reduce the administrative burden on the MECP. Where applicable and technically feasible, information is to be reported continuously with remote access available through the IIS. Where real time monitoring is not applicable other monitoring frequencies are outlined with the condition that the information is stored within the same IIS. The development of the IIS and overall monitoring platform will require substantial development prior to implementation. Initial 
investment in the development of the platform will be required however once developed it will allow for greater scalability for new permits.

The implementation of a multi-site ECA permitting structure can be feasible with the current state of technology. For non-sensor-based monitoring, NRT GIS and UAV technology can provide a solution for limiting field surveys while providing more proactive approaches to environmental management. With the advancements in open source sensors and publicly available source codes the prospect of mass deployment of IOT sensors throughout Ontario's watersheds for multi-site monitoring is a real possibility. 
Framework for Multi-Site Stormwater Environmental Compliance Approvals

\begin{tabular}{|c|c|c|c|c|c|c|}
\hline \multicolumn{7}{|c|}{ Framework for Multi-Site Stormwater Environmental Compliance Approvals } \\
\hline Proposed Objective & Proposed Criteria & Proposed Target & Proposed Threshold & $\begin{array}{l}\text { Proposed Monitoring } \\
\text { Techniques }\end{array}$ & Proposed Monitoring Frequency & Monitoring/Sampling Interval \\
\hline \multirow{11}{*}{ Water Quality } & \multirow{11}{*}{$\begin{array}{l}\text { Improved Water } \\
\text { Quality }\end{array}$} & Total Phosphorus (mg/L) & $\begin{array}{l}20 \mu \mathrm{g} / \mathrm{L} \text { (Ice Free Period) - PWQO } 10 \\
\mu \mathrm{g} / \mathrm{L} \text { (High Level Protection Ice Free } \\
\text { Period) - PWQO } \\
30 \mu \mathrm{L} / \mathrm{L} \text { (Rivers and Streams) }\end{array}$ & Hydrolab D5SX & Continuous/Remote Access & 5-minute Interval \\
\hline & & Nitrate $(\mathrm{mg} / \mathrm{L})$ & $\begin{array}{l}\text { Subwatershed specific, baseline or } \\
\text { historical data required }\end{array}$ & Adafruit TCS34725 & Continuous/Remote Access & 5-minute Interval \\
\hline & & Ammonia (mg/L) & $20 \mu \mathrm{g} / \mathrm{L}-\mathrm{PWQO}$ & Hydrolab D5SX & Continuous/Remote Access & 5-minute Interval \\
\hline & & BOD (Total) & $\begin{array}{l}\text { Subwatershed specific, baseline or } \\
\text { historical data required }\end{array}$ & Hydrolab D5SX & Continuous/Remote Access & 5-minute Interval \\
\hline & & Dissolved Oxygen (mg/L) & Note 1 & $\begin{array}{l}\text { Gravity Analog Dissolved } \\
\text { Oxygen Sensor DFRobot }\end{array}$ & Continuous/Remote Access & 5-minute Interval \\
\hline & & Metals (mg/L) & $\begin{array}{l}\text { Compound specific metal speciation } \\
\text { required) - PWQO, subwatershed } \\
\text { specific, baseline, or historical data }\end{array}$ & Discrete Sampling & Discrete Sampling & Quarterly \\
\hline & & TSS (Turbidity) (mg/L) & $\begin{array}{l}+10 \% \text { change of the natural Secchi disc } \\
\text { reading - PWQO }\end{array}$ & $\begin{array}{l}\text { Gravity Analog Turbidity } \\
\text { Sensor DFRobot }\end{array}$ & Continuous/Remote Access & 5-minute Interval \\
\hline & & Temperature (Degrees Celsius) & $\begin{array}{l}\text { Natural thermal regime of any body of } \\
\text { water shall not be altered as to impair } \\
\text { the quality of the natural environment } \\
\text { - PWQO, subwatershed specific, } \\
\text { baseline or historical data required }\end{array}$ & $\begin{array}{l}\text { Adafruit DS18B20 Digital } \\
\text { Temperature Sensor }\end{array}$ & Continuous/Remote Access & 5-minute Interval \\
\hline & & E.coli (cfu/100ml) & $100 \mathrm{cfu} / 100 \mathrm{~mL})-P W Q O$ & Discrete Sampling & Discrete Sampling & Quarterly \\
\hline & & Chloride (ppm) & $2 \mu \mathrm{g} / \mathrm{L}-\mathrm{PWQO}$ & Hydrolab D5SX & Continuous/Remote Access & 5-minute Interval \\
\hline & & $\mathrm{pH}$ & $6.5-8.5-P W Q O$ & $\begin{array}{l}\text { AtlasScientific } \\
\text { Environmental Robotics } \\
\text { EZO }{ }^{\mathrm{TM}} \mathrm{pH} \text { Sensor }\end{array}$ & Continuous/Remote Access & 5-minute Interval \\
\hline \multirow{3}{*}{ Water Quantity } & $\begin{array}{l}\text { Maintain In- } \\
\text { Streamflow Regimes }\end{array}$ & Streamflow (m3/sec) & $\begin{array}{l}\text { Subwatershed specific, baseline or } \\
\text { historical data required }\end{array}$ & $\begin{array}{l}\text { Adafruit Optomax Digital } \\
\text { Liquid Level Sensor }\end{array}$ & Continuous/Remote Access & 5-minute Interval \\
\hline & \multirow{2}{*}{$\begin{array}{l}\text { Maintain } \\
\text { Groundwater } \\
\text { Recharge \& Water } \\
\text { Balance }\end{array}$} & Baseflow $(\mathrm{m} 3 / \mathrm{sec})$ & $\begin{array}{l}\text { Subwatershed specific, baseline or } \\
\text { historical data required }\end{array}$ & $\begin{array}{l}\text { Adafruit Optomax Digital } \\
\text { Liquid Level Sensor }\end{array}$ & Continuous/Remote Access & 5-minute Interval \\
\hline & & Groundwater Level $(\mathrm{m})$ & $\begin{array}{l}\text { Subwatershed specific, baseline or } \\
\text { historical data required }\end{array}$ & $\begin{array}{l}\text { HolyKell Water Level } \\
\text { Sensor/ Adafruit } \\
\text { Optomax Digital Liquid } \\
\text { Level Sensor }\end{array}$ & Continuous/Remote Access & Daily \\
\hline
\end{tabular}




\begin{tabular}{|c|c|c|c|c|c|c|}
\hline & & $\begin{array}{l}\text { \% Change in Flood Plain, Wetlands, } \\
\text { Woodlots }\end{array}$ & $\begin{array}{l}\text { Subwatershed specific, baseline or } \\
\text { historical data required }\end{array}$ & NRT GIS & $\begin{array}{l}\text { NRT GIS \& Annual Field } \\
\text { Verification }\end{array}$ & As Available \\
\hline \multirow{3}{*}{ Stream Morphology } & \multirow{2}{*}{$\begin{array}{l}\text { Limit Stream Erosion } \\
\text { and Preserve Stream } \\
\text { Morphology }\end{array}$} & \% Change in Stream Cross-Sections & $\begin{array}{l}\text { Subwatershed specific, baseline or } \\
\text { historical data required }\end{array}$ & NRT GIS & NRT \& Annual Field Verification & $\begin{array}{l}\text { NRT: As Available } \\
\text { UAV: Annual }\end{array}$ \\
\hline & & \% Change in Channelization & $\begin{array}{l}\text { Subwatershed specific, baseline or } \\
\text { historical data required }\end{array}$ & NRT GIS & $\begin{array}{l}\text { NRT GIS \& Annual Field } \\
\text { Verification }\end{array}$ & As Available \\
\hline & $\begin{array}{l}\text { Maintain and } \\
\text { Preserve Flood Plains }\end{array}$ & \% Flood Plain Coverage & $\begin{array}{l}\text { Subwatershed specific, baseline or } \\
\text { historical data required }\end{array}$ & NRT GIS & NRT \& Annual Field Verification & As Available \\
\hline \multirow{5}{*}{$\begin{array}{l}\text { Terrestrial } \\
\text { Environment }\end{array}$} & \multirow{2}{*}{$\begin{array}{l}\text { Preserve and Restore } \\
\text { Woodlots }\end{array}$} & $\begin{array}{l}\% \text { Change Natural Vegetative \& } \\
\text { Woodlot Cover }\end{array}$ & $\begin{array}{l}\text { Subwatershed specific, baseline or } \\
\text { historical data required }\end{array}$ & NRT GIS & NRT \& Annual Field Verification & As Available \\
\hline & & $\begin{array}{l}\text { \% Change in Naturalized Riparian } \\
\text { Areas }\end{array}$ & $\begin{array}{l}\text { Subwatershed specific, baseline or } \\
\text { historical data required }\end{array}$ & NRT GIS & NRT \& Annual Field Verification & As Available \\
\hline & \multirow{3}{*}{$\begin{array}{l}\text { Preserve and Restore } \\
\text { Wetlands }\end{array}$} & $\begin{array}{l}\text { \% Change in Naturalized Riparian } \\
\text { Areas }\end{array}$ & $\begin{array}{l}\text { Subwatershed specific, baseline or } \\
\text { historical data required }\end{array}$ & NRT GIS & NRT \& Annual Field Verification & As Available \\
\hline & & $\%$ Change in Wetland Area & $\begin{array}{l}\text { Subwatershed specific, baseline or } \\
\text { historical data required }\end{array}$ & NRT GIS & NRT \& Annual Field Verification & As Available \\
\hline & & $\%$ Change in Shoreline & $\begin{array}{l}\text { Subwatershed specific, baseline or } \\
\text { historical data required }\end{array}$ & NRT GIS & NRT \& Annual Field Verification & As Available \\
\hline \multirow[b]{2}{*}{ Aquatic Environment } & $\begin{array}{l}\text { Improve Water } \\
\text { Quality }\end{array}$ & Refer to Water Quality Targets & Refer to Water Quality Targets & $\begin{array}{l}\text { Refer to Water Quality } \\
\text { Monitoring }\end{array}$ & Refer to Water Quality Monitoring & Refer to Water Quality Monitoring \\
\hline & $\begin{array}{l}\text { Maintain and } \\
\text { Promote Species } \\
\text { Biodiversity and } \\
\text { Biomass Density }\end{array}$ & $\begin{array}{l}\% \text { Change in Biodiversity \& Biomass } \\
\text { Density }\end{array}$ & $\begin{array}{l}\text { Subwatershed specific, baseline or } \\
\text { historical data required }\end{array}$ & $\begin{array}{l}\text { Aquatic Field } \\
\text { Surveys/eDNA }\end{array}$ & Aquatic Specie Specific & Annual \\
\hline
\end{tabular}

\section{Note 1:}

\begin{tabular}{|l|l|l|l|l|}
\hline \multicolumn{5}{|l|}{ Dissolved Oxygen Concentration } \\
\hline Temperature ${ }^{\circ} \mathrm{C}$ & $\begin{array}{l}\text { Cold Water Biota: } \\
\% \text { Saturation }\end{array}$ & $\begin{array}{l}\text { Cold Water Biota: } \\
\mathrm{mg} / \mathrm{L}\end{array}$ & $\begin{array}{l}\text { Warm Water } \\
\text { Biota: \% } \\
\text { Saturation }\end{array}$ & $\begin{array}{l}\text { Warm Water } \\
\text { Biota: } \mathrm{mg} / \mathrm{L}\end{array}$ \\
\hline 0 & 54 & 8 & 47 & 7 \\
\hline 5 & 54 & 7 & 47 & 6 \\
\hline 10 & 54 & 6 & 47 & 5 \\
\hline 15 & 54 & 6 & 47 & 5 \\
\hline 20 & 57 & 5 & 47 & 4 \\
\hline 25 & 63 & 5 & 48 & 4 \\
\hline
\end{tabular}




\subsection{Future Research}

Prior to the implementation of a multi-site ECA permitting system a substantial amount of additional research is required. Although there are examples of watershed-based regulations from other regions, a compliance and governance framework for a multi-site stormwater ECA system is required. Defining how compliance will be evaluated and enforced will need to be developed for the stakeholders who will be responsible for the permit's compliance. The stakeholders will need to understand the overall permitting process prior to accepting a multisite ECA. The MECP will need to develop a support system of government resources, consultants, and industry expert groups that can provide support effective management of a permit. This support system will need to assist with tasks such as stormwater design reviews, monitoring implementation, and mitigation/corrective actions. A collaborative approach to stormwater management will benefit the implementation of a multi-site ECA system.

A framework for non-compliance is required. Within the Water Framework Directive fines may be issued for non-compliance and could be used as a model for Ontario (Priestley 2015) Based on the WFD non-compliance. This research should focus on if non-compliance will result in financial penalties or if it will focus on correction/mitigative action.

As discussed within this research there is a lack of consistent approach to threshold development within watershed and subwatershed plans. A guidance document to assist with the development of permit specific thresholds is required prior to implementation. Similar to noncompliance threshold developed has been established through the WFD. Under the WFD thresholds are set at a slight deviation from a reference condition determined through:

1. Identifying minimally impacted receiving waters similar in nature;

2. Reviewing historical data which represents a pristine water course;

3. The use of predictive models; and,

4. Expert judgement.

This type of threshold model could be the basis for future research related to threshold setting within the Ontario based system. 
Further research relating to the open source technology proposed as part of this research will be required. Subsequently, development of an IIS architecture that can handle the data volume and visualization components will be required. Developing the IIS architecture in advance of a change in the ECA system will be required to ensure a consistent approach to data management. 


\section{Appendix A}

Example of Current Environmental Compliance Approval 
Melanie Construction Inc.

900 Route 500

Russell, Ontario

K4R 1E5

Site Location

Patenaude East Subdivision, Embrun

Lot 7, Concession 7

Township of Russell, United Counties of Prescott and Russell

You have applied under section 20.2 of Part II. 1 of the Environmental Protection Act. R.S. O. 1990, c. E. 19

(Environmental Protection Act) for approval of:

establishment of wastewater infrastructure to be constructed to service the approximately 42 hectare Patenaude East residential subdivision development, located east of St. Marie Street, south of the Castor River and Park Lane in the Township of Russell, including stormwater management facilities for the collection, treatment and disposal of stormwater run-off from the development, to provide Enhanced Level water quality control and erosion protection, and to attenuate post-development peak flows to pre-development levels for all storm events up to and including the 100 -year storm event, discharging to the Castor River and the Ottawa River, consisting of the following:

sanitary sewers on Streets 1 to 10 within the Patenaude East subdivision and on Park Lane, connecting to a proposed sanitary sewage pumping station, identified below;

sanitary sewage pumping station located north of the subdivision on the east side of St. Marie Street on the banks of the Castor River, consisting of a wet well, a diesel generator, and a control building, connecting to a proposed $300 \mathrm{~mm}$ diameter forcemain, identified below, complete with:

- one (1) $6.15 \mathrm{~m}$ by $3.00 \mathrm{~m}$ prefabricated wet well having two inlet pipes,

- up to two (2) submersible duty pumps and one (1) submersible stand-by pump capable of operating at $132.0 \mathrm{~L} / \mathrm{s}$ at full capacity with a total dynamic head of $59.6 \mathrm{~m}$,

- float control assembly for high/low pump control and alarms,

- one (1) Cummings diesel generator (to be registered in the Environmental Activity and Sector Registry by the Owner), - all other controls, electrical equipment, instrumentation, piping, plumbing, valves and appurtenances essential for the proper operation of the aforementioned sewage pumping station;

sanitary sewage forcemain: - approximately $5,700 \mathrm{~m}$ of $300 \mathrm{~mm}$ diameter sanitary sewage forcemain along St. Marie Street, Route 400 and St. Joseph Road, connecting the proposed sanitary sewage pumping station, identified above, to the existing sewage lagoons located on Route 400, east of St. Joseph Road;

storm sewers on Streets 1 to 10 within the Patenaude East subdivision and on Park Lane, discharging to a proposed stormwater management facility, identified below;

stormwater management facility (catchment area 41.73 hectares): - a wet pond located south of Park Lane, east of St. Marie Street, with a sediment forebay, having a permanent pool volume of $5,379 \mathrm{~m}^{3}$, an extended detention volume of $1,669 \mathrm{~m}^{3}$, and a total storage volume of $17,085 \mathrm{~m}^{3}$, including the permanent pool volume, at a total depth of approximately $4.3 \mathrm{~m}$, discharging via a $1200 \mathrm{~mm}$ diameter outlet pipe to the north and re-graded Swale B to the Castor River;

including erosion/sedimentation control measures during construction and all other controls and appurtenances essential for the proper operation of the aforementioned Works; 


\section{CONTENT COPY OF ORIGINAL}

all in accordance with the submitted supporting documents listed in Schedule "A" forming part of this Approval

For the purpose of this environmental compliance approval, the following definitions apply:

"Approval" means this entire document including the application and any supporting documents listed in any schedules in this Approval;

"Director" means a person appointed by the Minister pursuant to section 5 of the Environmental Protection Act for the purposes of Part II. 1 of the Environmental Protection Act;

"District Manager" means the District Manager of the Comwall office of the Ministry,

"Ministry" means the ministry of the government of Ontario responsible for the Environmental Protection Act and the Ontario Water Resources Act and includes all officials, employees or other persons acting on its behalf,

"Owner" means Melanie Construction Inc. and includes their successors and assignees;

"Source Protection Plan" means a drinking water source water protection plan prepared under the Clean Water Act, 2006;

"Water Supervisor" means the Water Supervisor of the Kingston and Ottawa-Conwall offices of the Ministry,

"Works" means the sewage works described in the Owner's application(s) and this Approval.

You are hereby notified that this environmental compliance approval is issued to you subject to the terms and conditions outlined below:

\section{TERMS AND CONDITIONS}

\section{GENERAL PROVISIONS}

(1) The Owner shall ensure that any person authorized to carry out work on or operate any aspect of the Works is notified of this Approval and the Conditions herein and shall take all reasonable measures to ensure any such person complies with the same.

(2) Except as otherwise provided by these Conditions, the Owner shall design, build, install, operate and maintain the Works in accordance with the description given in this Approval, and the application for approval of the Works.

(3) Where there is a conflict between a provision of any submitted document referred to in this Approval and the Conditions of this Approval, the Conditions in this Approval shall take precedence, and where there is a conflict between the listed submitted documents, the document bearing the most recent date shall prevail.

(4) Where there is a conflict between the listed submitted documents, and the application, the application shall take precedence unless it is clear that the purpose of the document was to amend the application.

(5) The Conditions of this Approval are severable. If any Condition of this Approval, or the application of any requirement of this Approval to any circumstance, is held invalid or unenforceable, the application of such Condition to other circumstances and the remainder of this Approval shall not be affected thereby.

(6) The issuance of, and compliance with the Conditions of this Approval does not:

(a) relieve any person of any obligation to comply with any provision of any applicable statute, regulation or other legal requirement, including, but not limited to, the obligation to obtain approval from the local conservation authority necessary to construct or operate the sewage Works; or

(b) limit in any way the authority of the Ministry to require certain steps be taken to require the Owner to fumish any further information related to compliance with this Approval 


\section{CONTENT COPY OF ORIGINAL}

(7) This Approval includes the treatment and disposal of stormwater nu-off from the approximately 368 single family homes, 76 townhouse units and 235 apartment/condo units (41.73 hectare) residential development located east of St. Marie Street, south of Park Lane, draining to Swale B and the Castor River, assuming an average imperviousness of $46 \%$. Any development changes within the total drainage area that might increase the required storage volumes or increase the flows to or from the wet pond or any structural/physical changes to the wet pond including the inlets or outlets will require an amendment to this Approval.

\section{EXPRY OE APRROVAL}

This Approval will cease to apply to those parts of the Works which have not been constructed within five (5) years of the date of this Approval.

\section{CHANGE OF OWNER}

(1) The Owner shall notify the District Manager and the Director, in writing, of any of the following changes within thirty

(30) days of the change occurring:

(a) change of Owner,

(b) change of address of the Owner,

(c) change of partners where the Owner is or at any time becomes a partnership, and a copy of the most recent declaration filed under the Business Names Act, R.S.O. 1990, c. B17 shall be included in the notification to the District Manager;

(d) change of name of the corporation where the Owner is or at any time becomes a corporation, and a copy of the most current information filed under the Corporations Information.Act. R.S.O. 1990, c. C39 shall be included in the notification to the District Manager.

(2) In the event of any change in ownership of the Works, other than a change in ownership to the municipal, i.e. assumption of the Works, the Owner shall notify the succeeding owner in writing of the existence of this Approval, and a copy of such notice shall be forwarded to the District Manager and the Director.

(3) Notwithstanding any other requirements in this Approval, upon transfer of the ownership of the Works to a municipality, if applicable, any reference to the "District Manager" within the Terms and Conditions of this Approval shall be replaced with "Water Supervisor".

\section{OPERATION AND MAINTENANCE}

(1) The Owner shall ensure that the design minimum liquid retention volume is maintained at all times.

(2) The Owner shall inspect the Works at least once a year and, if necessary, clean and maintain the Works to prevent the excessive build-up of sediments and/or vegetation.

(3) The Owner shall maintain a logbook to record the results of these inspections and any cleaning and maintenance operations undertaken, and shall keep the logbook at the Owner's office for inspection by the Ministry. The logbook shall include the following:

(a) the name of the Works; and

(b) the date and results of each inspection, maintenance and cleaning, including an estimate of the quantity of any materials removed.

\section{IEMPORARY EROSION AND SEDIMENT CONIROL}

(1) The Owner shall install and maintain temporary sediment and erosion control measures during construction and conduct inspections once every two (2) weeks and after each significant storm event (a significant storm event is defined 


\section{CONTENT COPY OF ORIGINAL}

as a minimum of $25 \mathrm{~mm}$ of rain in any 24 hours period). The inspections and maintenance of the temporary sediment and erosion control measures shall continue until they are no longer required and at which time they shall be removed and all disturbed areas reinstated properly.

(2) The Owner shall maintain records of inspections and maintenance which shall be made available for inspection by the Ministry, upon request. The record shall include the name of the inspector, date of inspection, and the remedial measures, if any, undertaken to maintain the temporary sediment and erosion control measures.

\section{RECORD KEEPING}

The Owner shall retain for a minimum of five (5) years from the date of their creation, all records and information related to or resulting from the operation and maintenance activities required by this Approval.

\section{SOURCEPROTECTION}

The Owner shall, within sixty (60) calendar days of the Minister of the Environment posting approval of a Source Protection Plan on the environmental registry established under the Environmental Bill of Rights, 1993 for the area in which this Approval is applicable, apply to the Director for an amendment to this Approval that includes the necessary measures to conform with all applicable policies in the approved Source Protection Plan.

\section{Schedule "A"}

1. Application for Environmental Compliance Approval, dated May 2, 2013 and received on May 17, 2013, submitted by McIntosh Penry Consulting Engineers Ltd;

2. Final Servicing Report, Patenaude East Subdivision, dated July 24, 2012, prepared by McIntosh Perry Consulting Engineers Ltd.;

3. Patenaude East Subdivision. Stormwater Management Report, dated June 25, 2012, prepared by McIntosh Perry Consulting Engineers Ltd.;

4. Pump Station Report. Patenaude East Subdivision, dated May 14, 2013, prepared by McIntosh Perry Consulting Engineers Ltd.;

5. Geotechnical Investigation St. Marie St. East Subdivision, dated January 5, 2011, prepared by Inspec-Sol Inc;;

6. Additional Geotechnical Investigation, Proposed Stormwater Management Pond, Patenaude East Subdivision, dated June 21, 2012, prepared by Inspec-Sol Inc.;

7. Pipe Data Form for the storm and sanitary sewers including the storm and sanitary sewer design sheets submitted on June 11, 2013, prepared by McIntosh Penry Consulting Engineers Ltd;

8. Set of Engineering Drawings (22 drawings) for the Patenaude East Subdivision Sanitary Forcemain, dated July 17, 2013, prepared by McIntosh Perry Consulting Engineers Ltd.; and

9. Set of Engineering Drawings (19 drawings) for the Patenaude East Subdivision, dated July 19, 2013, prepared by McIntosh Perry Consulting Engineers Ltd.

\section{The reasons for the imposition of these terms and conditions are as follows:}

1. Condition 1 is imposed to ensure that the Works are built and operated in the manner in which they were described for review and upon which approval was granted. This Condition is also included to emphasize the precedence of Conditions in the Approval and the practice that the Approval is based on the most current document, if several conflicting documents are submitted for review.

2. Condition 2 is included to ensure that, when the Works are constructed, the Works will meet the standards that apply at 


\section{CONTENT COPY OF ORIGINAL}

the time of construction to ensure the ongoing protection of the environment.

3. Condition 3 is included to ensure that the Ministry records are kept accurate and current with respect to approved Works and to ensure that any subsequent Owner of the Works is made aware of the Approval and continues to operate the Works in compliance with it.

4. Condition 4 is included to require that the Works be properly operated and maintained such that the environment is protected.

5. Condition 5 is included as installation, regular inspection and maintenance of the temporary sediment and erosion control measures is required to mitigate the impact on the downstream receiving watercourse during construction, until they are no longer required.

6. Condition 6 is included to require that all records are retained for a sufficient time period to adequately evaluate the longterm operation and maintenance of the Works.

7. Condition 7 is included to ensure that the Works covered by this Approval will conform to the significant threat policies and designated Great Lakes policies in the Source Protection Plan.

In accordance with Section 139 of the Environmental Protection Act, you may by written Notice served upon me and the Environmental Review Tribunal within 15 days after receipt of this Notice, require a hearing by the Tribunal Section 142 of the Environmental Protection Act provides that the Notice requiring the hearing shall state:

1. The portions of the enviroumental compliance approval or each term or condition in the envirommental compliance approval in respect of which the bearing is required, and;

2. The grounds on which you intend to rely at the hearing in relation to each portion appealed.

The Notice should also include:

3. The name of the appellant;

4. The address of the appellant:

5. The environmental compliance approval number;

6. The date of the enviroumental compliance approval;

7. The name of the Director, and:

8. The municipality or mumicipalities within which the project is to be engaged in

And the Notice should be signed and dated by the appellant.

This Notice must be served upon:

The Secretary*

Emvironmental Review Tribmal

655 Bay Street, Suite 1500

Toronto, Ontario

MSG IES
The Director appointed fir the purposes ofPart II 1 of

the Emironmental Protection Act

Ministry of the Environment

2 St Clair Avemue West, Floor 12A

Torouto, Ontario

MAV IL5

* Further information on the Euviromental Review Tribunal's requirements for an appeal can be obtained directly from the Tribunal at: Tel: (416) 212-6349, Fax: (416) 314-3717 or www.ert.gov.on.ca

The above noted activity is approved under s.20.3 of Part II. 1 of the Environmental Protection Act. 


\title{
CONTENT COPY OF ORIGINAL
}

DATED AT TORONTO this 9th day of August, 2013

\author{
Edgardo Tovilla \\ Director \\ appointed for the purposes of Part II.1 of the \\ Environmental Protection Act
}

$\mathrm{DC}$

c: Area Manager, MOE Cormwall

c: District Manager, MOE Ottawa

Todd Perry, McIntosh Perry 


\section{References}

3Peak. 2018. “TP5551 / TP5552 / TP5554 Specification Sheet," 1-15.

Afshari, Ramin, Mohammadreza Fattahi, Masood Sepehrimanesh, Ali Reza Safarpour, Maryam Nejabat, Seyed Mohsen Dehghani, and Seyedeh Azra Shamsdin. 2016. "The Seroepidemiology of Hepatitis C Infection in Drug Abusers Referring to Shiraz Drug Rehabilitation Centers." Govaresh 21 (3): 18893. https://doi.org/10.1002/rra.

Ahmed, Sameh S, and S Durucan. 2007. "A Methodology To Determine the Optimum Sampling Frequency for Continuous Water Quality Parameters 1 . Introduction and Objective" 35 (6): 154158.

Aquatic Informatics. 2017. "Water Data Management Software | Aquatic Informatics." 2017. https://aquaticinformatics.com/.

AtlasScientific. 2018. "EZO-PH Data Sheet."

Barnes, Matthew A., Cameron R. Turner, Christopher L. Jerde, Mark A. Renshaw, W. Lindsay Chadderton, and David M. Lodge. 2014. "Environmental Conditions Influence EDNA Persistence in Aquatic Systems." Environmental Science and Technology 48 (3): 1819-27. https://doi.org/10.1021/es404734p.

Bazinet, Normand L., Beth M. Gilbert, and Angela M. Wallace. 2010. "A Comparison of Urbanization Effects on Stream Benthic Macroinvertebrates and Water Chemistry in an Urban and an Urbanizing Basin in Southern Ontario, Canada." Water Quality Research Journal of Canada 45 (3): 327-41.

Borja, Angel, Mike Elliott, Jacob Carstensen, Anna-Stiina Heiskanen, and Wouter van de Bund. 2010. "Marine Management--towards an Integrated Implementation of the European Marine Strategy Framework and the Water Framework Directives." Marine Pollution Bulletin 60 (12): 2175-86. https://doi.org/10.1016/j.marpolbul.2010.09.026.

Bradford, Andrea, and Bahram Gharabaghi. 2004. "Evolution of Ontario's Stormwater Management Planning and Design Guidance." Water Quality Research Journal of Canada 39 (4): 343-55.

Brindle, M.D. Dickman J.R. Yang I.D. 1990. "Impact of Heavy Metals on Higher Aquatic Plan, Diatom and Benthic Invertebrate Communities in the Niagara River Watershed near Welland, Ontario." Water Quality Research Journal of Canada 25 (2): 131-59.

Brown, Laura J., Vahid Taleban, Bahram Gharabaghi, and Lee Weiss. 2011. "Seasonal and Spatial Distribution Patterns of Atmospheric Phosphorus Deposition to Lake Simcoe, ON." Journal of Great Lakes Research 37 (SUPPL. 3). Elsevier B.V.: 15-25. https://doi.org/10.1016/j.jglr.2010.09.008.

Burton, G. Allen, and Robert E. Pitt. 2001. Stormwater Effects Handbook. Environmental Protection. https://doi.org/10.1201/9781420036244.

Camacho, René A, D Ph, M Asce, Zhonglong Zhang, M Asce, Xiaobo Chao, D Ph, and M Asce. 2019. "Receiving Water Quality Models for TMDL Development and Implementation" 24 (Usepa 1996). https://doi.org/10.1061/(ASCE)HE.1943-5584.0001723.

Canadian Council of Ministers of the Environment. 2011. "Protocols Manual for Water Quality Sampling 
in Canada CCME (2011) 5.1." Canadian Council of Ministers of the Environment, 2-3. https://doi.org/ISBN 978-1-896997-7-0.

Carter, Nicole. 2006. "Integrated Watershed Management: Moving from Concept to Practice in Ontario." Municipal World 116 (11).

http://scholar.google.com/scholar?hl=en\&btnG=Search\&q=intitle:Integrated+Watershed+Manage ment:+Moving+from+concept+to+practice+in+Ontario\#6.

Casado, Monica Rivas, Rocio Ballesteros Gonzalez, Thomas Kriechbaumer, and Amanda Veal. 2015. "Automated Identification of River Hydromorphological Features Using UAV High Resolution Aerial Imagery." Sensors (Switzerland) 15 (11): 27969-89. https://doi.org/10.3390/s151127969.

Casado, Monica Rivas, Rocio Ballesteros Gonzalez, Ros Wright, and Pat Bellamy. 2016. "Quantifying the Effect of Aerial Imagery Resolution in Automated Hydromorphological River Characterisation." Remote Sensing 8 (8). https://doi.org/10.3390/rs8080650.

Chacon-Hurtado, Juan C, Leonardo Alfonso, and Dimitri P Solomatine. 2017. "Rainfall and Streamflow Sensor Network Design: A Review of Applications, Classification, and a Proposed Framework." Earth Syst. Sci 215194: 3071-91. https://doi.org/10.5194/hess-21-3071-2017.

Chappell, Nick A., Timothy D. Jones, and Wlodek Tych. 2017. "Sampling Frequency for Water Quality Variables in Streams: Systems Analysis to Quantify Minimum Monitoring Rates." Water Research 123. Elsevier Ltd: 49-57. https://doi.org/10.1016/j.watres.2017.06.047.

Chapra, Steven C. 2003. "Engineering Water Quality Models and TMDLs." Journal of Water Resources Planning and Management 129 (4): 247-56. https://doi.org/10.1061/(ASCE)07339496(2003)129:4(247).

Chen, Tao, Rui qing Niu, Ping xiang Li, Liang pei Zhang, and Bo Du. 2011. "Regional Soil Erosion Risk Mapping Using RUSLE, GIS, and Remote Sensing: A Case Study in Miyun Watershed, North China." Environmental Earth Sciences 63 (3): 533-41. https://doi.org/10.1007/s12665-010-0715-z.

City of Barrie. 2017. "Low Impact Development: Interim Guidance Document."

City of Edmonton. 2014. "Low Impact Development Best Management Practices Design Guide Edition 1.1," no. December: 1-269. https://doi.org/10.1007/978-1-61779-267-0_32.

Cloete, N.A., R. Malekian, and L. Nair. 2016. "Smart Sensors for Real-Time Water Quality Monitoring." IEEE Access 4: 3975-90. https://doi.org/10.1007/978-3-642-37006-9.

Conservation Ontario. 2010. "Integrated Watershed Management Navigating Ontario's Future."

Credit Valley Conservation; Schroeter \& Associates; Environmental Water Resources Group; Aquafor Beech Limited; Jacques Whitford Environmental Limited; Waterloo Hydrogeologic Inc. 2003a. "Silver Creek Subwatershed Plan: Phase I Characterization Report." Town of Halton Hills.

Credit Valley Conservation. 2003b. "Silver Creek Subwatershed Study: Implementation Report." Town of Halton Hills.

Credit Valley Conservation. 2014. "Real-Time Water Quality: Winter 2014 Seasonal Exceedance of Water Quality Objectives." http://www.creditvalleyca.ca/wpcontent/uploads/2015/01/Winter2014_Report_Fletcher.pdf.

Credit Valley Conservation. 2017. "Real-Time Water Quality - Credit Valley Conservation Credit Valley 
Conservation." 2017. https://www.creditvalleyca.ca/watershed-science/watershedmonitoring/real-time-water-quality/.

Credit Valley Conservation Authority. n.d. "Chapter 12 - Water Chemistry - Credit Valley Conservation Credit Valley Conservation." Accessed December 10, 2017. https://www.creditvalleyca.ca/watershed-science/watershed-monitoring/credit-river-watershedhealth-report/chapter-12-water-chemistry/.

Credit Valley Conservation Authority. 2005. "Credit Valley Conservation: Watershed Report Card."

Credit Valley Conservation Authority. 2010. "Watershed Planning and Regulation Policies."

Credit Valley Conservation Authority and Toronto Region Conservation Authority. 2010. "Low Impact Development Stormwater Management Planning and Design Guide."

CWE Corporation. 2014. "Los Angeles River Upper Reach 2 Watershed Management Area."

Delcan. 2005. "Dingman Creek Subwatershed Study Update Volume 1 Main Report." City of London.

Department of Environmental Resources. 1999. "Low-Impact Development Design Strategies An Integrated Design Approach Low-Impact Development : An Integrated Design Approach," no. June.

Dodd, Paul. 2009. "Easy Access to Near Real-Time Data Looking at a Methodology That Generates Aggregated Live Feeds for ArcGIS Clients," 36-38.

Dornsife, Alison M. 2005. "From a Nonpollutant into a Pollutant: Revising EPA's Interpretation of the Phrase 'Discharge of Any Pollutant' in the Context of NPDES Permits." Environmental Law 35 (175): 176-207.

Eimers, M Catherine, Jennifer G Winter, Wolfgang A Scheider, Shaun A Watmough, and Kenneth H Nicholls. 2005. "Recent Changes and Patterns in the Water Chemistry of Lake Simcoe." Journal of Great Lakes Research 31 (3). Elsevier: 322-32. https://doi.org/10.1016/S0380-1330(05)70263-X.

eleven-x. 2018. "A Network Optimized for the Internet of Things and Smart Cities - Eleven-X." 2018. https://eleven-x.com/network/.

Environment Canada. 2018. "Real-Time Hydrometric Data Map Search - Water Level and Flow Environment Canada." 2018.

https://wateroffice.ec.gc.ca/google_map/google_map_e.html?map_type=real_time\&search_type $=$ province $\&$ province $=\mathrm{ON}$.

Eureka. 2017. “Ion-Selective Electrodes.” 2017. https://www.waterprobes.com/ise-s.

European Commission. 2003. Common Implementation Strategy for the Water Framework Directive. Office for Official Publications of the European Communities.

Evans, D O, K H Nicholls, Y C Allen, and M J McMurtry. 1996. "Historical Land Use, Phosphorus Loading, and Loss of Fish Habitat in Lake Simcoe, Canada." Canadian Journal of Fisheries and Aquatic Sciences 53 (S1): 194-218. https://doi.org/10.1139/f96-012.

Eyles, N., M. Meriano, and P. Chow-Fraser. 2013. "Impacts of European Settlement (1840-Present) in a Great Lake Watershed and Lagoon: Frenchman's Bay, Lake Ontario, Canada." Environmental Earth Sciences 68 (8): 2211-28. https://doi.org/10.1007/s12665-012-1904-8.

Fan, Jing, Nan Chen, Chang Song Xiang, and Jin Long Wang. 2012. "Study on Networking Technology 
Based on ZigBee with Water PH Monitoring for Wireless Mesh Sensor Network." Advanced Materials Research 630: 302-7. https://doi.org/10.4028/www.scientific.net/AMR.630.302.

Fang, Shifeng, Li Da Xu, Yunqiang Zhu, Jiaerheng Ahati, Huan Pei, Jianwu Yan, and Zhihui Liu. 2014. “An Integrated System for Regional Environmental Monitoring and Management Based on Internet of Things." IEEE Transactions on Industrial Informatics 10 (2): 1596-1605. https://doi.org/10.1109/TII.2014.2302638.

Ferreira, J. G., C. Vale, C. V. Soares, F. Salas, P. E. Stacey, S. B. Bricker, M. C. Silva, and J. C. Marques. 2007. "Monitoring of Coastal and Transitional Waters under the E.U. Water Framework Directive." Environmental Monitoring and Assessment 135 (1-3): 195-216. https://doi.org/10.1007/s10661007-9643-0.

Frau, Ilaria, Olga Korostynska, Alex Mason, and Patrick Byrne. 2018. "Comparison of Electromagnetic Wave Sensors with Optical and Low-Frequency Spectroscopy Methods for Real-Time Monitoring of Lead Concentrations in Mine Water." Mine Water and the Environment 37 (3). Springer Berlin Heidelberg: 617-24. https://doi.org/10.1007/s10230-018-0511-7.

Garzio-Hadzick, A., D. R. Shelton, R. L. Hill, Y. A. Pachepsky, A. K. Guber, and R. Rowland. 2010. "Survival of Manure-Borne E. Coli in Streambed Sediment: Effects of Temperature and Sediment Properties." Water Research 44 (9). Elsevier Ltd: 2753-62. https://doi.org/10.1016/j.watres.2010.02.011.

Gong, Jianya, Jing Geng, and Zeqiang Chen. 2015. "Real-Time GIS Data Model and Sensor Web Service Platform for Environmental Data Management." International Journal of Health Geographics 14 (1): 1-13. https://doi.org/10.1186/1476-072X-14-2.

Gopavanitha, K, and P G Scholar. 2017. "A Low Cost System for Real Time Water Quality Monitoring and Controlling Using loT." 2017 International Conference on Energy, Communication, Data Analytics and Soft Computing (ICECDS). IEEE, 3227-29. https://doi.org/10.1109/ICECDS.2017.8390054.

Gotovtsev, A. V. 2016. "Evaluating BOD and the Coefficient of Oxidation Rate: Monitoring, Direct and Inverse Problems, Formulas, Calculations and Tables." Water Resources 43 (6): 885-98. https://doi.org/10.1134/S0097807816050067.

Government of Canada. n.d. "Water Survey of Canada - Canada.Ca." Accessed September 16, 2018. https://www.canada.ca/en/environment-climate-change/services/wateroverview/quantity/monitoring/survey.html.

Government of Canada. 2014. "Draft Canada Ontario Agreement on Great Lakes Water Quality and Ecosystem Health," no. July 72015.

Government of Ontario. 2012. “Ontario's Great Lakes Strategy,” 1-67.

Government of Ontario. 2014. "Provincial Policy Statement - 2014."

Grinham, Alistair R., Tim J. B. Carruthers, Paul L. Fisher, James W. Udy, and William C. Dennison. 2007. "Accurately Measuring the Abundance of Benthic Microalgae in Spatially Variable Habitats." Limnology and Oceanography: Methods 5 (5): 119-25. https://doi.org/10.4319/lom.2007.5.119.

Gunawardena, N., E. R. Pardyjak, R. Stoll, and A. Khadka. 2018. "Development and Evaluation of an Open-Source, Low-Cost Distributed Sensor Network for Environmental Monitoring Applications." Measurement Science and Technology 29 (2). IOP Publishing: aa97fb. https://doi.org/10.1088/1361-6501/aa97fb. 
Harrop, Stacey. 2001. "Municipal Separate Storm Sewer Systems: Is Compliance with State Water Quality Standards Only a Pipe Dream?" Evnvironmental Law 31 (3).

Harun, Z., E. Reda, and H. Hashim. 2018. "Real Time Fish Pond Monitoring and Automation Using Arduino." IOP Conference Series: Materials Science and Engineering 340 (1). https://doi.org/10.1088/1757-899X/340/1/012014.

Hering, Daniel, Angel Borja, Jacob Carstensen, Laurence Carvalho, Mike Elliott, Christian K. Feld, Anna Stiina Heiskanen, et al. 2010. "The European Water Framework Directive at the Age of 10: A Critical Review of the Achievements with Recommendations for the Future." Science of the Total Environment 408 (19). Elsevier B.V.: 4007-19. https://doi.org/10.1016/j.scitotenv.2010.05.031.

Hill, A R. 1978. "Factors Affecting the Export of Nitrate-Nitrogen from Drainage Basins in Southern Ontario" 12.

HydroLab. 2005. “DS5X, DS5, and MS5 Water Quality Multiprobes User Manual,” no. 003078: 1-72.

Jamieson, Elizabeth C., Matthew A. Ruta, Colin D. Rennie, and Ronald D. Townsend. 2013. "Monitoring Stream Barb Performance in a Semi-Alluvial Meandering Channel: Flow Field Dynamics and Morphology." Ecohydrology 6 (4): 611-26. https://doi.org/10.1002/eco.1370.

Jo, Byungwan, and Zafar Baloch. 2017. "Internet of Things-Based Arduino Intelligent Monitoring and Cluster Analysis of Seasonal Variation in Physicochemical Parameters of Jungnangcheon, an Urban Stream." Water (Switzerland) 9 (3). https://doi.org/10.3390/w9030220.

Jonge, V. N. de, M. Elliott, and V. S. Brauer. 2006. "Marine Monitoring: Its Shortcomings and Mismatch with the EU Water Framework Directive's Objectives." Marine Pollution Bulletin 53 (1): 5-19. https://doi.org/10.1016/j.marpolbul.2005.11.026.

Kaika, M. 2003. "The Water Framework Directive: A New Directive for a Changing Social, Political and Economic European Framework." Eur. Plan. Stud. 11 (3): 299-316. https://doi.org/10.1080/0965431032000070802.

Kallis, G. 2001. "The EU Water Framework Directive: Measures and Implications." Water Policy 3 (2): 125-42. https://doi.org/10.1016/S1366-7017(01)00007-1.

Kim, Dong Kyun, Samarth Kaluskar, Shan Mugalingam, and George B. Arhonditsis. 2016. "Evaluating the Relationships between Watershed Physiography, Land Use Patterns, and Phosphorus Loading in the Bay of Quinte Basin, Ontario, Canada." Journal of Great Lakes Research 42 (5). International Association for Great Lakes Research.: 972-84. https://doi.org/10.1016/j.jglr.2016.07.008.

Kröckel, L., G. Schwotzer, H. Lehmann, and T. Wieduwilt. 2011. "Spectral Optical Monitoring of Nitrate in Inland and Seawater with Miniaturized Optical Components." Water Research 45 (3): 1423-31. https://doi.org/10.1016/j.watres.2010.10.033.

Lake Simcoe Region Conservation Authority. 2012. “Barrie Creeks, Lovers Creek, and Hewitt's Creek Subwatershed Plan," 374. http://www.Isrca.on.ca/pdf/reports/barrie_subwatershed_plan_2012.pdf.

Lake Simcoe Region Conservation Authority. 2013. "Lake Simcoe Watershed 2013 Environmental Monitoring Report (2007-2011 Data)," 97. http://www.Isrca.on.ca/pdf/reports/monitoring_report_2013.pdf. 
Legislative Assembly of the Province of Ontario. 2008. Lake Simcoe Protection Act.

Legleiter, Carl J., Paul J. Kinzel, and Jonathan M. Nelson. 2017. "Remote Measurement of River Discharge Using Thermal Particle Image Velocimetry (PIV) and Various Sources of Bathymetric Information." Journal of Hydrology 554: 490-506. https://doi.org/10.1016/j.jhydrol.2017.09.004.

Liu, Jing, and Bo Mattiasson. 2002. "Microbial BOD Sensors for Wastewater Analysis." Water Research 36 (15): 3786-3802. https://doi.org/10.1016/S0043-1354(02)00101-X.

Long, Tanya, Christopher Wellen, George Arhonditsis, and Duncan Boyd. 2014. "Evaluation of Stormwater and Snowmelt Inputs, Land Use and Seasonality on Nutrient Dynamics in the Watersheds of Hamilton Harbour, Ontario, Canada." Journal of Great Lakes Research 40 (4). Elsevier B.V.: 964-79. https://doi.org/10.1016/j.jglr.2014.09.017.

Loomer, H A, and S E Cooke. 2003. "Water Quality in the Grand River Watershed:" Current Conditions \& Trends. https://www.sourcewater.ca/en/source-protectionareas/resources/Documents/Grand/Grand_Reports_WaterQuality_2011.pdf.

Lyautey, Emilie, Zexun Lu, David R. Lapen, Graham Wilkes, Andrew Scott, Tanya Berkers, Thomas A. Edge, and Edward Topp. 2010. "Distribution and Diversity of Escherichia Coli Populations in the South Nation River Drainage Basin, Eastern Ontario Canada." Applied and Environmental Microbiology 76 (5): 1486-96. https://doi.org/10.1128/AEM.02288-09.

Lyons, Nathan J., Michael J. Starek, Karl W. Wegmann, and Helena Mitasova. 2015. "Bank Erosion of Legacy Sediment at the Transition from Vertical to Lateral Stream Incision." Earth Surface Processes and Landforms 40 (13): 1764-78. https://doi.org/10.1002/esp.3753.

Marttila, Hannu, and Bjørn Kløve. 2012. "Use of Turbidity Measurements to Estimate Suspended Solids and Nutrient Loads from Peatland Forestry Drainage." Journal of Irrigation and Drainage Engineering 138 (12): 1088-96. https://doi.org/10.1061/(ASCE)IR.1943-4774.0000509.

Maunder \& Hindley. 2005. "Establishing Environmental Flow Requirements -Synthesis Repor," 77.

Maxim. 2008. “DS18B20 Data Sheet," 1-22.

Meriano, Mandana, Nick Eyles, and Ken W.F. Howard. 2009. "Hydrogeological Impacts of Road Salt from Canada's Busiest Highway on a Lake Ontario Watershed (Frenchman's Bay) and Lagoon, City of Pickering." Journal of Contaminant Hydrology 107 (1-2). Elsevier B.V.: 66-81. https://doi.org/10.1016/j.jconhyd.2009.04.002.

Miller, Matthew P., David D. Susong, Christopher L. Shope, Victor M. Heilweil, and Bernard J Stolp. 2014. "Chemical Hydrograph Separation Approach." Water Resources Research 50 (8): 6986-99. https://doi.org/10.1002/2013WR014939.Received.

Minan, John H. 2005. "Municipal Separate Storm Sewer System (MS4) Regulation Under the Federal Clean Water Act : The Role of Water Quality Standards ?" 1: 1215-57.

Minister of Justice. 2013. Fisheries Act.

Ministry of Environment, Ministry of Natural Resources, and Lake Simcoe Conservation Authority. 2009. "Lake Simcoe Protection Plan."

Ministry of Environment and Climate Change. 2016. "Water Management: Policies, Guidelines, Provincial Water Quality Objectives | Ontario.Ca." Provincial Water Quality Objectives. 2016. 
https://www.ontario.ca/page/water-management-policies-guidelines-provincial-water-qualityobjectives\#section-2.

Ministry of Infrastructure. 2006. "Growth Plan for the Greater Golden Horseshoe," 1-54. https://www.placestogrow.ca/content/ggh/2013-06-10-Growth-Plan-for-the-GGH-EN.pdf.

Ministry of Natural Resources. 1987. Guidelines on Erosion and Sediment Control for Urban Construction Sites. Transportation.

Ministry of Natural Resources. 2015. "Manual of Instructions for Broad-Scale Fish Community Monitoring" 2 (October): 2-4.

Ministry of Natural Resources and Ministry of Environment. 1991. "Interim Stormwater Quality Control Guidelines for New Development" 1. https://doi.org/10.1017/СBO9781107415324.004.

Ministry of Natural Resources and Ministry of Environment and Energy. 1993a. "Integrating Water Management Objectives into Municipal Planning Documents," no. June.

Ministry of Natural Resources and Ministry of Environment and Energy. 1993b. "Subwatershed Planning."

Ministry of Natural Resources and Ministry of Environment and Energy. 1993c. "Water Managment on a Watershed Basis: Implementing an Ecosystem Approach."

Ministry of the Environment. 2003. Stormwater Management Planning and Design Manual. Water Resources.

Ministry of the Environment. 2012. "Guide to Applying for an Environmental Compliance Approval," 1124.

Ministry of the Environment and Climate Change. 2013. "Environmental Compliance Approval Number 3801-99FPKY." Environmental Registry. https://doi.org/10.1179/037178411X12942393517651.

Ministry of the Environment and Climate Change. 2014. "Stormwater in Ontario: Pilot Testing and ECA Watershed Approach."

Ministry of the Environment and Climate Change. 2015. "Lake Simcoe Monitoring Report 2014," 1-114.

Ministry of the Environment and Climate Change. 2017. "Transfer of Review."

Ministry of the Environment and Energy. 1994. Stormwater Management Practices Planning and Design Manual. Journal of Chemical Information and Modeling. Vol. 53. Queen's Printer for Ontario. https://doi.org/10.1017/CBO9781107415324.004.

Ministry of the Finance. 2014. "Ontario Population Projections: Based on the 2011 Census." https://doi.org/10.1016/S0022-3913(12)00047-9.

Mitchell, Bruce, Charles Priddle, Dan Shrubsole, Barbara Veale, and Dan Walters. 2014. "Integrated Water Resource Management: Lessons from Conservation Authorities in Ontario, Canada." International Journal of Water Resources Development 30 (3). Taylor \& Francis: 460-74. https://doi.org/10.1080/07900627.2013.876328.

ModernWater. n.d. "Portable BOD Detection to Provide Real Time Monitoring of Organic Pollution." Accessed March 17, 2018. https://www.modernwater.com/pdf/MW_Factsheet_BODChek.pdf. 
Molar, Michelle, Stewart, Kelly, Iseman, Sandra. 2012. "Watersheds of the Ontario Greenbelt: Policy Options to Preserve, Protect, and Restore the Watersheds of the Greenbelt." David Suzuki Foundation, 5-26.

Moss, Brian. 2008. "The Water Framework Directive: Total Environment or Political Compromise?" Science of The Total Environment 400 (1-3): 32-41. https://doi.org/10.1016/j.scitotenv.2008.04.029.

Myint, Cho Zin, Lenin Gopal, and Yan Lin Aung. 2017. "Reconfigurable Smart Water Quality Monitoring System in loT Environment." 2017 IEEE/ACIS 16th International Conference on Computer and Information Science (ICIS), 435-40.

Nemes, Veronika, Andrea La Nauze, Christopher J Walsh, Tim D Fletcher, Darren Bos, Sharyn Rossrakesh, and Gary Stoneham. 2010. "Saving a Creek One Bid at a Time : A Uniform Price Auction for Urban Stormwater Retention." Australian Association of Agricultural and Resource Economics(AARES) National Conference 9006 (February 2015): 1-25. https://doi.org/10.1080/1573062x.2014.988732.

Neukom, Benjamin, Stefan Müller Arisona, and Simon Schubiger. 2018. "Real-Time GIS-Based Snow Cover Approximation and Rendering for Large Terrains." Computers and Graphics (Pergamon) 71. Elsevier Ltd: 14-22. https://doi.org/10.1016/j.cag.2017.10.003.

Nevers, Meredith B, Murulee N Byappanahalli, Charles C Morris, Dawn Shively, Kasia Przybyla-kelly, Ashley M Spoljaric, Joshua Dickey, and Edward F Roseman. 2018. "Environmental DNA ( EDNA ): A Tool for Quantifying the Abundant but Elusive Round Goby ( Neogobius Melanostomus )." PloS One, 1-22. https://doi.org/10.5066/F7GH9H6F.Funding.

Nicholls, K. H. 1997. "A Limnological Basis For A Lake Simcoe Phosphorus Loading Objective." Lake and Reservoir Management 13 (3): 189-98. https://doi.org/10.1080/07438149709354310.

Norouzi, Yaghoub Jacobe, and Tony Van Rossum. 2018. "Monitoring to Quantify Phosphorous Loadings City of London, Ontario , Canada February 2018 Table of Contents," no. February: 1-34.

Ontario Federation of Anglers and Hunters. 2017. "About the Program - Lake Ontario Atlantic Salmon Restoration Program." 2017. http://www.bringbackthesalmon.ca/about/.

Ontario Ministry of the Environment and Energy. 1994. "Water Management - Policies, Guidelines, Provincial Water Quality Objective," 1-61. http://agrienvarchive.ca/download/water_qual_object94.pdf.

Palmer, Michelle E., Jennifer G. Winter, Joelle D. Young, Peter J. Dillon, and Stephanie J. Guildford. 2011. "Introduction and Summary of Research on Lake Simcoe: Research, Monitoring, and Restoration of a Large Lake and Its Watershed." Journal of Great Lakes Research 37 (SUPPL. 3). Elsevier B.V.: 1-6. https://doi.org/10.1016/j.jglr.2011.04.003.

Phosphorus, Stream, Exports From, Watersheds With, Contrasting Land, and Usessouthern Ontario. 1981. “Contrasting Land Uses in Southern Ontario" 17 (4).

Pratihast, Arun Kumar, Ben DeVries, Valerio Avitabile, Sytze de Bruin, Martin Herold, and Aldo Bergsma. 2016. "Design and Implementation of an Interactive Web-Based Near Real-Time Forest Monitoring System." PloS One 11 (3): e0150935. https://doi.org/10.1371/journal.pone.0150935.

Priestley, Sara. 2015. "Water Framework Directive : Achieving Good Status of Water Bodies," no. July: 125. 
Prudhomme, Rachel. 2016. "Development and Infrastructure Servies - Engineering Services Information Report ES 2016-49."

Qin, Yiheng, Arif U. Alam, Si Pan, Matiar M.R. Howlader, Raja Ghosh, Nan Xing Hu, Hao Jin, Shurong Dong, Chih Hung Chen, and M. Jamal Deen. 2018. "Integrated Water Quality Monitoring System with PH, Free Chlorine, and Temperature Sensors." Sensors and Actuators, B: Chemical 255. Elsevier B.V.: 781-90. https://doi.org/10.1016/j.snb.2017.07.188.

Quinlan, Cathy. 2013. The Thames River, Ontario Prepared By.

Rabault, Jean, Graig Sutherland, Olav Gundersen, and Atle Jensen. 2017. "Measurements of Wave Damping by a Grease Ice Slick in Svalbard Using Off-the-Shelf Sensors and Open-Source Electronics." Journal of Glaciology 63 (238): 372-81. https://doi.org/10.1017/jog.2017.1.

Rahim, Herlina Abdul, Syahidah Nurani Zulkifli, Nurul Adilla, Mohd Subha, Ruzairi Abdul Rahim, and Hafilah Zainal Abidin. 2017. "Water Quality Monitoring Using Wireless Sensor Network and Smartphone-Based Applications : A Review." Sensors \& Transducers Journal 209 (2): 1-11. http://www.sensorsportal.com.

Rees, Helen C., Ben C. Maddison, David J. Middleditch, James R M Patmore, and Kevin C. Gough. 2014. "The Detection of Aquatic Animal Species Using Environmental DNA - a Review of EDNA as a Survey Tool in Ecology." Journal of Applied Ecology 51 (5): 1450-59. https://doi.org/10.1111/13652664.12306.

Reiche, Johannes, Sytze de Bruin, Dirk Hoekman, Jan Verbesselt, and Martin Herold. 2015. "A Bayesian Approach to Combine Landsat and ALOS PALSAR Time Series for near Real-Time Deforestation Detection." Remote Sensing 7 (5): 4973-96. https://doi.org/10.3390/rs70504973.

Resch, Bernd, Manfred Mittlboeck, Fabien Girardin, Rex Britter, and Carlo Ratti. 2009. "Real-Time GeoAwareness - Sensor Data Integration for Environmental Monitoring in the City." Proceedings of the International Conference on Advanced Geographic Information Systems and Web Services, GEOWS 2009, 92-97. https://doi.org/10.1109/GEOWS.2009.31.

Rogers Communications Canada. n.d. "CNW | Rogers to Launch National LTE-M Network to Power the next Era of IoT in Canada." Accessed December 22, 2018. https://www.newswire.ca/newsreleases/rogers-to-launch-national-Ite-m-network-to-power-the-next-era-of-iot-in-canada697913161.html.

Roxar Galvanic Probes. 2015. “Produce Data Sheet," 1-4.

Saravanan, K., E. Anusuya, Raghvendra Kumar, and Le Hoang Son. 2018. "Real-Time Water Quality Monitoring Using Internet of Things in SCADA." Environmental Monitoring and Assessment 190 (9). Environmental Monitoring and Assessment: 556. https://doi.org/10.1007/s10661-018-6914-x.

Scholten, Matthias. 2003. "Efficiency of Point Abundance Sampling by Electro-Fishing Modified for Short Fishes." Journal of Applied Ichthyology 19 (5): 265-77. https://doi.org/10.1046/j.14390426.2003.00505.x.

Settu, Kalpana, Jen Tsai Liu, Ching Jung Chen, Jang Zern Tsai, and Shwu Jen Chang. 2013. "Concept for E.Coli Detection Using Interdigitated Microelectrode Impedance Sensor." Proceedings of the Annual International Conference of the IEEE Engineering in Medicine and Biology Society, EMBS, 1712-15. https://doi.org/10.1109/EMBC.2013.6609849. 
Sherchan, Samendra, Syreeta Miles, Luisa Ikner, Hye-Weon Yu, Shane Snyder, and Ian Pepper. 2018.

"Near Real-Time Detection of E. Coli in Reclaimed Water." Sensors 18 (7): 2303.

https://doi.org/10.3390/s18072303.

Shrubsole, Dan. 2004. "Reflections on Recent Developments in Watershed Management in Ontario and Their Implications for Natural Areas Management." Environments 32 (1). https://doi.org/http://dx.doi.org/10.1108/17506200710779521.

Sliva, Lucie, and D Dudley Williams. 2001. "Buffer Zone Versus Whole Catchment Approaches To Studying Land Use Impact on River Water Quality." Wat. Res 35 (14): 3462-72.

Smart, Adam S., Reid Tingley, Andrew R. Weeks, Anthony R. Van Rooyen, and Michael A. McCarthy. 2015. "Environmental DNA Sampling Is More Sensitive than a Traditional Survey Technique for Detecting an Aquatic Invader." Ecological Applications 25 (7): 1944-52. https://doi.org/10.1890/14-1751.1.

Smart Cities Connect. 2017. "Eleven-x and Waterloo Partner To Collect Groundwater Data - Smart Cities Connect." 2017. https://smartcitiesconnect.org/eleven-x-and-waterloo-partner-to-collectgroundwater-data/.

Solinst. 2017. "Solinst Downloads - Software, User Guides, Datasheets \&amp; Operating Instructions." 2017. https://www.solinst.com/downloads/.

SST. 2018. "Liquid Level Switch."

Stone, Mandy L, Jennifer L Graham, and Jackline W Gatotho. 2013. "Continuous Real-Time WaterQuality Monitoring and Regression Analysis to Compute Constituent Concentrations and Loads in the North Fork Ninnescah River Upstream from Cheney Reservoir, South-Central Kansas, 19992012." Scientific Investigations Report, 1999-2012.

http://ezproxy.unal.edu.co/login?url=http://search.ebscohost.com/login.aspx?direct=true\&db=gu h\&AN=676015-1\&lang=es\&site=eds-live\%5Cnhttp://pubs.usgs.gov/sir/2013/5071/.

Sun, Yaqin, and Songnian Li. 2016. "Real-Time Collaborative GIS: A Technological Review." ISPRS Journal of Photogrammetry and Remote Sensing 115. International Society for Photogrammetry and Remote Sensing, Inc. (ISPRS): 143-52. https://doi.org/10.1016/j.isprsjprs.2015.09.011.

TAOS. 2012. "Adafruit TCS3472 RGB Sensor."

Tauro, F., R. Piscopia, and S. Grimaldi. 2017. "Streamflow Observations From Cameras: Large-Scale Particle Image Velocimetry or Particle Tracking Velocimetry?" Water Resources Research 53 (12): 10374-94. https://doi.org/10.1002/2017WR020848.

Ternier, Sabrina. 2012. "Review Of Stormwater Management In Ontario And A Case Study On The Etobicoke Exfiltration System."

Tesera. 2018. "Water Quality App - Tesera Systems." 2018. https://tesera.com/water-quality-app/.

Toronto and Region Conservation Authority. 2000. "FLOW AND PRECIPITATION MONITORING A Discussion Paper in Support of the Development of A Regional Watershed Monitoring Network." http://www.trca.on.ca/dotAsset/114189.pdf.

Toronto and Region Conservation Authority. 2008. "Humber River Watershed Plan," no. June.

Toronto and Region Conservation Authority. 2012. "Stormwater Management Criteria," no. August: 126. 
Toronto Regional Conservation Authority. 2018. "Understand - Toronto and Region Conservation (TRCA)." 2018. https://trca.ca/conservation/erosion-management/understand/.

United States Environmental Protection Agency. 1988. "National Water Quality Inventory 1988 Report to Congress."

United States Environmental Protection Agency. 1996. Interim Permitting Approach for Water QualityBased Effluent Limitations in Storm Water Permits, issued 1996.

United States Environmental Protection Agency. 2018. "Overview of Total Maximum Daily Loads (TMDLs)." https://www.epa.gov/tmdl/overview-total-maximum-daily-loads-tmdls\#1.

Upper Thames River Conservation Authority. 2012. "Dingman Creek Watershed Report Card," 1-6.

Windsor, Cristina, Ashley Steinbach, Amy E. Lockwood, and Robert J Mooney. 2011. "Verifying the Use of Specific Conductance as a Surrogate for Chloride in Seawater Matrices," 1-7. https://insitu.com/wp-content/uploads/2015/02/Chloride-Conductivity-Relationship-Verifying-the-Use-ofSpecific-Conductance-as-a-Surrogate-for-Chloride-in-Seawater-Matrices.pdf.

Winter, Jennifer G., and Hamish C. Duthie. 2000. "Export Coefficient Modeling to Assess Phosphorus Loading in an Urban Watershed." Journal of the American Water Resources Association 36 (5): 1053-61. https://doi.org/10.1111/j.1752-1688.2000.tb05709.x.

Woodget, Amy S., Robbie Austrums, lan P. Maddock, and Evelyn Habit. 2017. "Drones and Digital Photogrammetry: From Classifications to Continuums for Monitoring River Habitat and Hydromorphology." Wiley Interdisciplinary Reviews: Water 4 (4): e1222. https://doi.org/10.1002/wat2.1222.

Wright, Andrea, W. Andrew Marcus, and Richard Aspinall. 2000. "Evaluation of Multispectral, Fine Scale Digital Imagery as a Tool for Mapping Stream Morphology." Geomorphology 33 (1-2): 107-20. https://doi.org/10.1016/S0169-555X(99)00117-8.

Yamanoue, Takashi, Kentaro Oda, and Koichi Shimozono. 2012. "A Simple Application Program Interface for Saving Java Program Data on a Wiki." Advances in Software Engineering 2012: 1-9. https://doi.org/10.1155/2012/981783.

YSI. n.d. "MODEL H-3123 Submersible Transducer."

Zare Abyaneh, Hamid, A H Nazemi, M R Neyshabori, K Mohammadi, G H Majzoobi, Tuzlu Sularda, Elektiriksel Illetkenlik, and Ölçümünden Klor Tahmini. 2005. "Chloride Estimation in Ground Water From Electrical Conductivity Measurement" 11 (1): 110-14. http://dergiler.ankara.edu.tr/dergiler/15/174/1432.pdf.

Zimmer, C a, I W Heathcote, H R Whiteley, and H. Schroter. 2007. "Low-Impact-Development Practices for Stormwater: Implications for Urban Hydrology." Canadian Water Resources Journal. https://doi.org/10.4296/cwrj3203193. 